Chapman University

Chapman University Digital Commons

Educational Studies Dissertations

Fall 8-26-2016

\title{
¿Dónde Pertenecemos? Narrative Analysis of Afro-Boricua Women's Experiences of Belonging Within and Beyond College
}

Marie Nubia-Feliciano

nubiafel@chapman.edu

Follow this and additional works at: https://digitalcommons.chapman.edu/ces_dissertations

Part of the Adult and Continuing Education Commons, Personality and Social Contexts Commons, and the Race and Ethnicity Commons

\section{Recommended Citation}

Nubia-Feliciano, M. (2016). ¿Dónde pertenecemos? Narrative analysis of Afro-Boricua women's experiences of belonging within and beyond college (Doctoral dissertation). https://doi.org/10.36837/ chapman.000023

This Dissertation is brought to you for free and open access by Chapman University Digital Commons. It has been accepted for inclusion in Educational Studies Dissertations by an authorized administrator of Chapman University Digital Commons. For more information, please contact laughtin@chapman.edu. 
¿Dónde Pertenecemos? Narrative Analysis of Afro-Boricua Women's Experiences of Belonging Within and Beyond College

\author{
A Dissertation by \\ Marie Nubia-Feliciano \\ Chapman University \\ Orange, California \\ College of Educational Studies
}

Submitted in partial fulfillment of the requirements for the degree of Doctor of Philosophy in Education, Emphasis in Curricular and Cultural Studies August 2016

\author{
Committee in charge \\ Anaida Colón-Muñiz, Ed.D., Chair \\ Quaylan Allen, Ph.D. \\ Kimberly White-Smith, Ed.D. \\ Sharon Elise, Ph.D.
}


The dissertation of Marie Nubia-Feliciano is approved.
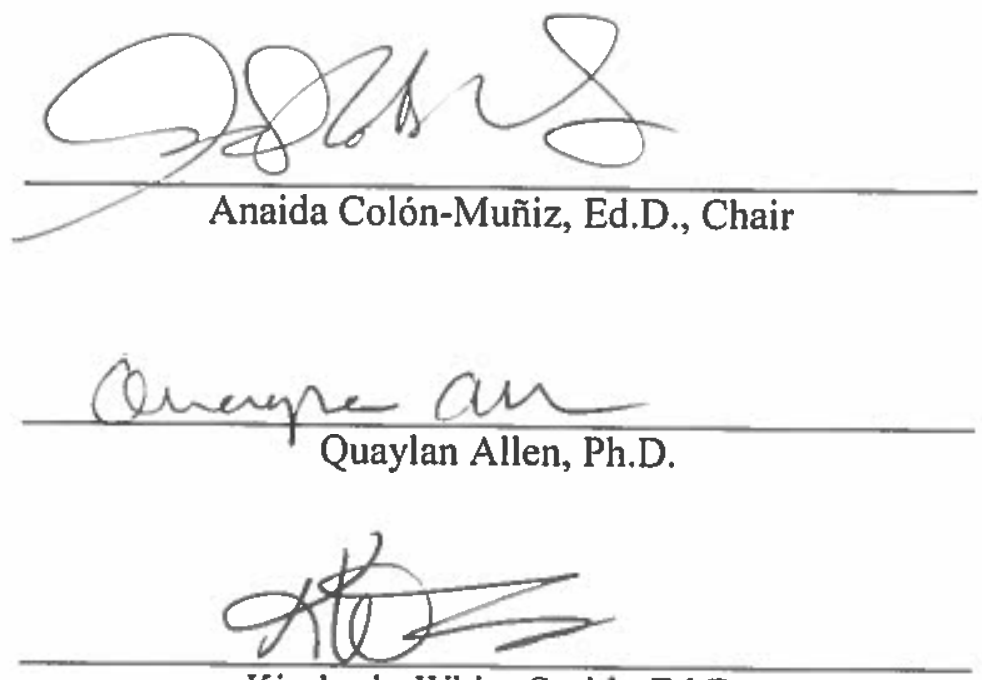

Kimberly White-Smith, Ed.D.

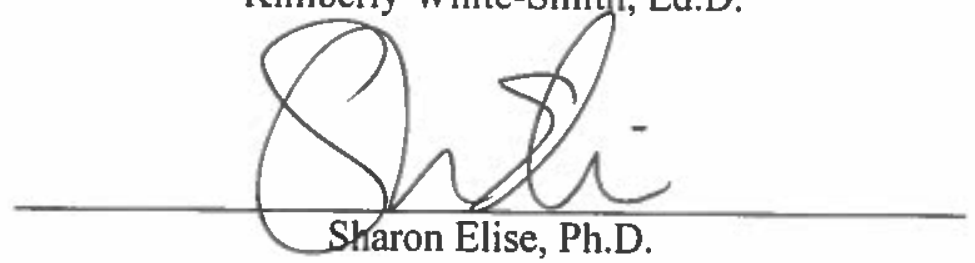

February 2016 
¿Dónde Pertenecemos? Narrative Analysis of Afro-Boricua Women's Experiences of

Belonging Within and Beyond College

Copyright (C) 2016

by Marie Nubia-Feliciano 


\section{ACKNOWLEDGMENTS}

Although long, the process to get to this point was worth the struggle. I want to

first thank my family for providing me the space and motivation to do my work:

- My mother for the sacrifices she made so that I can complete my education.

Gladys is a badass Boricua who personifies strength, commitment, and

compassion. It took a lot sacrifice to take your family from Culebra to California, and along the way we encountered many obstacles, but you sobrevivistes. You showed your children that, although you are not perfect, you are committed to our success. Please take this document as a symbol of all your sacrifices for me.

- My siblings, Debbie, Janet and Charles, for helping me write my story. We are all very different people, but we all embody an aspect of our mother. It is because of her that our stories make sense. It is through you that my story makes sense.

- Michael for being my love, life-partner, and father to our children. You have kept me grounded while giving me the space to develop my intellectual interests. Although a Ph.D. is an intellectual pursuit, you remind me that public intellectualism is the required outcome of my academic work. We both believe strongly that education is transformational and do what we can to pass that message along to others. Thank you for giving me the time and space to follow my path. It is now your turn to do the same.

- My children, Tymen and Tayla, for being the reason why I do what I do. It is for you that I pursue education in order to make the path to a degree less mysterious and more inclusive. It is for you that I advocate for multilingual public education. It is because of you that my work on issues of diversity means something. It is 
because of you that I see my sacrifices worthwhile. May this document someday help you understand who you are.

- For Merita: may you forever know you are enough.

I want to thank my committee, Drs. Anaida Colon-Muniz, Quaylan Allen, Kimberly White-Smith and Sharon Elise, for their unwavering encouragement, support, and validation of my work. Knowing that scholars of your caliber were willing to acknowledge my potential and help me bring it to fruition provided the validation I needed to keep going. I want to also thank Dra. Marta Cruz-Janzen who mentored me from afar after I reached out to her a couple of years ago. Although you were in Florida, you found the time to read and meet with me online to discuss my work and provide feedback and suggestions on how to improve. You provided insight and guidance, and reminded me that my community is waiting for me. Your selfless actions inspire me to pay it forward when it is my turn to do so. It is also a reminder that it takes a village to raise a doctora.

As someone who has worked in educational administration for over 10 years before pursuing my doctorate, I have seen the difference a supportive environment can make on the lives of students. I want to thank the faculty and staff of the College of Educational Studies at Chapman University. Your collegiality, comraderie, and support while I was a student and then an adjunct, provided me with the encouragement I needed to practice my skills and hone in on what I have come to believe is most important: authenticity. 
And finally, I want to thank my participants, Marta, Taina, Anastacia and Erica, for opening themselves up to me as we together explored our lives as Afro-Boricuas. During the year and a half we had together, we shared our triumphs and our challenges. We laughed and took note of the disparaging treatment we endured to get to where we are today. We also acknowledged the strength and perseverance it took to live our lives authentically. They provided feedback and guidance on my (our) work and allowed me to be our spokeswoman via my dissertation of our experiences as Afro-Boricuas. Our stories are a testament to the intersectionality of our everyday reality. Thank you from the bottom of my heart for allowing me into your lives. I hope I did justice to our experiences. 


\section{EDUCATION}

Doctorate of Philosophy in Education

Doctoral Candidate in Curricular and Cultural Studies

Chapman University, Orange CA

Conferral: August 2016

Master's of Science in Counseling, emphasis in Student Development in Higher

Education

California State University, Long Beach CA

Degree Conferred: May 2006

Bachelor of Arts, Social Sciences, minor in Psychology

University of California, Irvine CA

Degree Conferred: June 1994

\section{Research Interests}

African Diaspora in the

Americas

Intersectionality and Identity

Gender, Race, and Culture

Latin@s in Education

Leadership in Education
Adult Education

Social Context of Education

Transition and Adjustment in Higher Education

Social Capital and the Minority/Minoritized Student

Experience in Higher Education

Diversity, Difference, and Inclusion 


\section{COURSE TEACHING EXPERIENCE}

\section{Chapman University}

Education Fieldwork

Foundations of Education

Information, Communication, and Management

Organizations, Ethics, and Society

Self and Identity

Valuing Difference in American Society

\section{PROFESSIONAL EXPERIENCE}

CHAPMAN UNIVERSITY

May 2011 - Present

\section{College of Educational Studies}

Adjunct Faculty

Teach courses for undergraduate and graduate students in the College of Educational Studies (CES), and the CES Integrated Educational Studies program. Provide innovative teaching methods (such as the flipped classroom) to introduce the students to new material and encourage deeper understanding of the most important concepts in the course. Use Blackboard to manage coursework, class participation, communication, assignment submissions, and grades. Communicate and provide substantive feedback both in-class and online to help student progress in their learning and writing. Provide timely and substantive feedback on student assignments throughout the semester. 


\section{Instructor (Online)}

Using an online teaching platform, teach courses in English reading, comprehension, and writing. I utilize video conferencing to speak with up to seven students in grades 1-3. We engage in reading passages and answering questions in order to gauge level of English language comprehension and mastery. We practice conversational English to reinforce the concepts learned in the assignments and practice using them in everyday situations. I assign homework that is read, graded with feedback, and returned prior to the next session.

UNIVERSITY OF CALIFORNIA IRVINE July 2001 - August 2012

School of Education: Admissions Counselor

School of Humanities: Program Manager, Academic English \& ESL School of Medicine, Office of Educational Affairs: Student Affairs Counselor

\section{CAREER SKILLS \& ATTRIBUTES}

Progressive experience in teaching undergraduate and graduate level education courses, with very positive student and peer feedback.

Excellent communication and oral presentation skills.

Extensive experience in collaborating with faculty, staff and students.

Well-developed skill and experience in establishing and maintaining interpersonal relationships, effective ability to listen, and willingness to delegate as well as to work collegially.

Expert experience with student affairs programs, policies, and practices, and college and graduate school entrance requirements. 
Knowledge of and experience in working in culturally diverse environments.

Bilingual English-Spanish: expert fluency in English (reading, writing, speaking), above average fluency in Spanish (reading, writing, speaking).

\section{RESEARCH EXPERIENCE}

Nubia-Feliciano, M. Narrative Study (dissertation research project). ¿Dónde

Pertenecemos? Narrative Analysis of Afro-Boricua Women's Experiences of Belonging Within and Beyond College. Chapman University. March 2014 to February 2016.

Nubia-Feliciano, M. Mini-Ethnography (course-based). Afro-Latinas - How They Use Language to Navigate Their Academic Identity. Chapman University, February May 2012

Nubia-Feliciano, M. Mixed Methods Study (master's thesis). The Transition Experiences of First-and Second-Year Medical Students. CSU Long Beach, February 2005 - May 2006.

\section{PROFESSIONAL SERVICES}

Session Administrator: California Sociological Association, Mission Inn, Riverside, CA, November 4-5, 2016

Session Presider: CES Senior Symposium, Spring Semester, Chapman University, May 13,2016

Manuscript Reader: Ethnicities Journal, Sage Publications, 2016

Session Leaders: Parent Discussion, Ethnic Studies Summit, Chapman University, April 16,2016 
Session Chair: IES Senior Symposium, Fall Semester, Chapman University, December 11,2015

Session Discussant: IES Senior Symposium, Spring Semester, Chapman University, May 15,2015

Session Administrator: California Sociological Association, Mission Inn, Riverside, CA, November, 2014

Session Discussant: IES Senior Symposium, Spring Semester, Chapman University, May 17,2014

Session Presider: CES Senior Symposium, Spring Semester, Chapman University, May 4,2014

Session Discussant: IES Senior Symposium, Fall Semester, Chapman University, December 6, 2013

IES Senior Student Profiles Reviewer: Spring 2013, Fall 2013, Spring 2014, Fall 2014, Spring 2016, Chapman University

IES Program Faculty Team Member: 2014-2015 Academic Year, Chapman University

\section{PROFESSIONAL AFFILIATIONS}

Member - California Sociological Association

Second Vice President - National Conference of Puerto Rican Women, Inc. (NACOPRW - Southern CA Chapter)

Member - Kappa Delta Pi (International Honor Society in Education, Chi Beta Chapter, Chapman University)

Member - Chi Sigma Iota Counseling Academic \& Professional Honor Society (Lambda Beta Chapter, CSU Long Beach) 


\section{PRESENTATIONS}

Nubia-Feliciano, M. Panelist: De Raices Viejas y Temas Florecidas: Afro-Latinidades and New Directionsin Latin@ Studies. Latina/o Studies Association 2016 Conference, Pasadena, CA. July 7-9, 2016.

Nubia-Feliciano, M. Race, Racism and White Privilege in Education. Class Presentation. Voice, Diversity, Race and Social Justice, Chapman University. March 8, 2016.

Nubia-Feliciano, M. Puerto Rican Superhero-LAK6. Class Presentation. Race and Identity in Comics, Chapman University. December 1, 2015

Nubia-Feliciano, M. Session Organizer \& Presider: Social Responsibility and Intersectionality. 2014 California Sociological Association. Mission Inn, Riverside, CA. November 7-8, 2104.

Nubia-Feliciano, M. Es Major Aqui or Alla: A Comparison of the Afro-Boricua Woman's College Experience. International Latino/a Studies Conference. Palmer House Hotel. Chicago, IL. July 17-19, 2014.

Nubia-Feliciano, M. Panelist: Reflection on the Proposed Latino/a Racial Category in the 2020 United States Census. International Latino/a Studies Conference. Palmer House Hotel. Chicago, IL. July 17-19, 2014.

Nubia-Feliciano, M. Classroom Presentation: Experiences of Afro-Puerto Rican Women in College. Latino Education in the U.S. CSU Long Beach. April 2014.

Nubia-Feliciano, M. Nepantla as Transition: Latinas During the First Year of College. National Academic Advising Association (NACADA) Region 9 Conference, San Diego, CA. May 2-4, 2011. 
Nubia-Feliciano, M. Session Leader: First Generation Student Advising Interest Group breakout session. National Academic Advising Association (NACADA) Region 9 Conference, San Diego, CA. May 2-4, 2011.

\section{BLOGS \& OTHER ONLINE ACTIVITIES}

Nubia-Feliciano, M. Personal Site: http://www.marienubiafeliciano.com

Nubia-Feliciano, M. (July 2014-present). Site Administrator: Latina/o Studies Initiative Facebook Page. Source site:

https://www.facebook.com/groups/latinostudiesinitiative/

Nubia-Feliciano, M. (April 2016-present). Site Administrator: Binders of WOCEducation Facebook Page. Source site: https://www.facebook.com/groups/1554200878212172/

Nubia-Feliciano, M. (11 August 2014). Guest Blogger: Marie Nubia-Feliciano at the First International Latina/o Studies Conference. Source site: http://doctoralatina.blogspot.com/

Nubia-Feliciano, M. (24 September 2014). Meet Marie Nubia-Feliciano! Source site: http://www.latinegras.com/\#!Meet-Marie-NubiaFeliciano-/cy97/1782B81AF1CE-4F49-B62D-B39FD7648A4D

Nubia-Feliciano, M. (14 October 2014). Kids Acquiring Languages. Source site: http://langokids-irvine.blogspot.com/

Nubia-Feliciano, M. (6 November 2014). Afro-Boricua Marie Nubia-Feliciano Focuses on Afro-Latino Identity in Education. Source site: http://aintilatina.com/2014/11/06/everyday-chica-afro-boricua-marie-nubiafeliciano/ 


\begin{abstract}
¿Dónde Pertenecemos? Narrative Analysis of Afro-Boricua Women's Experiences of Belonging Within and Beyond College
\end{abstract}

by Marie Nubia-Feliciano

Afro-Latinas, Latinas of African descent, exist at the intersections of culture, race, gender, and class, and this position informs how we experience our world. This unique experiential perspective is present when we decide to attend college. It was the goal of this research project to explore the post-secondary educational experiences of AfroLatinas. One particular group of Afro-Latinas was the subject of the research project: Afro-Boricua women.

The unique relationship that Puerto Rico has with the United States provided a backdrop for these women's college going experiences. It provided a historical framework of colonialism and racialization that occurred both on the island and stateside. Critical Race Theory was utilized as an analytical tool with which to interrogate the outcomes of intersections of this relationship. The experiences of the Afro-Boricuas were captured through narratives, in the form of conversations that gave way to testimonios that captured the thematic lives of the women. Through the use of Sociocultural Theory, the researcher incorporated qualitative research approaches including narrative inquiry to address the question: What are the experiences of college-educated Afro-Boricua women? The results of these conversations were then analyzed using a Critical Race Theory framework in order to investigate the role of race and how it manifested in the lives of women who live within a conflicting racial understanding of what "one drop" 
means. The conversations resulted in testimonios ${ }^{l}$ that added complexity to the narratives of other Latin@ $@^{2}$ and Afro-Latina voices speaking of their college experiences as well as their experiences in general.

'All Spanish language words will be noted in italics with a translation in parenthesis.

${ }^{2}$ The moniker "@" will be used as an inclusive symbol representing both male and female references inherent in the term Latin@. 


\section{TABLE OF CONTENTS}

CHAPTER 1: INTRODUCTION

Background

Statement of the Problem

Purpose of the Research Project

Summary of Theoretical Framework and Methodology 12

$\begin{array}{ll}\text { Assumptions of this Research Project } & 16\end{array}$

$\begin{array}{ll}\text { Limitations of this Research Project } & 17\end{array}$

Significance of this Research Project $\quad 18$

Summary

CHAPTER 2: REVIEW OF RELEVANT LITERATURE AND THEORETICAL FRAMEWORKS

Relevant Literature $\quad 21$

$\begin{array}{ll}\text { Theoretical Frameworks } & 28\end{array}$

$\begin{array}{ll}\text { Critical Race Theory } & 28\end{array}$

Sociocultural Theory 37

Borderland Mestizaje Feminism / Chicana Feminism 39

Black Feminist Standpoint Theory 41

Colorism and Microaggressions $\quad 42$

Colorism $\quad 42$

Microaggressions $\quad 45$

Intersectional Aspects of Afro-Latinidad $\quad 47$

$\begin{array}{ll}\text { Espiritismo } & 48\end{array}$

Womanism $\quad 49$

$\begin{array}{ll}\text { Africana Womanism } & 50\end{array}$

Mujerista Feminist Theology 51

Diagram 1: The Relationship of Theoretical Frameworks to the Afro- 53

Boricua

$\begin{array}{ll}\text { Summary } & 54\end{array}$

CHAPTER 3: METHODOLOGY $\quad 56$

Introduction $\quad 56$

Rationale for Research Approach: Using Narrative Inquiry to Explore the $\quad 58$

Lives of Afro-Boricuas

Recruitment $\quad 63$

$\begin{array}{ll}\text { The Participants } & 65\end{array}$

Participant \#1: Taina $\quad 66$

Participant \#2: Anastasia $\quad 66$

$\begin{array}{ll}\text { Participant \#3: Marta } & 67\end{array}$

Participant \#4: Erica $\quad 67$

Participant \#5: Marie $\quad 68$

Problems with Recruitment $\quad 68$

$\begin{array}{ll}\text { Sources of Data } & 71\end{array}$

Interviews: Face-to-Face and via Facetime/Skype $\quad 71$

$\begin{array}{ll}\text { Transcripts } & 73\end{array}$ 
$\begin{array}{ll}\text { Roundtable Discussion } & 75\end{array}$

Researcher Journal $\quad 75$

Data Collection Methodology

$\begin{array}{ll}\text { Data Analysis Methodology } & 79\end{array}$

Issues of Trustworthiness $\quad 81$

Validity and Trustworthiness $\quad 81$

Confidentiality and Anonymity $\quad 82$

Assumptions, Limitations, and Delimitations $\quad 83$

$\begin{array}{lr}\text { Assumptions } & 83\end{array}$

Limitations $\quad 83$

Delimitation $\quad 85$

Risks and Benefits $\quad 87$

Possible Ethical Considerations $\quad 88$

$\begin{array}{lr}\text { Subjectivity } & 89\end{array}$

$\begin{array}{lr}\text { Summary } & 92\end{array}$

CHAPTER 4: LO QUE ENCONTRAMOS [Findings] 94

Theme \#1: "You're Puerto Rican?" - Politics of Belonging 96

Subtheme \#1: Language $\quad 98$

Subtheme \#2: Archetypes and Expectations 102

Subtheme \#3: Feeling Along Among Your Own - Balancing a Sense 105 of Belonging with Alienation

Theme \#2: "I'm Not Mexican": More than a Monolith - Puerto Ricans 111

Lost in the Latin@Other

Subtheme \#1: Cataloguing Difference

Subtheme \#2: The Unknown/Hidden Colony - Collapsing of 119

Difference within the Veil of Ignorance

Theme \#3: "But You Look Black..." - Colorism and the Role of 123

Phenotypes

Subtheme \#1: Being Latin@ in the Black Community 124

Subtheme \#2: Being Black in the Latin@ Community 128

Subtheme \#3: Hair - "pelo malo, pelo bueno"

Theme \#4: "You Can Make It!" - Transforming the Politics of Exclusion $\quad 144$

Summary 149

CHAPTER 5: LA HISTORIA DENTRO DEL CUENTO [The Story Behind the 152 Story]

Marie - Merita

Where I'm From 155

Erica 156

Finding the Sosa in the Southern 158

Anastasia 159

Where I'm From 159

Marta 160

The height of your note (C) 161

Taina 
CHAPTER 6: DISCUSSIONS AND IMPLICATIONS 164

Coming Home 164

Revisiting the Research Question $\quad 167$

$\begin{array}{ll}\text { Testimonios } & 168\end{array}$

Diagram 2: The Testimonios as New Definitions of Self 170

$\begin{array}{ll}\text { Angry Black Latina } & 171\end{array}$

$\begin{array}{ll}\text { Incognegro } & 174\end{array}$

$\begin{array}{ll}\text { Coming Out / Combing Out } & 179\end{array}$

Cultural Litmus Tests $\quad 181$

$\begin{array}{lr}\text { Declaiming Voice } & 182\end{array}$

$\begin{array}{lr}\text { Implications } & 183\end{array}$

$\begin{array}{lr}\text { Further Study } & 187\end{array}$

$\begin{array}{ll}\text { My Responsibility as a Researcher } & 190\end{array}$

$\begin{array}{ll}\text { REFERENCES } & 191\end{array}$

$\begin{array}{ll}\text { APPENDICES } & 212\end{array}$ 


\section{Chapter One}

\section{Introduction - Background}

From the very beginnings of European travel and exploration, the imposition of a cast system favoring the presence of European phenotypical features, and admonished the presence of native or African phenotypical features has been the basis for exploitation of the native populations over the centuries. Zinn (2003) wrote about the use of terms such as black and white to provide a binary with which to distinguish badness from goodness. He writes, "Sometimes it is noted that, even before 1600 , when the slave trade had just begun, before Africans were stamped by it—literally and symbolically—the color black was distasteful"; and "Elizabethan poetry often used the color white in connection with beauty." Martinez (2008) wrote about the limpieza de sangre [cleansing of the blood], a concept developed in Spain during the 1500s. Spain was concerned with differentiating those who were native to Christianity (Old Christians) from Jews and Muslims who converted as a result of being persecuted for being non-Christian (New Christians). Old Christians requested evidence of New Christians back two generations for proof of religious affiliation. This eventually became a logistical impossibility to maintain because with time, New Christians became Old Christians. Still, Martinez states that "the idea of limpieza de sangre became a powerful tool of exclusion and one of the central fictions, ideological and genealogical, of early modern Spain." From the 1500s until today, the unequal relations created by colonialism have taken a toll on both the colonizer and the colonized populations.

Dr. DeGruy (2009) speaks of the post-traumatic slave syndrome that resulted from centuries of physical, psychological, and emotional trauma resulting from the 
transatlantic slave trade that began in the 1500 's. She asserts that both the colonizer and the colonized (in her example slave owner and slave) suffered distinct injuries from this history that can be seen manifested in our society today. The trauma is both psychological and epidemic. She notes that a psychological and cultural dissonance needed to be maintained in the minds of whites for them to come to believe that another human being was deserving of such violent and disparate treatment by another human being. As a result, she believes that our society is suffering from psychological damage created by, and maintained still, racism.

Zinn (2003) also writes of the psychological and physical injury slavery inflicted upon the population:

The system was psychological and physical at the same time. The slaves were taught discipline, were impressed again and again with the idea of their own inferiority to "know their place," to see blackness as a sign of subordination, to be awed by the power of the master, to merge their interest with the master's, destroying their own individual needs. To accomplish this there was the discipline of hard labor, the breakup of the slave family, the lulling effects of religion (which sometimes led to "great mischief," as one slaveholder reported), the creation of disunity among slaves by separating them into field slaves and more privileged house slaves, and finally the power of law and the immediate power of the overseer to invoke whipping, burning, mutilation, and death. (Zinn, 2003, online).

Within this experience, the idea of racism was created as part of an oppressive structure that imposed value on lightness over darkness. This response could be seen as a 
psychological rationalization to adjust to, and justify to one's self, an unconscionable reality that included purposeful subjugation and abuse of another human being. Cahill (1994) discusses how social constructions of race and ethnicity were used to classify and subdivide the peoples of central and South America (specifically Peru). Rosenthal (2004) provides a literary analysis of the origins of the concepts of miscegenation and mestizaje. She notes that "the Catholic monarchy did not send women with the conquistadors, leaving the men free to marry, cohabit with, or rape native women." (p. 6) Whereas "English women accompanied their men to the New World...such practices minimized interracial mixing and kept Anglo Protestant bloodlines pure." (p. 6). This provides a historical framework for understanding why the U.S. had anti-miscegenation laws, and why no such laws existed south of the U.S. border. Castas [casts], or classifications of lineage, was a concept used throughout the Spanish Americas during the 1500-1700 centuries. The primary purpose for the system was social control and determining a person's place in society. The four main categories of race included:

"(1) Peninsular, a Spaniard born in Spain; (2) Criollo (feminine, criolla), a person of Spanish descent born in the New World; (3) Indio (fem. india), a person who is descendent of the original inhabitants of the Americas; and (4) Negro (fem. negra) - a person of black African descent, usually a slave or their free descendants." (Native Heritage Project, 2013).

Here is a painting outlining the different castas that could result from the different variations of categories coming together: 


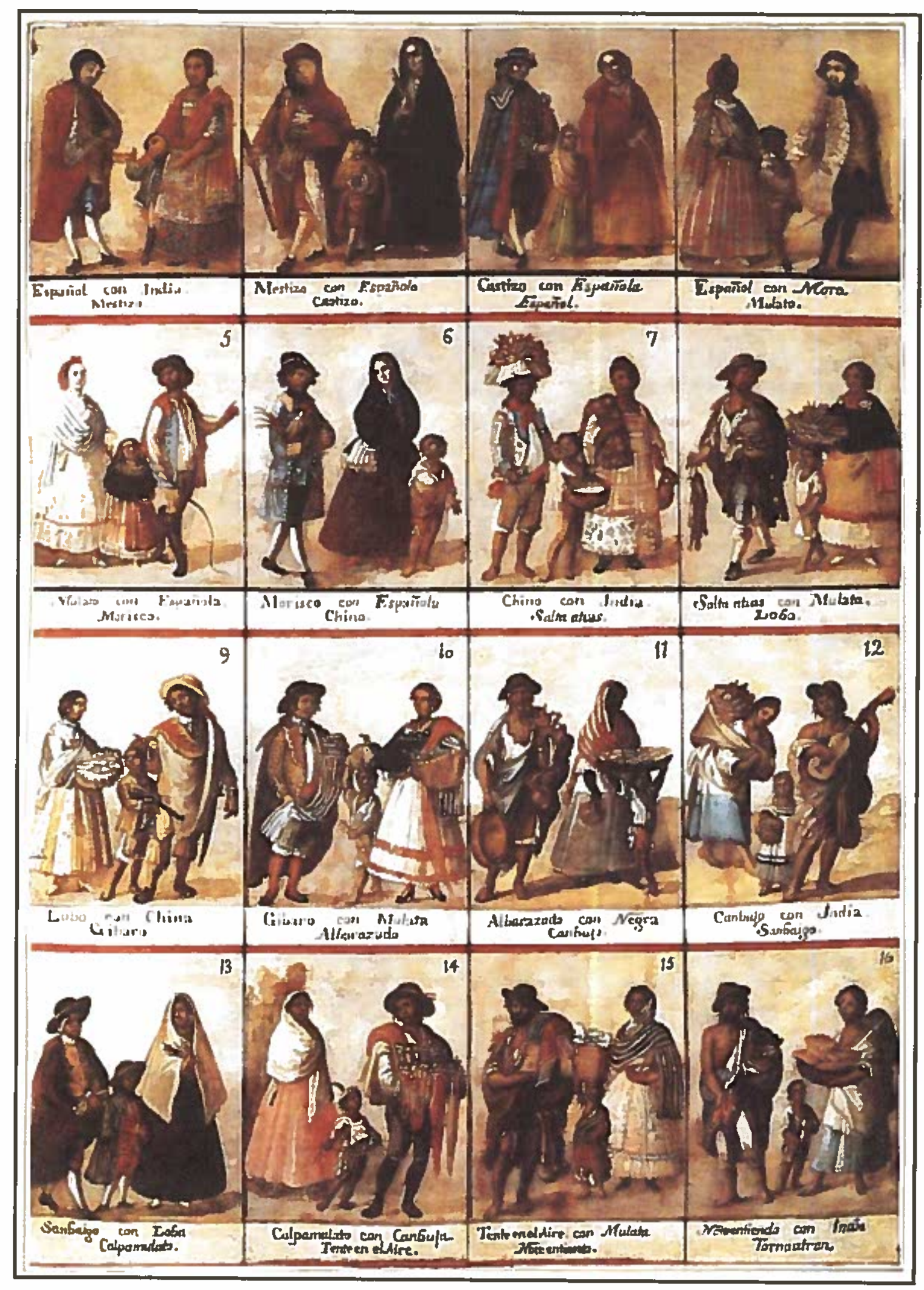

Image 1: Las castas. Anonymous, 18th century, oil on canvas, $148 \times 104 \mathrm{~cm}$, Museo Nacional del Virreinato, Tepotzotlán, Mexico. 
Wording from Panels in Row 1:

- Español con Indio: Mestizo

- Mestizo con Española: Castizo

- Casitzo con Española: Español

- Español con Moro: Mulato

Castas came about because it was assumed that:

"character and quality of people varied according to their birth, color, race and origins of ethnic types. It impacted every aspect of life, including economics and taxation. Both the Spanish colonial state and the Church expected more tax and tribute payments from those of lower socio-racial categories." (Native Heritage Project, 2013).

Castas also informs the conversations regarding blood quantum and the "one-drop rule" that was used in primarily the Southern U.S. initially during the 1800 s and 1900 s, then extended into the $20^{\text {th }}$ century. The "one-drop rule" determined whether one was nonwhite, specifically black, brown or of mixed heritage. Davis (1991) defines the one-drop rule as "any person with any known African black ancestry". This definition also informs the idea of hypo-descent, meaning "racially mixed persons are assigned the status of the subordinate group". It was used to perpetuate and substantiate anti-miscegenation laws preventing whites from marrying non-whites. This idea of "one drop" will begin to shift as it is reintegrated into the Caribbean consciousness as nationalism becomes the overwhelming ideology that dictates who belongs and how does not. 
Within this social and historical backdrop, I explored the educational experiences of Afro-Boricua women. I choose to call the participants Afro-Boricuas, rather than just Boricuas, as an acknowledgement that we must name ourselves using the language and ideas of our current location and historical context. It is also an acknowledgement of our inclusion in the African Diaspora. This is an acknowledgement that is often discouraged, or explicitly denied. With this acknowledgment we can then utilize a common language with those in our environment in order to force recognition of a reality that can remain hidden and not recognized by those with whom we are trying to engage. History and time is on our side as shifts in the consciousness of the Spanish America are seen as recently as this month. On December 8,2015, Mexico decided to add a racial category to its census. According to the Buletin de Prensa Nümero 524/15, "1.2 percent of Mexicans, 1.38 million people, are of African descent." (Instituto Nacional de Estadística y Geografia, 2015, p. 4). Very little is known about the educational experiences of AfroBoricua women. It is my intent to add our voices to the discourse, and how a sense of belonging is impacted by the historical, political, and social context in which we find ourselves.

Another example is the increase in Latin@ students enrolling in Historically Black Colleges and Universities (HCBUs). In a May 30, 2016 recent article in the online Huston Public Media project (Houstonpublicmedia.org), Laura Isensee discusses the increase in Latin@ enrollment at HCBUs in Texas. At Huston-Tillotson University, the increase in enrollment for the 2016-17 academic year was $15 \%$ from the previous academic year. One student who was highlighted in the story, Angelica Erazo, was looking for a place where she belonged, "I wanted a place that was small, one-to-one 
learning, because I wasn't so sure how prepared I was to go." Erazo goes on to say, "we don't feel excluded. At an HBCU, you feel included, you will get that help." Jerry Crawford II, a professor at the University of Kansas, who studies the HBCU system, states in the story that "this trend reaffirms their [the HBCUs'] mission to education people often oppressed by society." And finally, the Museum of African American Art is having an exhibition from June 5 - September 18, 2016 highlighting the African Diaspora in Mexico (Where Black is Brown: The African Diaspora in Mexico, http://www.maaala.org/exhibits.html). The tides are shifting and the acknowledgement of blackness in the Latin@ community is gaining prominence in the public consciousness. Where do we belong? Especially in college, the sense of belonging is crucial to personal and academic develop as it is tied to long-term college success (Astin, 1993). From this idea of belonging in college, one then is lead outwards to see where the AfroBoricua finds a home culturally. Identity is very much a product of the options we have available to us and how those opinions resonate with our environment. Who we think we are is a result of the material reality of our lives - where we live, who is in our lives, what types of schools are available, where we are welcomed. The opposite is also true: where don't we live, who is not in our lives, where do we not go to school, where do we not feel welcomed. Assuming we see ourselves as part of the Latin@ community, does the AfroBoricua woman encounter resistance from the Latin@ community in her efforts to claim her identity? Or is she like Jakiyah McKoy who, at 7 years old was told she was not "Latina enough" to be crowned the 2013 Little Ms. Hispanic Delaware (NBCLatino,com, 2013). This is despite the fact that she is Dominican, but presents to the world as an African American girl. Given that the African Diaspora is perceived differently 
depending on which ethnic groups it is situated in, this may make it difficult to have my project be more than just a collection of stories without an underlying contextual theme or thread connecting all these seemingly disparate stories. In order to narrow down even further the types of stories I wanted to collect, I decided to see how Afro-Boricuas (Puerto Rican women) experienced their world, beginning with their post-secondary educational experience. As a point of full disclosure, I included myself as part of the participants. Being an Afro-Boricua from Vieques and Culebra, the impetus for the research project was informed by my experiences. It would be disingenuous for me to stand outside the experience.

A List of Terms is provided in Appendix 1 (see p. 213) to help remind the reader of the factors influencing the research project. All Spanish language words and phrases not in quotes will be types in italics with the English translation in brackets following the word or phrase when necessary. Initially, the project examined the educational experiences of Afro-Boricuas stateside. Very quickly the participants and the researcher realized that the question needed to be expanded in order to highlight other aspects of the life of the women in the study. The following research question was used to guide the beginning of the project: (1) How Do Afro-Boricua women experience college? The final question was informed by the conversations that the women shared: What are the experiences of Afro-Boricua women? From this question, came others:

a. Where do we belong?

b. Who makes this determination?

c. When do we not want to belong?

d. What factors influence the decisions we make about our sense of belonging? 
From these points began the journal of uncovering the stories of the Afro-Boricua and her journey of becoming.

\section{Statement of the Problem}

It was and still remains a struggle to find any mention of Afro-Latin@s, in general, but Afro-Boricuas specifically, in the academic literature. Since 1900, when the first U.S. Census was done in Puerto Rico, the classifications used to capture the fluid identities of Puerto Ricans have changed over time (Office of Management and Budget 1997, as cited in Duany, 2002). In Duany's analysis, "the U.S. government sought to apply a binary race model to a fluid multiracial situation in Puerto Rico" (Duany, 2002, p. 250). Living in the U.S. adds a level of cognitive dissonance for many Puerto Ricans when asked to fill out a census form, or any other form where it asks for one to note her race. Even the term Afro-Boricua is an adjustment to the racialized ideology that exists in the United States. Many Puerto Ricans, both on and off the island, do not have a racial identity. The strong sense of nationalism supersedes the necessity to have a racial identity. In the United States mainland, racial identity trumps national identity. All those with European features are White, all those with African features (regardless of skin tone) are Black, and all those with "Asian" features are Asian. There is no room for those in between. This leaves Puerto Ricans of obvious African descent in a bind. The existence of the Afro-Boricua in the liminal space (Turner, 1969) of Latin@ and African identities, makes them difficult to pinpoint. From the research, it appears that Afro-Latina students in general face similar challenges as African American and Latino students. Their experiences living in the in-between spaces of cultural, ethnic, and racial reality informs their life both in and outside college. Knowing more about their experiences and how 
they make meaning of and contribute to their world will be vital to expanding the understanding of how this population of students experience postsecondary education.

Even in the US Census (2010), data is not kept for those of Black/African and Hispanic/Latino descent. The closest numbers reflect "Black in Combination", and this comprises $34.3 \%$ of those who identified as being of more than one race (The Two or More Races Population: 2010, p. 8). Their life in the spaces between identities and communities positions them to be seen both as bridges and crossroads, uniters and dividers, insiders and outsiders. Some of the literature refers to Afro-Latin@s as Black Hispanics. Given that Puerto Rico is a commonwealth of the United States, the census data - in general - includes their demographic information in the general discussion about Latin@s in the U.S. This is complicated further by the fact that throughout its use on the island, the Census in Puerto Rico has not had a consistent set of categories to capture the "discrepancy between self-representation and representations by others" (Duany, 2002, p. 252). When one disaggregates the data for college attendance, those who attended college in Puerto Rico, 94.7-100\% identified as Hispanic/Latino, with no designation of racial identification. What follows is information regarding Latin@s in general in the United States. Logan (2003) in the Lewis Mumford Center report, How Race Counts for Hispanic Americans, outlines the following:

a. "There are nearly a million black Hispanics. These people have socioeconomic profile much more similar to non-Hispanic blacks than to other Hispanic groups..." (p. 1)

b. "A very small share of Mexicans identifies as black. Still there are nearly a quarter million black Mexicans in the United States. Dominicans and Puerto 
Ricans are mostly to identify as black. Cubans, in contrast, mostly identify as white." (p. 1)

c. "Their [black Hispanics] individual characteristics such as income and unemployment make them in many ways more similar to non-Hispanic blacks than to other Hispanic groups." (p. 10)

From the data above, my choice of focusing on Afro-Boricuas is important and supported by the tendencies of stateside Puerto Ricans to choose "black" as a racial category. Despite our presence in the population, we are usually lost among the data. Logan's report gives us an understanding of the social and economic situation of Black Latinos in the United States. It parallels the realities of African Americans, both in income and unemployment rates, as well as living situations and educational outcomes. The challenge is to determine how the Afro-Boricua fairs in her world. Does she selfidentify with being of African descent? If she does, do others see her that way as well? How then does this identification done by her and others impact her educational and personal experiences?

One issue that this project hoped to highlight was the degree to which race is a social construct. The "one-drop" rule, a concept in the United States whereby blood quantum is used to designate the level of European or Black blood in a person, is inverted in the rest of the Americas. In Latin America, money has a lightening effect. By this it is meant that even those individuals who are unmistakably African, can be seen as "white" because they have a high income (Harris, 2013, Negro Documentary; Duany, 2002, p. 241). Money does not seem to have this same level of "whitening" in the United States. As Duany (2002) articulates, "Afro-Puerto Ricans continue to be represented as marginal 
and subaltern outsiders, as less Puerto Rican than white people" (p. 25). This reinterpretation of the "one-drop" concept is one of the issues this project will explore.

\section{Purpose of the Research Project}

It is the purpose of this project to explore how perceptions within and outside of the Latin@ community in general, and the Puerto Rican community specifically, impacted the interpretation of self and the overall experiences of college-educated AfroBoricuas. Our close proximity to the Black community places us in a space where we appear to belong but at the same time do not. We are like reliefs on cathedral walls that are a part of, but distinct from, the background. It is significant to highlight the lives of Afro-Boricuas for a number of reasons: it gives all of us a general understanding of this Latina sub-group; it provides a better understanding of the role of migration, and the history of colonialism and their impact on the lives of these women; it provides a deeper understanding of how colorism and other intersectional experiences have impacted this population of Latinas; and helps us better understand how the concept of the "one-drop" rule has been reinterpreted within the Puerto Rican community. This research project provided Afro-Boricuas a forum with which to have our voices heard. Developing an

integrated sense of self is vital to achieve success in school, work, and life. With time and continued conversations, we hope that our experiences bring us closer to that cultural and personal integration. The following research question was used to guide the research project: What are the experiences of college-educated Afro-Boricuas?

\section{Summary of Theoretical Framework and Methodology}

Rogoff's notion of cultural ways of knowing (2003), and development through participation in sociocultural activities (1995), was used to remind myself that we are all 
created from a cultural context. With this heighted awareness of my own cultural knowledge (I, too am Puerto Rican) I visited with the women and asked them to reflect upon their time in college, think about their level of engagement in the activities they chose to participate in, and look at the interactions they had with fellow students, faculty and staff both inside and outside the classroom. Looking at action in context, action being the unit of analysis within sociocultural theory (John-Steiner \& Mahn, 1996), this allowed me to see and hear the sometimes untold and unheard stories of the AfroBoricuas. As identities, ideas, and desires are products of our material reality, hearing through conversations the testimonios of Afro-Boricuas as they experienced college provided a glimpse into how the places and spaces in which they found themselves influenced the types of experience they had. It told a story of the type and quality of the relationships the women formed while living their lives. It also illustrated in what ways the Afro-Boricuas utilized the resources available to her in order for her to navigate the educational environment specifically and her world in general. Cruz-Janzen (2000) summaries this eloquently when she states "oral histories tell more and are often closer to the truth that what is written or discussed in polite society." (p. 1) In this project, I strove to provide an atmosphere where we all felt comfortable to have authentic discussions that brought us all closer to own truth.

In developing the idea for my dissertation topic, exploring the lives of AfroBoricuas has always been at the center. As I read and reflected, I began to wonder in what ways were our lives in school, in college specifically, influenced by our multiple positionalities (race, class, and gender). Were we seen as African American women, or dark skinned Latinas? Did the Latino community on campus welcome us (as 
demonstrated by our possible participation in leadership roles within cultural clubs), or were we kept to the margins? Did we choose not engage with the Latin@ community? Or we ignored altogether? Did we have to endure what I call cultural litmus tests to prove our claims to ethnic and cultural identity were real despite what our phenotype might inform the world as to who we are? Did the Latin@ community in general see us as one of their own? Did the African American community see us as one of their own, and was this invitation received well by the Afro-Boricua woman? These last two points are important to make because the level of racism, as inferred by the commonly heard sentiment mejorar la raza (improve the race), and its meaning to improve upon the "race" of Latinos by mixing with European rather than African people, can manifest in a form of internalized racism and ultimate rejection by Afro-Boricuas of overtures by the Black community to be a part of them. Also, the rejection by the Latin@ community can reflect the sentiment among many Puerto Ricans in the U.S. that blackness is not part of the "national identity", and "have avoided identification as black to escape their negative racialization" (Duany, 2002). To ignore the impact these two dynamics can have on the experiences of Afro-Boricua women would be to ignore a significant component of their life.

The design of this research project is qualitative in nature, focusing on narrative inquiry in the form of testimonies brought out through conversations. The overarching theory framing the methodological approach will be Critical Race Theory (Bell, 1995). This approach to structuring a research project focuses how race is defined and utilized in our everyday lives across the many contexts in which we find ourselves. It takes into account the racial context and the cultural nuances that influence the way interactions are 
enacted. It also informs how one should interpret what is said and done by participants and researchers engaged in a research project such as this one. Critical Race Theory was also used to analyze the themes and frame the discussion and implications of the findings.

Narrative inquiry is a useful tool for this particular research project. It can be used to examine the lives of marginalized communities like Afro-Boricuas by letting the women themselves "tell [their] own stories, write [their] own versions, in [their] ways for [their] own purposes" (Smith 2009, p. 29). As a group that finds itself in the contested spaces of society (ethnicity, gender, race, class, just to name a few) Afro-Boricuas can utilize narrative inquiry in order get their stories out to the world. Beverley (1991 and 2004), speaks extensively of one form of narrative inquiry that has been used to document and explore the specific lives of Latinos across the diaspora - the testimonio. Beverley (2004) notes the Spanish definition of testimonio describes it as "the act of testifying or bearing witness in a legal or religious sense" (Beverley, 2004, p. 32). Implicit in this definition is the lived experience as performed by an individual. For Beverly, the testimonio can take the form of a "novel or novella-length narrative", embodies the sentiment "the personal is political", a "direct-participant account, usually presented without any literary or academic aspirations whatever". In essence, a testimonio is a story within the Latin American traditional forms of literary narrative.

For Latinas in general, narratives are successful in capturing the experiences of those of us who live at the crossroads because they "integrate the personal and the political, the individual and the community, and link personal empowerment to social empowerment" (McCracken, 1999, p.65). A coming together of the person and society, the individual in context, Latina narrative requires us to move beyond just hearing stories 
of individuals, to stories as windows into the social environment in which these individuals find themselves. Testimonios, and the individuals who create them, are pathways to understanding current (or past) social phenomena. McCracken (1999) sees this connection as "the individual and the collective coexist[ing] in this autobiographical narrative" (p. 67). For the Afro-Boricua, she is connected to her identity through history, story, migration, and conflict. To use any other form of research methodology to capture her stories would require an intentional rejection of an essential way to capture her voice, and amount to a dismissal of a rich human history. By first looking at the Afro-Boricua's college experiences will also allow space to include any migration stories that may surface which are common in the Puerto Rican experience. It is a convenient starting point with which to explore other areas of our lives where we are engaged in the meaning making process. This research project contextualized the testimonios (a form of storytelling akin to cuentos) of the women as outgrowths of the sociological, political, and historical frameworks that references the colonial relationship that Puerto Rico still has with the United States.

\section{Assumptions of this Research Project}

This project made a number of assumptions before proceeding. These included the following:

- Issues important to Afro-Boricua women stateside will differ from those of other subgroups of Puerto Rican women both on and off the island, and other Latin@s in general.

- Not all Afro-Boricua women will identify as Afro-Boricua, but possibly as Puerto Rican, or Black. Cruz-Janzen in her writings uses the term LatiNegra 
in reference to the Latin@ cultural group within which the African identity exists. These shifts in cultural consciousness may prevent some Puerto Rican women from considering themselves part of the participant pool.

\section{Limitations of this Project}

This project was limited to Afro-Boricua women only. As a result, the gender neutral nature of Afro-Boricua will be changed and used in this research project to refer to women only. As a result, no men were included in the conceptualization, recruitment, and participation of this research project. This project was limited to Afro-Boricuas who resided stateside. One limitation included the factor of who attended a post-secondary educational institution (for associate's, bachelors or master's degree) within the last five years. This educational variable was used as a springboard for conversation, but did not limit our conversations to solely those experiences in college. College is a place where we are often confronted with the demand to tell our story. Students come together from different parts of life and in college, learn from one another. During this process, stories must be shared, therefore one must figure out what your story is. This unique time in a person's life presents a space where we flesh out what our story is and is not. This project was limited to those women who came forward and acknowledged that they are not only Puerto Rican but have a racialized identity to their cultural identity. In the end the participant pool included five women, including myself.

The literature review was primarily of English-language sources. The findings and conclusions may not be generalized to other Afro-Latin@ populations due to specific cultural relevance of being Puerto Rico had on the project. The findings can also not be generalized to Afro-Boricuas who live in Puerto Rico, as the participants were those who 
lived stateside only. Since the focus was on Afro-Boricuas, the testimonios were limited to those surveyed who identify themselves as Afro-Boricua. Language played a vital role in the collecting and engaging in conversations that resulted in testimonios. The conversations occurred either in English and/or Spanish, depending on what the participant wanted to use to express herself. Since I as the researcher, am a heritage Spanish language learner (one who learned the language at home but had limited formal instruction), there were points in the project where my limited language ability interfered with either the flow or understanding of the conversation. I am an Afro-Boricua woman, and while this perspective and cultural history supports my work in gathering data within the framework of Critical Race Theory, interpretation bias of the data may be inferred by other theoretical frameworks.

\section{Significance of the Research Project}

The inclusion of Afro-Boricuas' testimonios will add to the knowledge of how this group of Latinas lives in their world. It will provide a glimpse into the Latin@ and Black communities and how the Afro-Boricuas interacts with them. It will provide a perspective on the lives of Afro-Boricuas as they experience their world outside of the college setting. It will also extend the information we have of the fluidity and complexity of the Puerto Rican identity. It will inform how the Puerto Rican identity influences the concepts of belonging, influences personal and professional relationships, and how this is inextricably linked with the colonial history of Puerto Rico and the U.S. that spans 118 years. This research project will contribute to the growing literature on Afro-Latin@s in the African and Latin@ diaspora. It will also expand the conversations had in the areas of American, Caribbean, and Cultural Studies in general. It will inform education policy by 
showing how schools can see students as more complex beings who, when giving opportunities to do so, can contribute to the cultural tapestry of an educational setting. It will inform the efforts of those working to bring Ethnic Studies to the TK-16 educational environment. As recent racial incidents on college campuses prove, early knowledge of ourselves in context would provide a more informed perspective on how to integrate difference and value pluralism within and outside of the educational environment. And finally, this research project will expand the concept of Latinidad to be more inclusive of those of us who live a racialized reality within our Latin@ identity.

\section{Summary}

In this chapter, I introduced the motivations behind the research project, the background of who Afro-Boricuas are within the context of Afro-Latin@s. The statement of the problem highlights the rationale for the study. There is a summary of the postsecondary experiences of Latin@ in the United States, and an explanation of the theoretical framework and methodology utilized for the project. The purpose and research question and sub-questions were outlined as well and the assumptions, limitations and significance of the project. Chapter Two provides a review of relevant research, as well as a more substantive discussion of the theoretical framework that was used to inform the project. The major theories discussed include Critical Race Theory, Borderland Mestizaje Feminism/Chicana Feminism, Black Feminist Standpoint Theory, and Colorism. Although only Critical Race Theory is utilized, the others provide a rationale and context for the form and function of the project. Their limitations were discussed as well as how they informed the form and function of the research project. There is also rationale provided as to why one theoretical framework was chosen over another. 
There are conceptual frameworks that informed the research project by providing glimpses into the cultural and gendered realities that impact the lives of Afro-Boricuas. These include Espiritismo, Womanism, and African Womanism. Chapter Three describes the explicit steps I took to ensure that the project was sound and reflected the qualitative methodology that I was using to engage in conversation with the women in the project. Narrative inquiry was used to explore the lives of the Afro-Boricua women. Chapter Three also includes my subjectivity which informs my motivations for engaging in this topic for this project. In Chapter Four I provide a discussion of the themes that emerged from our conversations. I present my unique findings as testimonios, a politically infused form of storytelling that captures the sentiments and lived experiences of the women in this project.

In Chapter Five, I provide a biographical sketch of the participants. The chapter includes a narrative of our respective background as well as a poem or original work that the participants provided for inclusion in this document. Finally, in Chapter Six, I present a summary of the themes and testimonios framing them within the theories presented in Chapter Two, propose topics for further exploration, and present recommendations for the use of Narrative Inquiry and Critical Race Theory to explore the stories of other AfroLatin@s, as well as others who live in the liminal, cultural, racial, and gendered intersectional spaces of our society. 


\section{Chapter 2:}

\section{Review of Relevant Literature and Theoretical Frameworks}

What follows is a brief discussion of the theoretical and conceptual frameworks informing this research project. Critical race theory was used to frame the analysis of the unique findings of the conversations, which I call testimonios. A term borrowed from Beverly (2004), testimonios represent significant themes or statements and situates them in a social and political context. In the process of deciding on Critical Race Theory, and for comparison and acknowledgement of the racialized realities of Afro-Boricuas, Black Feminist Standpoint Theory and Borderland Mestizaje Theory were explored as cultural and racial points of perspectives with which to begin the analysis. They were juxtaposed to Critical Race Theory as a way to discern the specific and global relevance of each theoretical framework. Sociocultural theory informed the structure of the project and what approaches I used to engage with the participants. Within the same vein as sociocultural theory, but to afford a more nuanced understanding integrating spirituality and gender expression, other approaches were considered to frame my conceptual understanding of the experiences of Afro-Boricua women. These approaches included Espiritismo, Womanism, and Africana Womanism. There is explanation and analysis, as well as a discussion on the framework and its level of appropriateness to exploring the lives of Afro-Boricua women.

\section{Relevant Literature}

In looking at studies exploring the lives of Latinas in general, I looked to see what theoretical frameworks they used to inform the construction and analysis of the lives of Afro-Boricua women specifically. Many studies used a combination of narrative inquiry 
and mixed methods utilizing auto-ethnographies, narratives, quantitative date, and large national data sets. Through this inquiry, I came across some studies but they were broad in their scope as they addressed the Afro-Latin@ experience in general. Those that focused on Afro-Latinas specifically focused on such areas as: the Afro-Latin@ community and mental health issues (Comas-Diaz, 1994; Lopez, 2008); dating, mate selection, and desirability (Cruz-Janzen, 2001; Feliciano, Lee \& Robnett, 2011); ethnic identity and diversity (Trueba, Takaki, Munoz, Nieto, 1997; Raymondi, 2005; Villenas, 2007, Garcia, 2008; Torres-Saillant, 2007); skin color and phenotype (Telzer \& Vazquez Garcia, 2009; Lopez, 2008; Darity, Dietrich \& Hamilton, 2005); the legacy of slavery in the Americas (Davis, 2007); and the census (Amaro \& Zambrana, 2000). Some focused on the presence of the African people in particular cultural groups: Puerto Ricans (Rivera, 2006; Duany, 2002), Dominicans (Duany, 2002; Baily, 2001), and Cubans (Garcia, 2008; Mirabel, 2002). None really delved deep into the lives of Afro-Boricua women to document their stories of how they experienced their world.

When expanding the search to include other derivations of the Afro-Latina concept, I found some literature on the LatiNegra experience (Cruz-Janzen, 1999, 2001). There is no documentation distinguishing Afro-Latinas from LatiNegras. From the literature, both terms seem to refer to the same population of Latinas. Both refer to the brown or black skin, curly or kinky hair, and other phenotypical features assigned to people of African descent that are found within the Latin@ community. Cruz-Janzen (2001) considers LatiNegras "Latinas of obvious black ancestry and undeniable ties to Africa" (p. 108). In her article (a personal and historical analysis of the lives of AfroLatinas), Latinegras: Desired Women-Undesirable Mothers, Daughters, Sisters 
and Wives, Cruz-Janzen portrays Latinegras as "marked by a cruel, racialized history" because of their phenotypically African features. Cruz-Janzen (2002) sees racism within the Latin@ community as an "historical negation of the Black presence" (p. 12). We once again see repeated the acknowledgement and subsequent denial of blackness in the Latin@ community. To the researcher, the difference between Afro-Latina and LatiNegra is the emphasis on the cultural origin. For Afro-Latinas, the emphasis is on the African, while for LatiNegras, the emphasis is on the Latin@. Both of these positions will be explored further in the document.

There were articles that focused on the pathology created by the multi-ethnicity inherent in the positionality of the Afro-Boricuas. For example, Comas-Diaz (1994) looks at "her [the Afro-Latina] racial and gender exclusion throughout her life cycle" and "their impact on her mental health status" (Abstract). Amaro \& Zambrana (2000) discussed the different names Latin@s had to choose from in their home country (examples like criollo, mestizo, mulato, latinegra, indigena, White or Black) and how this created some confusion when Latin@s tried to translate these nationally and historically embedded codes of identity into the options provided on the U.S. Census. The article asks us to reflect upon the challenges created by "collecting race and ethnicity data that have considered the complexity of tabulating multiple race responses among Hispanics" (Abstract). This lack of consideration for how Latin@s self-identify, and what informs this self-identification, has now created the situation where it is difficult to accurately identify those Latinos who also identify racially as Black/African/African-American. Such oversight continues to perpetuate the invisibility of this borderland population, inadvertently silencing us in an apparent (either unconscious or intentional) attempt to 
erase us from our collective consciousness. I found no research that situated the lives of Afro-Latinas within a balanced (let alone positive) framework. In other words, there is no documented evidence in the academic literature that being Afro-Latina resulted in any positive social, economic, educational, or political outcomes. Those findings change, however, when one expands the search to see how the Afro-Latina, and the Afro-Boricua specifically, chooses to represent herself to the world in her own words. The world of the music, art, and literature, as well as first-person accounts, provide a rich and multifaceted understanding of the lives of the Afro-Latina, and the Afro-Boricua specifically. It provides a picture of strength, resilience, and sobreviviendo [surviving and thriving] and is informed by our unique positionality in the Puerto Rican and US imagination.

When expanding the search to literature, the arts, and public media, we find more mention of the Afro-Boricua experience. Llorens (2005), in her dissertation Fugitive Blackness, writes about the presentation of race in art in Arroyo, Puerto Rico during one of the carnival celebrations in the city. Through narrative analysis of the representations of Blackness she explores the use of Vejigantes to tell the story of the town's founding. In the end she found that the "narratives place women at the center, particularly black women as the embodiment of the hybridity, which characterizes the Caribbean." (Abstract, p.1). Quiñones Rivera (2011), in her dissertation Mediating Blackness, explores the relationship Afro Puerto Rican women have with popular culture. She contends that "Black Puerto Rican women mediate their Blackness by challenging folklorized representations of themselves that are perpetuated in local commercial media and advertising." (p. 1). Her methodology included analyzing narratives of Black Puerto Rican women as they viewed, interpreted, and responded to Puerto Rican media images 
of Black women. She looked to see how "Black Puerto Rican women interpret such commercial images in opposition and relation to everyday lived experiences." (p. xvi). Quiñones Rivera's dissertation revealed that "Black Puerto Rican women often posit radical rearticulations of Black identity from an interstitial audience position that involves oppositional readings of advertisements." (p. xvi). Her research also illustrated "the normative absence of Afro-Puerto Rican women from mainstream popular culture and, when they are visible, their simultaneous negative depiction." (111). This simultaneous presence and absence of women of African descent in Puerto Rican popular media articulates a dissonance as it relates to the level of acceptance of blackness in the Puerto Rican imaginary.

In other works by Quiñones Rivera, she explores her personal journey through the intersectionality of the Afro-Boricua's experience as it exists between the fluid interpretation promoted in Puerto Rico and the binary understanding of race that exists stateside. In her 2006 work entitled, From Triguena to Afro-Puerto Rican, Quiñones Rivera shares her experiences growing up in Puerto Rico. Through the use of autoethnography, she documents her life on the island and shares that she "grew up in a culture of racial silence where to speak of prejudice or Blackness was considered taboo." (p. 4) She documented the regularity with which the Afro-Boricua woman was "blamed or said to ser un acomplejado [have an inferiority complex]" (p. 4). In her writing, she challenges the utopian reality presented by Puerto Ricans that there is no racism among the people. She notes that "Black Puerto Rican women and men must function in a racially mixed society under the pretense of racial utopia. Presumably, we are all equals; therefore, it is assumed that racial discrimination does not exist." (p. 6). In the end, her 
move stateside allowed her to "embrace both [her] national identity (Puerto Rican) and racial identity (Afro-Spanish Caribbean)." (p. 9). She goes on to express her comfort in acclimating with the African American community, "In the United States, becoming Afro-Puerto Rican gives me the opportunity to have a community of people that look and feel in a similar way as I do myself." (p. 9). This resonance with the Black community in the U.S. is in some ways encouraged by design. Black and Latin@ communities are often situated next to one another. The findings of this project suggest that this may create issues for the Afro-Boricua in that she is then situated both literally and figuratively between two cultures and forced to engage with and confront external and internalized racism.

In their editorial work, and some would argue the definitive compendium of essays on the Afro-Latin@ experience, Jimenez Roman and Flores (2010) in The AfroLatin@ Reader explore the lives of Afro-Latin@s from almost every vantage point and social, political and historical perspective. In the following quote, we see the rationale for their work and the important contribution it makes to the study of the representation of the African diaspora in the Latin@ community:

The inadequacy of the Latin@ concept along with the need to broaden and complicate the notion of Blackness in the United States has given rise to the understanding that Latinidad and Blackness are not mutually exclusive and to a recognition of their interface in the Afro-Latin@presence.This term 'AfroLatin@' as applied to people in the United States emerged in the early 1990s when it became clear that race matters in the Latin@ community, and that these 
racial realities make it a grave distortion to think of Latin@s as a monolithic group" (p. 10)

Afro-Latin@ are at the vanguard of deconstructing the notions of what it means to be Latin@. Through our mere existence, we force all of society to see us as part of one collective history. We challenge our representations in public and private spaces, and confront those attempts to erase or distort what our presence means to the personal and societal relationships we engage in. Our bodies in action are the medium with which we engage in social change and demand that a shift in understanding occurs both within ourselves and in the broader society so that the idea of Latinidad is more inclusive. There are also recent efforts to bring to light the experiences of Afro-Boricuas. In her project, Black Borikua, Dr. Sharon Elise, professor of sociology at California State University San Marcos, along with her colleagues, explores the representations of Blackness in Latino culture, language, and identity. She has the particular interest in investigating this representation as it manifests in the Puerto Rican community. Other examples on social media include the websites of Boricua Chicks (http://www.boriquachicks.com/), Ain't I Latina (http://aintilatina.com/), and Black Latina Negra Bella (http://www.negrabella.com/). Put together, Afro-Latin@, specifically Afro-Puerto Ricans, are forging new paths and forcing the disaggregation of the data on Latin@s in the United States. Afro-Puerto Ricans are sometimes lost in the numbers and distort the notions of whiteness and blackness across all cultural, political and social spaces. 


\section{Theoretical Frameworks}

What follows is a discussion on the theoretical frameworks considered and ultimately decided upon which best illuminate the issues facing Afro-Boricua women. One in particular, Critical Race Theory, was decided upon as the best approach to analyzing the experiences and themes of the Afro-Boricua women in this research project. Other theories discussed in this section were considered for their relevance to the lived experiences of Afro-Boricua women (Black Standpoint Theory), cultural similarity (Borderland Mestizaje-Chicana Feminism), experiential analysis (colorism and microaggressions) and intersectionality (espiritismo, womanism, Africana womanism, and mujerista theory of justice). A diagram summarizing the discussion is provided at the end of the section.

\section{Critical Race Theory}

An outgrowth of Critical Legal Studies (CLS), Critical Race Theory (CRT) continues the effort to recenter the voices and experiences of those marginalized by the dominant culture and institutions in the United States. It is seen and used as an "analytical tool for interrupting racism and other forms of oppression" (McCoy and Rodricks, 2015, p. 5). CRT emerged in the early 1990's almost at the same moment that Afro-Latin@ as a concept entered the social dialogue of identity politics. It was seen as a cohesive theory during a time when there was "a perceived stalling of traditional civil rights litigation in the United States" (Taylor, 2009, p. 2). Legal scholars of the time came to the realization that "new theories and strategies were needed to combat the subtler forms of racism." (Delgado \& Stefacic, 2012, p. 4). Yosso (2005) contended that CLS "questioned the U.S. legal system's role in legitimizing oppressive social structures" (p. 4; as cited in McCoy 
and Rodricks, 2005). To this end, CRT became a vehicle for questioning "the very foundation of liberal order, including equality theory, legal reasoning, Enlightenment rationalism, and neutral principles of constitutional law." (Delgado \& Stefancic, 2012, p. 3). CRT challenged the very notions of fairness, rationality, and objectivity. It became a way to "engage race as both the cause of and the context for disparate and inequitable social and educational outcomes." (Dixon \& Lynn, 2013, p. 1). Taylor (2009) states that, "like other forms of critical inquiry, this scholarship began with a recognition of the relationship between knowledge construction, name and power." (p. 4; as cited in Taylor, Gillborn \& Ladson-Billings, 2009). Legal scholars of color were struggling with the omission of racism and the promotion of a meritocracy in the discussions surrounding legal issues involving people of color (Taylor, 2009). Ignoring this, many believed, lead to a distortion and misapplication of the law as it related to people of color. It also maintained a false sense of neutrality that distorted the lived realities of many people of color.

Most notable of these legal scholars of color who were instrumental in bringing this theory into the public consciousness, was Derrick Bell, one of the founders of CRT. In his critiques, Bell (1995) challenged the tendencies of the law to decontextualize and therefore "mask unregulated - even unrecognized - power." (p. 6). He has written extensively in the legal literature on the reliance of the presumption of neutrality within the law and how this was utilized to systematically disenfranchise people of color (see Delgado \& Stefacic, 1993, p. 468-475). Bell (1995) goes on to characterize the CR'T community as those who challenge the traditional notions of liberalism and "seek to empower and include traditionally excluded views and see all-inclusiveness as the ideal 
because of our belief in collective wisdom" (p. 5). This notion of collective wisdom speaks directly to the experiences of Afro-Boricua women in this project. Through our conversations we often were in agreement on the experiences we shared and what informed our understanding of those experiences. We had a collective wisdom that helped up help ourselves and provided a fund of knowledge from what to advocate for others.

Funds of knowledge are ways of knowing and being that a person or group uses to live in their world. A term originally used by Wolf (1996), funds of knowledge are "resources and knowledge that households manipulate to make ends meet in the household economy. These include caloric funds, funds for rent, replacement funds, ceremonial funds, and social funds" (as cited in Hogg, 2011, p. 667). How the idea of funds of knowledge can be applied to the Latin@ community was explored by such researchers as Velez-Ibanez (1988) and Moll, Amanti, Neff \& Gonzalez (1992). With their respective work in the Latin@ communities, the definition of funds of knowledge became more of a

"strategic knowledge and related activities essential in households" functioning, development and well-being. It is specific funds of knowledge pertaining to the social, economic and productive activities of people in a local region, not 'culture' in its broader, anthropological sense..." (Moll, Amanti, Neff \& Gonzalez, 2001, p. 139).

Velez-Ibanez (1988) infuses the "strategic knowledge" of Mexican and Mexican American families with context. He speaks of how these funds are composed of "familial households, neighborhoods, and institutional contexts." (p. 38). Context is important 
because it provides relevance and an idea of appropriate time and place for the implementation of knowledge. This understanding of funds of knowledge provides the Afro-Boricua woman a place from with to have an informed perspective on her life and allows her to connect with others. It gives her a source of unique knowledge that is informed by her history, the history of those she is in contact with. It informs the connections she carries with her and legitimates her claims of cultural and racial identity.

Bell (1995) addresses the criticisms of focusing on marginalization by noting that "it is not because we are victim-mongers seeking empathy in return for a sacrifice of pride." (p. 6). He stresses that through identification and recognition of those ordinarily excluded in the discourse of social justice can we hope for a "transformative resistance strategy" to occur. Afro-Boricua women have been historically and systematically excluded from the discourse on Puerto Rican identity, history and culture. CRT allows for a repositioning to the center these women's experiences in order to create a place from which to be recognize and transform the current realities in which we live.

Solorzano \& Yosso (2002, p. 24) outline the major tenets undergirding and informing CRT. These tenets help position CRT not only as a theory but as a methodology. The tenets assert that:

a. race and racism are central to the discussion

b. the dominant ideology must be challenged as the source of universal truths

c. experiential knowledge is important and central to understanding

d. only through a multi-disciplinary perspective can we begin to have an authentic understanding of the many truths informing our human experience 
Threaded throughout these tenets is the need to make visible the invisible; to acknowledge that knowledge is found in many places, spaces and bodies; to honor experience as a source of that knowledge and way of knowing; to acknowledge that differential treatment based on race is part and parcel of the lives of many; and to acknowledge that claims of universal truths are incomplete without the inclusion of all voices. Notable CRT scholars Delgado \& Stefancic (2012) speak to the need for a multidisciplinary approach by noting that "no person has a single, easily stated, unitary identity" (p. 10). In their statement they make the case for the need to address the intersectionality of our existence by using multiple approaches. We are all, to some extent, impacted by the intersectionality of our existence. This is a reality whether we are a working-class lesbian Korean American combat veteran, or an upper class transgender African America paleontologist, or a middle class Afro-Boricua college student. We all live intersectional lives, and when society ignores this fact - in thought or in action - it harms those of us who do not fit the prescribed outlines of what counts as part of the norm. By essentializing those who we do not deem a part of us in order to place them in a position to bolster our own superiority, society ignores the contributions such perspectives can make to the multidimensionality of our human experience. Through the use of the legal system, Critical Legal Studies speak to the challenges required of the structures that perpetuate the suppression of voices not seen as relevant or representative of the mainstream notions of what it means to be Puerto Rican. By extension, CRT brings that analytical approach to other areas of our social reality.

Zamudio, Russell, Rios, and Bridgeman (2011), in their book, Critical Race Theory Matters: Education and Ideology, discuss the four basic assumptions of CRT, 
which in summary are that race matters, history matters, voice matters, interpretation matters, and praxis matters. Like Bell (1995), Zamudio et al, stress in their highlighting of the praxis of CRT, that for critical race theorists, "it is not enough to simply produce knowledge, but to dedicate this work to the struggle for social justice." (p. 6). This praxis is situated in advocacy, a theme that emerged from the findings of this research project. It was vital for the women to put into action their experientially informed funds of knowledge in service to others. Through praxis, a space was created for all involved to see our truth through our purposeful interactions with others. This helped inform a kind of universal truth around which we as Afro-Boricuas came together. In addressing universal knowledge, Zamudio et al (2011) also contend that CRT "moves us all closer to the truths that critical thinking produces and the desire to right untruths" (p. 7). Including many voices brings us closer to understanding what makes us human, what informs our reality, and helps us see not only the intersections, but the interconnections of our human experiences with one another.

Delgado \& Stefacic (2012) present themes embedded within CRT that address the need for us to create spaces that allow nuanced analysis, create an existential space to have a reflective theory, in order to reach the understanding that the intellectual instruments we use to assess what is right and normal is limited by our own reality. These themes include: interest convergence, material determinism and racial realism; revisionist history; critique of liberalism; and structural determinism. Present in these themes is the tension between "idealists" and "realists" (p. 21). Idealists are those who believe that "racism and discrimination are matters of thinking, mental categorization, attitude, and discourse" (p. 21) While realists contend that "racism is a means by which society 
allocates privilege and status." (p. 21). This tension, as I understand, is a representation of the tension between the individual and the structure. It exemplifies different starting points from which to engage in the conversation of change. Idealists put the onus and responsibility for change on the individual, contending if only the individual changes, then society will change in concert. In contrast, realists see the onus and responsibility for change existing squarely within the walls of the structures of society. Change the structure, you change society.

Unfortunately, as CRT illustrates, the individual cannot be separated from the context (or structure) from which she or he emerges. It is my view that in order to initiate and sustain long-lasting change, all perspectives must be engaged with simultaneously in an act of praxis. Both the idealist and the realist from his or her relative position must work towards dismantling the strictures that limit human potential and foster racism. In the end, Derrick Bell (1995) conveys the sentiment of most critical race theorists when he says, "critical race theorists are committed to a program of scholarly resistance, and most hope scholarly resistance will lay the groundwork for wide-scale resistance." (p. 5). The hope is that individual and small-scale collaborative efforts lead to large-scale social movement and progress resulting in permanent structural change.

Bell (1995) notes that critical to the development of CRT is the existence of "a body of legal scholarship, now about a decade old, a majority of whose members are both existentially people of color and ideologically committed to the struggle against racism, particularly as institutionalized in and by the law." (p. 5). The objective of critical race scholars is to at once elevate the perception of inequality so that it is seen as an institutionally embedded issue, while expanding the conversation to include voices of 
those ordinarily left out of the discussions. This elevation and expansion is necessary if we are to truly reach the point in our social evolution where all voices, all perspectives, all experiences, and all lives matter. Having this quality and level of inclusion brings us closer to understanding the experiences of all members of our human family, and therefore provides a much fuller picture of who we are as a people. Only then can we engage in a discussion of universal truths that inform our understanding of human relationships and by extension our legal institutions.

As described above, Critical Race Theory is both a concept and a methodology that helps bring to light those voices and experiences that live at the intersections of our human experience, and provide an essential contribution to our quest for social justice and equity. This research project uses narrative inquiry (in the form of conversations) as a primary vehicle with which to showcase the lives of Afro-Boricuas and bring to light their lives within the contexts of being Latina and being part of the African Diaspora. Bell (1995) notes that "the narrative voice, the teller, is important to critical race theory in a way not understandable by those whose voices are tacitly deemed legitimate and authoritarian" (p. 9). Words have power, and are often used to determine guilt or innocence, inclusion or exclusion, social position, and educational experiences; in essence words add value and worth to an individual or situation. To this end, Critical Race Theory is an important and appropriate framework with which to example the themes of the testimonios that the Afro-Boricua women shared in this project. Narratives are important also because they "refut[e] notions of merit and colorblindness." (p. 8; as cited in Taylor, Gillborn \& Ladson-Billings, 2009). CRT challenges the notion of meritocracy and colorblindness directly. Just as one cannot avoid see us as women, one 
cannot avoid seeing us as black women. Both facts inform our realities and the quality of the interactions we have with the world.

One sentiment that most Critical Race Theorists agree on is that "an oppositional voice to the dominant or master narrative is an effective tool in making visible the structures, processes, and practices that contribute to continued racial inequality" (Zamudio, Russell, Rios, and Bridgeman, 2011, p. 5). Having Afro-Boricuas speak of our experiences is providing an often oppositional voice to what is purported to be an authentic voice of experience in the Puerto Rican community, as well as the broader Latin@ community. It also provides a different, yet equally appropriate, source of cultural knowledge.

Critical Race Theory "insists on grounding itself in a specific historical context" (Taylor, 2009, p. 7; as cited in Taylor, Gillborn \& Ladson-Billings, 2009), so in order to do justice to the testimonios that the women share, we need to acknowledge the history that we carry with us. We locate ourselves in a particular space and time within that history so our positionality informs our narratives. The historical and present colonial relationship that Puerto Rico has with the United States is evident in our very being: curl of our hair, the darkness of our skin, the broadness of our nose. This positionality has an intersectional quality, where we are not just women, we are black/brown women, we are Latinas, we are Caribeñas [women of the Caribbean]. We are marked by class, race, and gender and therefore experience "the intersectionality of subordination" (Taylor, 2009, p. 9; as cited in Taylor, Gillborn \& Ladson-Billings, 2009). Voice matters as an oppositional force to the subordination and dominant narrative, and "makes visible the structures, processes and practices that contribute to continued racial inequality" (Zamudio, et al, 
2011, p. 5). Because of these key conceptual points, critical race theory is the most appropriate approach to analyzing the testimonios of the participants. Critical race theory places at the center the experiences of marginalized communities, acknowledged the legal framework (informed by history) in place that dictates our lives, and provides a place from which to interrogate the problem and develop comprehensive solutions that take into account the entirety of our lives as intersectional beings. As corollaries to the CRT framework, the following concepts will be explored in an effort to expand the space in which we deconstruct and disaggregate the factors impacting the lives of Afro-Boricua women: colorism and microaggressions.

\section{Sociocultural Theory}

For this research project, I utilized sociocultural theory to examine the AfroBoricua's lives across many contexts, but beginning with their post-secondary educational experiences. John-Steiner and Mahn (1996) note that "sociocultural approaches emphasize the interdependence of social and individual processes in the coconstruction of knowledge" (Abstract). Vygotsky (1978) is credited with developing the concept of the person in context. The three major themes of his theory were summarized by Wertsch (1991) as the following: (a) individual development comes from social interaction; (b) human action is mediated by tools and signs; (c) when looking at social interactions and the tools we use to mediate those interactions, it is best to look at them through a developmental lens if we want to understand the interplay between them. (as cited in John-Steiner \& Mahn, 1996). When examining the lives of Afro-Boricuas, we must see them as women living in context, in relationship with their environment, in relationship with their culture, and navigating their racial identity. We use the tools that 
are familiar to us and that are part of what we interpret as the Puerto Rican culture to mediate our interactions. During these interactions, we change or modify the tools we utilize in order for them to better allow us to express our needs and wants to the world.

We also utilize these tools in order to change the perceptions of others so that they help the world see us. Sometimes the interactions and the tools that we use to mediate them are seen at best interesting, and at worse, suspect. In the end, sociocultural theory provides a framework with which to discover the cultural norms that Afro-Boricua women find themselves interacting with in their daily lives. We find that some of these norms are then adopted by the women for a variety of reason. For instance, in the discussion about hair that emerged during our conversations, the project participants all had at one time straightened her hair. The understood notion that Latinas have straight (or at least not kinky) hair was a norm that the women used when they felt they needed to in order to diminish their embodied difference within a group or situation. This and other experiences shared by the women highlight some of the outcomes of this adoption of cultural norms, and their interaction with their world.

Rogoff's notion of cultural ways of knowing (2003) helps situate the knowledge we have as Afro-Boricuas at the center of the conversation. It argues that cultural ways of knowing are valid sources of knowledge from which to critique the larger society. This cultural way of knowing is fostered and nurtured through participation in sociocultural activities (1995). As Afro-Boricuas, we uncovered through conversation, our shared understanding of Puerto Rican cultural ways of knowing that is informed by us as we embody the African diaspora in our lived experiences. There were at times variations on those themes, depending on the context we individually found ourselves in, and the 
meaning making process we engaged in to understand ourselves within those contexts. Through the conversations we engaged in, we co-created the space where testimonies emerged. Our conversations included the types of activities we participated in while in college, the quality of the relationships we had, how our actions were impacted by our sense of who we were, and how this self-perception interacted with the perceptions others had of us. To continue this discussion of what informs our ways of knowing, the following theories of positionality are presented in order inform the context in which the Afro-Boricua woman found herself navigating: Borderland Mestizaje Feminism/Chicana Feminism, and Black Feminist Standpoint Theory.

Borderland Mestizaje Feminism / Chicana Feminism. Aspects of Borderland Mestizaje Feminism (Anzaldúa, 1999) can be used to approach the experiences of AfroBoricuas. As a sub-group within the Latino community, Afro-Latinas in general have a unique vantage point from which to experience the world. We often stand in between many realities: Africana, Latina, woman, student, mother, sister, and so on. In this research project, all the women saw themselves first and foremost as Boricuas, while at the same time have a racially-informed identity that distinguishes us from other Boricuas. We also see ourselves being more than the essentialized representations of what is meant by Latina or Black. Because of this unique positionality, Anzaldúa's framework has some application. It is in these in-between spaces where Anzaldúa (1999) said exists the borderlands - a place where worlds come together, where meaning is imparted on the aspects of our lives we want to remember, take in, and make our own. This third space provides the Afro-Boricua the opportunity to explore multiple world views, and bring them together to form a new level of awareness of our engagement with our world. This 
engagement allows for a redefinition of what it means to be Latina or Black. It is similar to the counter-space that Solórzano, Ceja and Yosso (2000) speak of, or counterstorytelling that is central to the CRT theoretical framework. It is truly an example where one plus one is more than two. In our discussions we interrogated what informed the testimonios embedded in our conversations that were created in this space, and if the Afro-Boricua women are conscious of the process taking place. Simultaneously, I explored my own consciousness of my own in-between-ness and what sort of testimonios came out of my stories that I shared as I explored my own life and educational experiences as an Afro-Boricua.

The Afro-Boricua woman is a difficult population to identify. Only a handful of writers dedicate their work on this population specifically (see Quinones Rivera, and Cruz-Janzen). After a lengthy review of the literature to see if Anzaldúa's Borderland Mestizaje Theory had been applied to analyze the different aspects of the Afro-Latina in general, let alone the Afro-Boricua specifically, this author must conclude that there is no evidence of its use. Even in her seminal book, Borderland Mestizaje (1999), Anzaldúa only mentions the words African or Black four times. Her emphasis was primarily a study of the indigenous and feminine/feminist influences of the Latin@ culture on the concept of womanhood. This limitation then prevents me from using this theory exclusively, but was part of a composite of theories that I used to inform the intellectual underpinnings of this research project.

Despite these efforts to document the lives of Afro-Latin@s, none of the work I found looked at the Afro-Latina from the perspective taken by Anzaldúa. None have used the words mestiza, borderlander, nepantlera, to explore and describe the lives of the 
Afro-Latina. Although this is not an indictment on the ideas of Anzaldúa, it brings to mind the limits of this approach in exploring the lives of Afro-Boricuas. As a result, I found it necessary to expand the frameworks to see if other concepts could be used to examine the testimonios of Afro-Boricuas.

Black Feminist Standpoint Theory. The concept of the "outsider within" (Collins, 1986) can be used to describe the existential position of the Afro-Boricua within U.S. society. Although Collins was speaking about the epistemological position of Black women in the United States, her concepts can be applied to the Afro-Boricua. Duany (2002) echoes this sentiment because "the treatment of blacks [were] accorded a subordinate status in both societies" (p. 240), meaning U.S. and Latin America. Because of this assertion, the lived experiences of Afro-Boricuas can be assumed to be similar to those of African American women. Within the Latin@ culture, as well as outside of it, there is an expectation of what a Latin@ should look like. When thinking of a Latin@, many think of people like the singers Rickie Martin or Jennifer Lopez. Latin@s of visible European heritage with skin coloration considered trigueño/a [wheat-colored]. Very often, Afro-Boricua women in general do not see themselves portrayed in Spanish language television - aside from the occasional maid or adulteress. Nowhere on the Spanish language news television broadcasts does one see a dark brown face. In 1996, I wrote to Telemundo, the Spanish language television company, and asked why there were no Afro-Latin@s on their news team. In a written response, I was told that the newscasters (at that time) represent the majority of the viewing audience.

As Collins (1986) speaks of the positioning of African American women as "the inferior half of several dualities" (p. 520), one can see how the Afro-Boricua, who is 
positioned against her lighter-skinned sisters and the broader society's standards of beauty, is viewed as the one with less desirable features. Collins continues saying, "this placement has been central to their continued domination" (p. 520). As in Puerto Rico, "Afro-Puerto Ricans continue to be represented as marginal and subaltern outsiders, as less Puerto Rican than white people" (Duany, 2002, p. 25). This sociopolitical placement at the lower levels, or the margins, of society has an impact on how the Afro-Boricua experiences her world both in and outside of the educational setting. Black Feminist Standpoint theory speaks directly to the experiences of Afro-Boricua women. The only limitation is that Collins is speaking about the experiences of African American women, leaving out the Spanish colonial history that informs not only the Puerto Rican culture but the sense of national identity that Puerto Ricans carry with them as an essential component of who we are. Like Anzaldúa, Collins' work speaks directly to the racialized experiences of Afro-Boricua women and therefore comes close to providing a theoretical framework to examine the testimonios that come out of our conversations. As mentioned earlier, the limitations of Black Feminist Standpoint theory prevents me from using it exclusively, but was part of a composite of theories that I used to inform the intellectual underpinnings of this research project.

\section{Colorism and Microaggressions}

Colorism. Colorism is a concept first used extensively by Alice Walker in her 1982 book, The Color Purple. She makes reference to color when speaking about the relationships between the women and men in the book, using it to outline the details of privilege as it manifested in the lives of the characters. It is defined as "the allocation of privilege and disadvantage according to the lightness or darkness of one's skin (Darity, 
2007, p. 17). It differs from racism in that it exists within as well as outside of groups. As a result, discrimination based on skin color "is not based on racial categorization but rather on assumptions about the meaning associated with one's skin color" (Darity, 2007, p. 18). This is to say that colorism, like race, is informed by socially constructed ideas of beauty that are used to limit or restrict access to resources based on the perceptions of those in positions of power. Colorism falls within a larger group of biases called "racial phenotypicality", that describes a form of discrimination "which differences in facial characteristics that are typically associated with various racioethnic groups" and this difference constitutes "the basis for prejudiced beliefs or unfair treatment toward individuals" (Maddox, 2004).

As is the case, many of the women in this research project presented a variety of skin tones, facial features, and hair textures. Our skin tones ran the gamut of vanilla (during the winter), to nutmeg brown. Our noses were all broad, and our hair textures were all some variation of curly (loose to kinky). We embodied the various shades and textures that manifest when the African diaspora is present in a community. With this understanding, our stories were infused by how colorism manifested itself in our everyday lives. As a result, it was important to acknowledge and explore the ways in which colorism has been defined and interpreted in the academy.

Quiros \& Dawson (2013) note that "light skin operates as a form of social capital" (p. 289). Preference for lightness is found in literature, the arts, and in the media. As Russell, Wilson, and Hall (2013) assert that within the colorism process, there is an ideation and favoring of lighter skin tones over other darker shades. One can even look at cartoons to see that lighter characters are usually given positive characteristics while 
darker shaded characters are portrayed negatively. [For examples of this, I will direct you to analyze any Disney movie.] Because negative connotations and outcomes from colorism impact the psychological wellbeing of others, it may not be surprising to find discussion of colorism in psychology and counseling journals. Marira \& Mitra (2013), in their article Colorism: Ubiquitous Yet Understudied, discuss how colorism can and does cross the many indices in which we exist. Consistent with the CRT framework, Marira \& Mitra also conclude that colorism as a phenomenon "has implications that are capable of cutting across categories such as race, religion, gender, age, sexuality, nationalism, and occupation" (p. 103). In writing within the framework of Industrial and Organizational psychology, they stress that the "nexus of colorism and the labor market" highlights the disproportionate favoritism of lightness over darkness as evidenced by job attainment, income, and advancement (p. 104). As research within the Industrial and Organizational psychology field focuses on colorism and skin-color discrimination, one of the recommendations they make is for practitioners and researchers to "take a more active and vocal role in supporting an understanding of colorism in the legal system" (p. 106). Quiros and Dawson (2013), in their article, The Color Paradigm, look at the impact that colorism has on the identity formation process of Latinas within the context of Social Work. The participants in their qualitative study mention the impact of not only skin color but other phenotypical markers (shape of nose, texture of hair, etc.) as factors in how colorism affected their lives. Their findings suggest that it is crucial to understand "the simultaneous impact of negotiating varying social constructions of race and its impact on racialized Latino/as is complex and requires consideration of multiple factors specific to the Latino/a experience" (p. 294). 
In a June 9, 2015 submission to La Respuesta, an online Puerto Rican news magazine, Dorian Ortega spoke about Boricua colorism as it manifested in her family. She notes in her opening sentences that "a colorblind mentality is often used to invalidate the 'colored' Boricua experience." Similar to the experiences of the participants in this research project, much of the discrimination Ms. Ortega experienced was within her own family. She notes that it was "among mi gente", her family, that she experienced the most overt discrimination. To contrast this narrative, she speaks of her grandmother, a woman described as trigueña [wheat-colored] or prieta [dark] in skin tone and features. Being a woman who was proud of her skin tone, her grandmother told Ms. Ortega to "never let anyone make her feel inferior" and "siempre era orgullosa de mi color". Although it is within families that Afro-Boricuas often experience the most overt racial discrimination, it is also within the same families that we find our sources of strength and resiliency. One of the participants in this research project also credited her abuela [grandmother] for instilling a sense of pride in the African heritage in her family.

Microaggressions. A term coined in 1977 by Dr. Chester Pierce (along with his colleagues Carew, Pierce-Gonzalez, and Willis), microaggressions are "subtle, stunning, often automatic, and non-verbal exchanges which are 'put-downs' of blacks by offenders." (p. 65). Dr. Pierce and his colleagues first used this concept when discussing the impact of television, and specifically television commercials, on the psychosocial health of the young of the United States. They called microaggressions the "chief vehicle of proracist behaviors" (p. 65). He and his colleagues used their analysis to challenge the perceived innocuous nature of television and expose it as a vehicle through which racist social norms and priorities were being perpetuated. It was an attempt to taise awareness 
of the deleterious effects of microaggressions as portrayed by racial stereotypes on television. It was also an attempt to influence the quality of television children were exposed to in the hope of reducing racial animosity between blacks and whites. To quote them, "at least such awareness provides a possibility of no longer expecting and accepting as unremarkable that one group should always be life-shortened (in terms of rendering over time, space, energy, mobility), and the other life-transferring." (p. 66).

In subsequent decades, microaggressions have been studied more substantially across subject areas, and inclusively among other populations of people of color. Solórzano, Ceja and Yosso (2000) were one of the first researchers who looked at microaggressions in the college environment. In their study, Critical Race Theory, Racial Microaggressions, and Campus Racial Climate: The Experiences of African American College Students, Solórzano et al found that among African Americans, "many students spoke of feeling 'invisible' within the classroom setting" (p. 65). The students discussed also experiencing microaggressions in their interactions with faculty and other students. Solórzano et al contend that "whether inside or outside the classroom, racial microaggressions within academic spaces are filtered through layers of racial stereotypes." (p. 68). In their study, Solórzano et al propose the creation of "counterspaces as a response to racial microaggressions" (p. 70). Similar in form and function to the CRT concept of counter-story, counter-spaces "serve as sites where deficit notions of people of color can be challenged and where a positive collegial racial climate can be established and maintained." (p. 70). In discussing their experiences in college, the AfroBoricuas in this research project expressed similar interactions, and at times used the 
word "microaggressions" to describe what was happening to them both on and off the college campus.

In their 2014 study, Microaggressions and Latina/o Americans: An Analysis of Nativity, Gender, and Ethnicity, Nadal, Mazzula, Rivera and Fujii-Doe explored the manifestations of microaggressions within the Latin@ community specifically. In their mixed methods study, they sought to determine if microaggressions presented themselves differently "based on gender, ethnicity, or nativity among a sample of 311 Latino/a Americans." (Abstract). They reference a qualitative study done by Rivera, Forquer and Rangel (2010), which uncovered several themes of how microaggressions present themselves within the Latin@ community. They include the following as themes: intelligence is questioned, being seen as second class citizens, having pathological communication styles and cultural values; having an accent; being seen as an alien in their own land; being seen as criminals; and not having their lived experiences seen as valid (p. 69). The findings by Nadal et al (2014) suggest that "Latina women were significantly more likely to experience workplace and school microaggressions than Latino men" (p. 74). They also found that "Latina/os who were born outside of the United States were more likely to be seen or treated as an inferior than those Latina/os who were born within the United States" (p. 74). The intersection of race, immigration/migration status, and other social identities provide a complex space in which Latin@s experience microaggressions.

\section{Intersectional Aspects of Afro-Latinidad}

Finally, four conceptual frameworks were considered important to rounding out the discussion of Afro-Boricuas and the uniqueness of our experiences. They include: 
Espiritismo, Womanism, Africana Womanism, and Mujerista Theory of Justice. All four speak to the fluid existence of Puerto Ricans in general, and Afro-Boricuas specifically, that allowed for a capturing of the colonial, religious, spiritual, regional, and cultural influences on the world view of Puerto Ricans. It also demonstrates how the African diaspora is (or can be) situated within a Latin@ cultural frame.

Espiritismo. The Puerto Rican world view has within it a combination of perspectives: migration (mainlander vs. islander), Amerindian, African, and European. Within these different world views are woven the spirituality of the people. Hurtado (2003), in her discussion on Feminist frameworks, note that "ignoring the spirit leads to illness - both physical and psychological." (p. 217-218). In order to discuss the experiences of the Afro-Boricua, one cannot overlook the influence that spirituality, or espiritismo, has on the consciousness of Puerto Ricans. Rivera (2005) calls espiritismo the "flywheel" of Puerto Rican spiritual traditions. By this she means that it is "a metaphor to illustrate espritismo as an ethnocultural faith that maintains balance among four different cultures" (p. 295). It provides not only a sense balance within and among the cultures that make up the Puerto Rican people, but gives Puerto Ricans "who believe in espiritismo a collective world view" (p. 298) Among the many reasons I decided to bring attention to espiritismo is that is provides a medium for fluid understanding of the world in which we as Afro-Boricuas live in. According to Rivera, "...the eclectic nature of espiritismo gives Puerto Ricans a flexible means to rehearse the ongoing formation of their cultural identity." (p. 298).

This ability to adapt and remain flexible that is grounded in a spiritual tradition provides the Afro-Boricuas a unique set of skills that are further informed by her lived 
experiences. Just like the Afro-Boricua is a combination of different racial and cultural groups, "espiritismo is truly a combination of different religious beliefs such as African beliefs, Taino beliefs, and European beliefs (Catholic and Protestant)" (p. 297), and thus embodies the Afro-Boricua's spiritual existence in context. It informs a cultural identity that is distinctively Puerto Rican "within the context of continued political and economic dependence on the United States" (Duany, 2002, p. 17). It also is a reminder that Puerto Rican identity often encompasses a "fluid continuum of physical types" (Duany, 2002, 239). The Afro-Boricua is the embodiment of this ethnocultural worldview and utilizes it to make meaning of her lived experiences.

Womanism. Another perspective that takes the conversation of spirituality as a cultural component of one's world view one step further is womanism. Contrary to traditional feminist thought, womanism recenters the experiences of Black women to make it the primary perspective from which to view the world. Being both a renewed understanding of a particular world view, it is also an acknowledgement of the role of spirituality in the lives of the African diaspora. Williams and Wiggins (2010) states that “...womanism is focused on the issues of empowerment and life enhancement for African American women who embrace both their genders and their race and draw on the cultural/spiritual strengths of these aspects of self to confront the vicissitudes of life" ( $p$. 177). Harris (2007) sees womanism as "an approach to religious thought that is centered on the theological reflections and ethical world view of black women across the diaspora" (p. 393).

Womanism honors the spiritual and cultural aspects of the African woman of the diaspora. Using this perspective is important in representing the space occupied by the 
Afro-Boricua with regards to race, gender, and the espiritismo that is present in the Puerto Rican culture, wherever it may exist. Regarding the utility of womanism to capture the testimonios of Afro-Boricua women, Harris (2007) believes that "womanist analytical approaches are also constructive in that they name black women's stories and experiences as valid epistemologies and use these epistemologies as sources from which to uncover strategies of resistance and survival" (p. 393). The testimonios of the AfroBoricua will provide a window from which to understand our epistemologies and how we resisted and sobrevivimos (survived and overcame) during our time in college and beyond. It also highlights the intersections of our reality that are not necessarily anchored in our material reality. It also speaks to our realities within the black-white racial binary of the United States. Although we may not see ourselves as African American women, we are perceived as such, and therefore must us this understanding to make sense of our world in order to respond in accordance to our cultural priorities.

Africana Womanism. Hubbard delves deeper into the African aspects of womanism by discussing Africana womanism. For Hubbard (2012), Africana womanism is a broader concept, as it "is an ideology created and designed for all women of African descent." (p. 70). Like Harris, and Williams \& Wiggins, Hubbard believes that it is the African culture, history and spirituality that informs the world view of Black women, and therefore can be extended to include the world view of all women in the African diaspora, including Afro-Boricuas. Hubbard discusses a concept called sani-baat. This is "a Wolof word and Senegalese concept of 'voice throwing' (Kolawole, 1997-, pp. 6-7). By this is meant a disruptive and self-affirming insertion of women's voice in spaces and discourses which would exclude or silence them." (p. 74). For me, sani-baat is similar to 
a testimonio in its ability to redirect the conversation towards and infuse the perspectives of the Afro-Boricua into the Puerto Rican cultural discourse. It provides a vehicle with which to recenter our story and infuse it with a sense of urgency that is required for us to truly stop and hear her authentic voice. It provides a way of hearing the world differently by placing the Afro-Boricua at the center.

Mujerista Theory of Justice. A term coined by Isasi-Diaz (2010), is "a proposal that arises from the lived experiences of Latinas living in the U.S.A., committed to our liberation and the liberation of all peoples." (Abstract, p.37). According to Isasi-Diaz, Latina women have been ignored in their attempt to "contribute to a praxis of liberation a reflective action - grounded on our everyday reality." (p. 38). Given that this proposal of theology and ethics is grounded in an understanding of the colonial past of the Americas, it appropriate as a lens through which to examine the experiences of AfroBoricua. It is informed by Isasi-Diaz's experiences in Cuba and with the indigenous communities in Chiapas, Mexico. It is also informed by her analysis of the action, or inaction, of the Catholic Church. At one point, the Church in New York City decided to close some churches because of their inability remain economically viable. She mentioned that "what was most offensive for the women was that the Cardinal did not consul or in any way dialogue with the community." (p. 39) Isasi-Diaz wants the $21^{\text {st }}$ century to be "understood as a reconciliatory praxis of care and tenderness." (p. 40). She aligns her thinking to those of "different oppressed groups - women, children, the elderly, gays and lesbians and many others - and in reality of the nations of the so-called Third World." (p. 40). 
Although Isasi-Diaz's focus is an extension of a liberation theology, it falls short in being able to fully speak to the nuanced experiences of Afro-Boricuas. She collapses all Latinas into a monolith, and ignores the racialized realities that inject complexity into the lives of Afro-Boricuas complicating how they enact praxis. One aspect that does contribute to the analysis of the lived experiences of Afro-Boricuas is Isasi-Diaz's notion of present-future. She speaks of reconciliation as "healing the divisions that exist in order to create a common future." (p. 44). In order to move to the future, we must acknowledge the present realities. Espousing a nationalist belief that we are "All Boricuas" creates a veil of ignorance that helps perpetuate the racism that Afro-Boricuas experience both within and outside of our communities. Using a lens informed by a "present-future" epistemology will help us as a Puerto Rican community redefine and reaffirm all of our selves.

Below is a diagram outlining the theoretical concepts explored in this chapter, and how they are related to one another. It also provides a visual representation of how the concepts help us better understand the Afro-Boricua and her unique perspective vis a vie race, culture, gender, and history. 


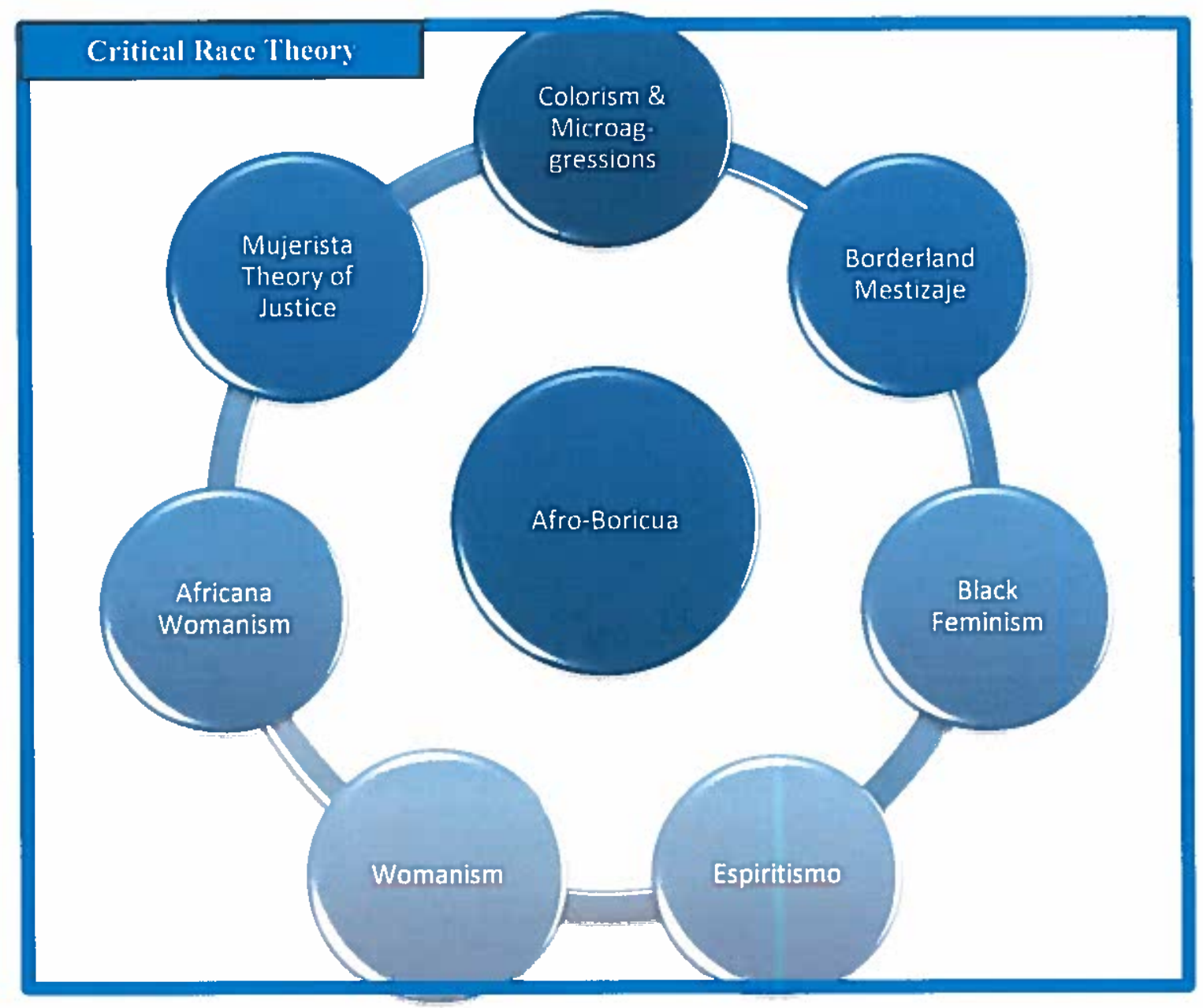

Diagram 1: The Relationship of Theoretical Frameworks to the Afro-Boricua 


\section{Summary}

This chapter included the review of relevant research and theoretical frameworks. It identified the utility of using Critical Race Theory for a framework for the analysis; Sociocultural Theory as a theoretical approach to the project; Borderland Mestizaje/Chicana Feminism, Black Feminist Standpoint theory, and Colorism and Microaggressions as ways of interpreting the elements found within the positionality of the participants. The chapter also provided a rationale for the appropriateness of these theories as well as the limitations inherent in them. Espiritismo, Womanism, Africana Womanism, and Mujerista Theory of Justice were concepts presented as intersectional aspects of Afro-Latinidad, which spoke particularly to the cultural, historical, racial, gendered, and spiritual experiences of the Afro-Boricuas in the project. These theories provided a guideline with which to approach, interpret, and discuss the methods used to begin and conclude this project. As with all guidelines, there is room for more detail.

The deficiencies in the application of theoretical frameworks to provide a full explanation of the issues confronting Afro-Boricuas highlight the need for further study and exploration of the intersections of identity where the Afro-Boricua resides. In the end, Critical Race Theory was chosen as the overarching theoretical framework with which our story is best told. Our racialized intersectional experiences require us to not ignore the shifting definition of race, and how it is utilized by many to delineate membership in cultural and racial groups. All other theories discussed are some aspect of Critical Race Theory, and provide a more nuanced understanding of positionality, intersectionality, spirituality and agency. 
Our story is inadequately told with the theoretical perspectives currently available. This project brings light to the neglected liminal space in which Afro-Boricuas inhabit. What now follows is a discussion of the method that this project used to conceptualize, construct, recruit, and execute this project. 


\section{Chapter 3: Methodology}

\section{Introduction}

This research project's primary objective was to document how Afro-Boricuas experience college. As the project progressed, it became clear that the participants also wanted to speak about their lives outside of school. As a result, the project shifted to include a detailing of those experiences outside of college as well. It initially focused on the college-going experiences of Afro-Boricuas who attended college stateside. Beginning here is important because it is in college where we often are placed in the position to tell our story to others who do not know us. In telling our story and experiencing the responses to those who hear it usually for the first time, we develop an insight into who we are, how we are perceived, and come to understand where we fit in the larger conceptualization of what it means to be a person.

Exploring the lives of Afro-Boricuas within and outside of the Puerto Rican diaspora allowed for a discussion of how the concept of tace is conceptualized and framed within and outside of college, within and outside mainstream U.S. culture, as well as within and outside of the Puerto Rican community. This level of contextual analysis added to the understanding of the role the matrix of race played in the lives of the participants, and that permeates the US social structure and influences the concept of race within the Puerto Rican community.

In order to document the multidimensional relationship of Puerto Rico and the U.S. is manifested in the lives of the Afro-Boricuas, I asked them to engage with me in conversation to share our stories. These stories in turn became testimonios [testaments] to our experiences, focusing primarily on our experiences while attending college, and then exploring other aspects of our lives as the conversations evolved over time. In so doing, it 
allowed me the opportunity to examine how the college environment reflected the social, political, and historical contexts and realities the women found themselves in, and how this impacted their lives and relationships both on and off the college campus. The hope was to build "knowledge about the multilayered tensions and their management as individuals position themselves and are positioned in everyday life" (Nasir \& Saxe, 2003, p. 17). Afro-Latinas in general live in many cultural and political worlds. As Latinas of African descent, our presence represents over two hundred years of colonialism and enslavement of African peoples in the Americas. Being darker skinned Latinas, we also occupy the lower socioeconomic levels of society, as is the fate of other dark-skinned people of the Americas (Roman \& Flores, 2010). Specifically Afro-Boricuas are seen as "less Puerto Rican than white people" (Duany, 2002, p. 25). Beginning with an exploration of the sociocultural, as well as political context of the college experience, then expanding to the experiences in other social contexts, will provide a glimpse into the lives of the Afro-Boricuas in this research project.

From the little research that exists, it appears that Afro-Latinas in the U.S. in general attend college or university in similar numbers as other Latinos. NCES (2010) documents that $31.9 \%$ of all students in 2010 that attended a post-secondary educational institution were Hispanic, with $13.3 \%$ being Hispanic women, and Afro-Latinas making up approximately $2.5 \%$ of the total Latino populations. Put together, Afro-Latinas inhabit a unique, albeit small, place in the Latino community that is impacted by the intersection of race, class, gender, and economic status. They are often overlooked when educational administrators seek to develop programs to reach out and service the Latino community on college campuses. They also may be difficulty to identify on campus because they 
could either not affiliate with any cultural group on campus, affiliate with a non-cultural service organization, or affiliate with the Latino or Black student population. It is my desires to give voice to the experiences of Afro-Boricua women by documenting their testimonios about their college experiences in order to gain a deeper understand of their nuanced existence within post-secondary education. The following research question was used to guide the project: How does the Afro-Boricua experience college? However as time progressed the research question changed to better capture the content of the conversations that informed the findings of this project: What are the experiences of Afro-Boricua women?

\section{Rationale for Research Approach:}

\section{Using Narrative Inquiry to Explore the Lives of Afro-Boricuas}

Narrative inquiry can be used to explore the lives of marginalized communities like Afro-Boricuas by letting the women themselves "tell our own stories, write our own versions, in own ways for our own purposes" (Smith 2009, p. 29). As a group that finds itself in the contested spaces of society (ethnicity, gender, race, class, just to name a few) Afro-Boricuas can utilize narrative inquiry in order get their stories out to the world. Beverley (1991 and 2004), speaks extensively of one form of narrative inquiry that has been used to document and explore the lives of Latinos across the diaspora - the testimonio. Beverley (2004) notes the Spanish definition of testimonio describes it as "the act of testifying or bearing witness in a legal or religious sense" (Beverley, 2004, p. 32). Implicit in this definition is the lived experience as performed by an individual. For him, the testimonio can take the form of a "novel or novella-length narrative", embodies the sentiment "the personal is political", a "direct-participant account, usually presented 
without any literary or academic aspirations whatever". In essence, a testimonio is a story within the Latin American traditional forms of literary narrative.

When written down, the stories of Afro-Boricuas become part of a form of communication that privileges written literacy. For Beverley (2004), testimonios "gives voice in literature to a previously 'voiceless', anonymous, collective popular-democratic subject" (p. 38). The content of the communication is to be assumed to be authentic, and the researcher should be more "concerned with sincerity rather than literariness." (Beverley, 2004, p. 32). It is the role of the researcher to bear witness and record what the storyteller wants recorded and to understand that the choice of what is said is impacted by the researcher's inclusion in the lived experience of the storyteller. The stories come to exist in what Beverley (1991, p. 4) considers "a discursive space", a space where multiple lines of reasoning and historical periods may be woven together in a logic only known to the storyteller in order to describe a uniquely personal experience.

When the stories of persons like Afro-Boricuas are told, "it allows the entry into literature of persons who normally, in those societies where literature is a form of class privilege, be excluded from direct literary expression, persons who have had to be 'represented' by professional writers." (Beverley, 2004, p. 35). Narrative inquiry privileges the ways of documenting life by those who have different cultural experiences than those of what Smith (2012) would call "colonizer" or "imperialist". For Beverley (1991), "testimonio appears where the adequacy of existing literary forms and styles even of the dominant language itself - for the representation of the subaltern has entered into crisis." (p. 6). Meaning, when no other narrative form can capture the essence of the experiences of the marginalized, the disenfranchised, the ignored, and those living at the 
intersections of society, testimonio is a method through which their lived experiences can be brought to light and shared with the world; where their worlds can speak to the struggles for power and recognition. Testimonio allows for what Wise (2013) calls the "encyclopedic version of ourselves" to be revealed in order to decompartmentalize the lives of those that society find hard to compartmentalize in the first place; to disaggregate those who disappear in the aggregate data; to parse out the stories of those whose own stories are lost in the subtext. In so doing we infuse story with power.

Goodson (n.d.) discusses the concept of narrative capital as it relates to the idea of social capital. First articulated by Hannifas in 1916, social capital is defined as "those tangible substances that count for most in the daily lives of people, namely good will, fellowship, sympathy, and social intercourse among the individuals and family who make up a social unit" (Hannifas, 1916, as cited in Kikuchi \& Coleman, 2012, p. 187-88). Taking Bourdieu's contemporary definition of cultural capital as a conceptual corollary where "the cultural and symbolic capital represent, in fact, those aspects of interest of the dominant groups that can be considered and accredited as a learning success" (Bourdieu and Passerson, 2000, as cited in Goodson, 2007, n.p.). Goodson sees narrative capital is a "new form of capital" that has increase in relevance and appropriateness in providing a vehicle from which to center other voices in the discourse of life experiences. Embedded in this idea of narrative capital is the concept of power. Goodson (2007) speaks to the presence of that power as existing in the space he calls "the interface", a space "between knowledge and interests of powerful groups of society." (n.p.). This is reminiscent to Anzaldúa's (1990) concept of interface, "the very spaces and places where our multiplesurfaced, colored, racially gendered bodies intersect and interconnect" (p. xiv). These are 
both examples of how Afro-Boricuas can live in contested spaces, spaces where power, authority and voice are sought-after commodities. Possessing this power allows for a kind of capital that can only come with telling stories of what it is like to exist in such spaces.

Narrative inquiry can also be seen as a way of creating identity. Somers (1994) sees narrative as a way for "those groups and individuals who have been marginalized by prevailing social theoretical accounts for why people act the way they do" to assert their presence and demand validation of their experiences (p. 608). It is a way of "getting heard" that may require new theoretical and methodological frameworks (p. 610). Narrative inquiry allows for new stories to be told and read as a way of pushing against what is considered the "stable content of the new categories of identity" (p. 611). For the Afro-Latina, it is important that she be allowed to tell her story in order for her to infuse her space with her history and her context, validating her experience through the power of voice, and challenging the "essential or fixed categories constructed from given attributes" (p. 611)

For Latinas, narratives are successful when they "integrate the personal and the political, the individual and the community, and link personal empowerment to social empowerment" (McCracken, 1999, p.65). A coming together of the person and society, the individual in context, Latina narrative, and by extension those of Afro-Boricuas, requires us to move beyond stories of individuals to stories of individual as windows into the social environment in which they find themselves. Stories, and by extension individuals, are pathways to understanding current (and past) social phenomena. McCracken (1999) sees this connection as "the individual and the collective coexist[ing] in this autobiographical narrative" (p. 67). For the Afro-Boricua woman, she is connected 
to her identity through history, story, migration and conflict. To use any other form of research methodology to capture her stories would require an intentional dismissal of a rich human history.

Despite its unique applicability for capturing stories, specifically those of the Afro-Boricuas, narrative inquiry has received criticism because of its lack of reliability. Goodson (2006) outlines some problems he found:

"Life stories are only constructed in specific historical circumstances and cultural conditions that have to be brought into our methodological grasp". "Second then, the individual life story far from being personally constructed is itself scripted. The social scripts people employ in telling their life story are derived from a small number of acceptable archetypes available in the wider society." The life story, therefore, faces a third dilemma in that it can be a de-contextualizing device, or at the very least an under-contextualizing device." (Goodson, 2006, p. 15)

In Critical Race Theory, narrative is used as a source of "storytelling resistance", and a "method of telling stories of those people whose experiences are not often told (i.e., those on the margins of society.)" (Solórzano \& Yasso, 2009, p. 138; as cited in Taylor, Gillborn \& Ladson-Billings, 2009). Narrative allows access to the experiences had at the intersections of race, class, and gender. It is a form of expression that is often used to elevate the voices of those who feel they have not been heard enough. Storytelling is, as Solorzano \& Yasso contend "racialized, gendered, and classed, and these stories affect racialized, gendered and classed communities." (Solórzano \& Yasso, 2009, p. 138; as cited in Taylor, Gillborn \& Ladson-Billings, 2009). 
There is nothing clean or straightforward about narrative inquiry; subjectivity and context are embedded within its framework. The person telling the story is the central character, so to speak, of all the data being collected. Somers (1994) states that "narrative analysis is not something easily assimilated into the social-science research agenda" ( $p$. 606). As storytelling lends itself to the humanities, Somers (1994) also states that narrative "is non-theoretical, rather than one of the theoretically-driven social sciences" (p. 606). Concepts that come out of the qualitative research approach would challenge this assertion (for instance grounded theory). Regardless of the criticism, there exists a sense of vindication of experiences when someone is allowed to speak her truth. Narrative inquiry and analysis allows us to read and hear that truth.

\section{Recruitment}

Since the research project focused exclusively on women, the term gender-neutral term Afro-Boricua was used to exclusively refer to women of Afro-Boricua descent. No men were included in the project. The women were initially recruited from my membership in the National Conference of Puerto Rican Women, Southern California (NACROPRW-SoCal) which provided me access to Puerto Rican women living in Southern California. Being part of the National Conference of Puerto Rican Women (NACOPRW), it allowed me to extend my recruitment nation-wide. There is also a Puerto Rican cultural center in San Diego, the House of Puerto Rico in Balboa Park, through which I also solicited participation. I also contacted a non-profit organization in southern California named Multiracial Americans of Southern California. The organization has a section for Latinos of Mixed Heritage, where I was able to solicit participants. I followed up with all the individuals, groups and organizations mentioned 
above and made arrangements to make presentations outlining the purpose of the research project. This informed the individuals, groups and organization members of my intentions and the level of commitment that is required of those who chose to participate. Solicitation was also done using social media platforms. Participants were recruited using online communities on Facebook® and Afro-Latin@ blogs. Colleagues also posted the recruitment flyer on other listservs, and communicated directly with students at their educational institutions.

The participants were selected based on their self-identification as Afro-Boricua, that they are (or were) in the last half of their college experience or recently graduated from college, and that they had the time to commit to the project. A snowball method was used as a form of purposive sampling (Schwandt, 2007, p. 271) to provide current participants the opportunity to suggest others who would be interested in participating in the research project. Ultimately, four women came forward and participated in the project. Because of the dearth of participants, $I$ as the researcher, in consultation with my dissertation chair and advisor, made the decision to include myself as one of the participants. This allowed for an insider and outsider positionality that informed my contribution to the project, and added a unique collaborative dimension to the endeavor. It also was emblematic of the ways many Afro-Boricuas interact with their world, so it was a natural accommodation.

In order to receive permission from Chapman University, an Institutional Review Board (IRB) application was submitted in the latter part of the Spring semester 2014, specifically May 8 . The application was drafted answering all the required questions and reviewed by my dissertation chair in order to ensure that the application was complete. 
The IRB was approved on July 7, 2014, allowing me to begin the outreach efforts in time to begin the project in mid-Summer 2014. Because of the small number of participants, the decision was made to increase the number of interactions with the participants in the project. This increase in interactions would allow for more discussion and follow up. The decision to extend the project necessitated requesting an extension by the Chapman University Institutional Review Board (IRB). An application for Continuance was approved on June 23, 2015. This allowed the project to continue through June 22, 2016.

\section{The Participants}

The importance of focusing on Afro-Boricuas was vital to expand the idea of what it means to be Puerto Rican. No Latino@ community is a monolith, so it was important for this research project to resist the tendency to continue to essentialize the Puerto Rican identity to the exclusion of the Afro-Boricua. As Duany (2002) noted, there is a "continuing perception that being black is foreign to national [Puerto Rican] identity" (p. 27). This intentional or unintentional denial or setting aside of a vital cultural component of the Puerto Rican identity was important to explore. This research project became a testimonio to the lived experiences of Afro-Boricuas. They literally embody the history, culture, and political realities of the Puerto Rican community. The adage, " $i y t u$ abuela donde 'sta?" [And your grandmother, where she at?] is an attempt to remind those who chose to forget or ignore the presence of the African Diaspora in the Puerto Rican community that, despite the claims of national unity, and insistence on the absence of racism, most of the people of Puerto Rico are of African descent.

The project depended on purposeful sampling, meaning that there was "the explicit establishment (and explanation) of a relevant criterion (or criteria) on the basis of 
which the selection of units will be made." (Schwandt, 2007, p. 270). The participants were selected on the basis that they met two vital criteria - they identify as Afro-Boricua, and attend (or attended) a college stateside in the U.S. There were five participants that began and finished their participation in the project, with the researcher being one of the participants. Although the initial goal was to have at least eight to ten participants, the difficulty in recruitment necessitated that the project work with the five participants. It still fit the rationale for having a minimum number of participants in that, given the analysis that narrative inquiry required this still seemed like a manageable number to adequately and respectfully capture the experiences of these women. What follows is a brief description of the participants.

\section{Participant \#1: Taina}

Taina is a woman in her $30 \mathrm{~s}$, who graduated with her educational doctorate in 2014. She was born in Hawaii of Puerto Rican and African American parents, and raised in southern California. She is one of three children. She attended public colleges for her bachelor's and educational doctorate, and a private college for her master's degree. She currently resides and works in southern California. She was recruited because she is a friend of the researcher. She also participated in a pilot study done by the researcher as a course assignment during the Spring of 2013. Taina is a pseudonym she chose for the research project.

\section{Participant \#2: Anastasia}

Anastasia is a woman in her 20 s who graduated with her bachelor's degree in May 2012 from a private college in Illinois. She was born in Illinois of Puerto Rican parents. She is one of two children. She currently resides in the Chicago area, and works 
as a school counselor at a historically Puerto Rican community-serving high school. Anastasia was recruited via online efforts using Facebook. A flyer was forwarded to her by a college sorority sister who saw it posted online and thought that Anastasia would appreciate participating in the study. Anastasia is a pseudonym she chose for the project.

\section{Participant \#3: Marta}

Marta is a woman in her 50s who ultimately withdrew from a doctorate in philosophy program in 2013. She struggled to get the support she needed to graduate. She has a master's degree from the United States. Marta was born in Puerto Rico of Puerto Rican parents and attended public K-12 school in Puerto Rico. She attended public institutions stateside for her Bachelor's and master's degrees, as well as the doctoral coursework she completed during her time in the Ph.D. program. Marta described herself as a working mother, activist, and scholar. She resides in central California, and works as an instructor at a community college. Marta is a friend of the researcher for the past fifteen years. She chose to use her real name for the project.

\section{Participant \#4: Erica}

Erica is a woman in her 20s who graduated with her bachelor's degree in May 2013. She was born in San Juan, Puerto Rico of Puerto Rican parents. She was raised in California and in South Carolina. She is one of two children. She attended a small, private college in South Carolina. She currently resides in South Carolina, and works for a bank. Erica was recruited by a friend of the researcher who is friends with Erica's mother. Erica chose to use her real name for the project. 


\section{Participant \#5: Marie}

I am in my 40s and graduated with my bachelor's degree in June 1994. I was born in Vieques, Puerto Rico of Puerto Rican and African American parents, and was raised in Culebra (Puerto Rico) and southern California. I am one of four children. I attended public K-12 school, public community college to earn transfer credits, a public UC for my bachelor's degree, and a public CSU for my master's degree. I attending a private non-profit college for my doctorate. I currently reside in southern California and work as a part time faculty person at the same private on-profit institution where 1 completing my doctorate.

\section{Problems with Recruitment}

After an exhaustive outreach effort to recruit participants, and seeing very little interest, I was left with doubt as to the viability of the research project. One visit to the Puerto Rican cultural center in Southern California left me with more questions than participants. It was, however emblematic of the undiscussed issues impacting the AfroBoricua. During my time as a scheduled speaker during their monthly member meetings, I was approached by one of the members of the group. An older woman in her 60's with light skin and black hair, she told me that, although "perros y negros" [dogs and Blacks] are said to come from Puerto Rico, there is so much more to the island. I was left stunned that someone would share such a racially tinged statement with me, a woman who had obvious African features and was from Puerto Rico. During our conversation, a man approached us and she introduced him as her husband. This man was of obvious African features (very dark skin, kinky curly hair, and broad "curly" nose), and stood in stark physical contrast to the woman. It also presented to me a juxtaposition of conflicting 
views of how race is interpreted in the imagination of this Puerto Rican woman. They both agreed to pass along my flyer to their daughters who are studying at the one of the University of Puerto Rico campuses.

I had conversation with another member in attendance. She was a young woman in her mid-20s who was attending law school in the area. She said that she doesn't know if she would qualify as a participant because she thinks of herself as Puerto Rican, not Black. I welcomed her to share her story with me. She took that opportunity to mention some of her interactions with the Black community at her undergraduate campus. She noted that the interactions were tense. She shared that when she did not respond to the overtures by some of the Black women on campus in a culturally appropriate way, they responded by calling her names. She recalled being called "uppity" because she didn't know "how to say hello to people". Her inability to discern the codes of conduct that were embedded within the African America community at her undergraduate campus confirmed to her that she was not Black but Puerto Rican. After about an hour of talking with her, I gave her my contact information and said that I would really appreciate hearing her story. She never communicated with me again.

Other attempts at recruitment resulted in little to no interest. I repeatedly posted the recruitment flyer on social media, and requested assistance from friends, family, and colleagues at other educational institutions across the country. The participants who had already committed themselves to the research project volunteered to share details about it to their friends and family. Many professors and educational administrators forwarded my information to students they felt would be interested in participating in the project. Others reposted the flyer to internal listservs. In the end, I was left with four participants. 
Two were personal friends of mine, one was the daughter of a friend of a friend, and the last one received the flyer from a sorority sister who was apprehensive in passing the flyer on to her because she didn't know if the participant "saw herself as Black". This left me with a small population of women, and the dilemma of whether I should include myself in order to provide some breadth to the participant pool. After consulting with my dissertation chair and advisor, it was decided that it was appropriate to include myself in the study and to focus on the depth of experiences of each woman in order to bring to light the uniqueness of our lives as Afro-Boricuas.

The problems with recruitment provided an unusual perspective on the Puerto Rican community. It confirmed the sentiments of researchers that documented the issues that the Latin@ community had with its own Blackness, and was a harbinger of what was to come out of our conversations. It became evident that being Black, despite outward behaviors and proclamations to the contrary, was not what any Puerto Rican wanted to be considered. Both the literature and the conversations shared during the research project confirmed this finding. The project itself then became a testimonio to the lived experiences of Afro-Boricua women. It was an acknowledgement of the realities of our lives, and a testament to our desire and right to be seen as part of the Puerto Rican diaspora. We exist and represent the history, culture, and political realities of the Puerto Rican community. Our story needed to be told in order to rightfully claim our place in the history of the people of Puerto Rico and of the United States. We are visible and we are presente. 


\section{Sources of Data}

\section{Interviews: Face-to-Face and via Facetime $\left(/\right.$ Skype ${ }^{\circledR}$}

The approach to data collection varied depending on the location of the participant and her proximity to the researcher. In other words, the conversations were either done in person or via electronic media. The researcher had six conversations with each participant. Each conversation was approximately an hour long. All conversations were audio recorded and later transcribed for analysis. A small proportion of conversations were done face-to-face, but the majority of them occurring via an electronic medium like Skype® or Facetime $($. Three of the five participants lived either in another part of the state or another part of the United States. Therefore, discussions via electronic media provided flexibility and convenience. I as the researcher had concern that having an artificial electronic barrier between participant and researcher would make more difficult the data gathering process. Narrative inquiry benefits from sharing a space and being able to pay attention to not only what was said but how it was said. Given that human communication occurs primarily via non-verbal transmission, it was important to consider what impact having conversations via an electronic medium would do to the quality of the conversation. After engaging in a couple of conversations with participants via electronic media, what was found was that it actually made the data gathering process much easier. This awareness was brought to light through my interactions with Taina.

Taina and I began our conversations in person, usually in coffee shops. She and I both noticed early on that we felt as if we were being eavesdropped on by others who were in close proximity to where we were sitting. She once noted that a man seated at a table nearby turned to look in our direction during one of our conversations that focused 
on the concept of race. After our third conversation, she and I decided to try and have our meetings via some electronic medium. We decided to use Facetime (B) and made some interesting observations. First, we found it to be more freeing. By that I mean that being in one's own space, in relative privacy, gave us both the freedom to speak authentically to one another. For both convenience (we lived about 80 miles apart), and expediency, we decided to continue our meetings via Facetime $($. We were able to log in during mutually convenient times in places and spaces (and clothing!) that we felt comfortable in. This comfort and intimacy contributed to us having what we both agreed were substantive and authentic conversations. We were not in a public space, but rather in our own homes sharing a conversation with just one other person. I provided the online medium of communication as an option to all of my participants as they signed on to the research project. All were open and excited about participating in the project via this convenient form of communication, and they also shared that they found the format easy to adjust to and provided an openness to sharing their stories with me.

After this experience with Taina, I became more proficient with the online medium of communication, and the technological preparation that it required: securing a device that had adequate memory and capacity to run the Facetime $₫$ or Skype $(B$ application, understanding how to use the Facetime $(\mathbb{B}$ or Skype $(\mathbb{B}$ application so that I can instruct the participants how to use it; coordinating date and time of meetings, ensuring that the recording device was recording both me and the participant's words, and finally managing any electronic glitches that occurred during the conversations. Glitches included the sound and/or video being delayed (which impacted the quality of the audio recording), the electronic connection being lost because of an incoming call, low battery 
life on the device, and other often inexplicable technological issues. These technological issues presented minor delays and were easily remedied by either calling back the participant, or rescheduling if the electronic connection could not be reestablished again. After understanding how to engage in conversation within this electronic environment, it lessened my hesitation to extend my recruitment beyond my immediate area. The electronic media allowed me and the participants to feel welcome in the project regardless of where we resided in the United States.

\section{Transcripts}

The conversations were audio-recorded and then transcribed by the researcher. The transcripts were then catalogued by the participant's first name, location, and the date of the conversation. At the end of our conversations, a summary of each participate conversation was sent to them with the information I gathered, and their contributions to the themes. The participants then reviewed sections of the transcripts that contained our conversations, as well as their biographies, and they provided input on their accuracy. This form of member checking provided a way of "corroborating or verifying findings", an internal verification of the content and limited the impact of the researcher's subjectivity on the findings. (Schwandt, 2007, p. 187-88)

The conversations occurred primarily in English, with Spanish language words used when the participant or researcher felt it was necessary and/or appropriate. All participants had varying levels of proficiency with the Spanish language, but at minimum we all comprehended the language when it was spoken to us. Any Spanish language wording was placed in italics and the translation is in brackets. With one participant, Marta, our conversation was equally in Spanish and English, so the quotes used from that 
were also translated into English and placed in brackets. It was important to allow the linguistic and epistemological space for the Afro-Boricuas themselves to "tell [their] own stories, write [their] own versions, in [their] ways for [their] own purposes" (Smith, 2009, p. 29). Therefore, it was appropriate and necessary for the testimonios to emerge in whatever language the participants felt they needed to use to convey the intent of their message.

Because these women were sharing their stories with me, I did the same. I chose to include myself in the study in order to provide a co-participatory component to the project. It also introduced a collaborative dimension that provided a setting where we can co-create as well as explore our lives together. As an Afro-Boricua, I felt that my story was the impetus for the research project and therefore warranted inclusion with the others. I chose to use my own name for the research project. I shared with them my journey to know myself both academically and personally. This is an "obligation of reciprocity" (Harrison, MacGibbon \& Morton, 2001, p. 324) that is essential for rapport building and ensuring that trust was created between me and the participants. I also felt that since the women trusted me with their stories, I needed to do the same, no matter how much trepidation I felt with the process. Holloway (2010) speaks about a resonance that is needed in order to "draw out that which is already present in undeveloped form, of brining different experiences into resonance with one another" (p. 84-85). Through my understanding of the need to engage with sincerity and depth of sharing, I acknowledged that these women are giving of themselves, and therefore, I must give of myself. This helped us "tune in" to one another and find a resonance with which to sing our stories to the world. 


\section{Roundtable Discussion}

From the thematic analysis of the individual conversations, I found many similarities across them. I felt it necessary to see if the participants would be open to an end-of-project roundtable discussion. Towards the end of my individual conversations, I revisited with the participants the themes that emerged and asked if they would be willing to participate in a roundtable that provided a place to see and share. All gave both written and verbal consent to participate. The roundtable discussion took place on April 20 in the evening via Google Hangout $\circledast$. It lasted 75 minutes. At one point, I was disconnected from the video and audio, where the other participants could not see me, but were able to read my written comments in the text section of the Google Hangout $\$$ platform. I was able to still hear and see the rest of the group. I kept recording their conversation. At first this felt like a major technological glitch that had derailed my data collection. When I relaxed in the moment and saw that the participants were able to connect with one another, without me, I was able to see that this glitch was serendipitous. The only thing the participants had in common prior to the group discussion was me. I was the common thread that brought us together. With me unable to participate in the conversation, the participants were left to develop relationships with one another. As I sat back and watched this unfold, I felt like I was witnessing a unique aspect of narrative inquiry, the development of community. Elements of the discussion were incorporated into the finds and supplemented the themes uncovered and testimonios shared by the participants.

\section{Researcher Journal}

In addition to the audio recordings, transcripts, and round-table discussion, I maintained a researcher journal where I wrote down my thoughts as I engaged in 
conversation with the women. It was a place where I recorded thoughts and issues that came up for me before, during, and after the conversations with the participants. It was a place where I deconstructed the conversations I had with myself while I was in conversation with the participants and continuing my literature review. For example, during my initial conversations with Taina, I was reading Quinones Rivera's work, From Trigüeña to Afro-Puerto Rican. In my notes I state that "her article spoke to me about different aspects of who I am." Quinones's paper provided a framework from which to examine racial identity formation when one goes from one cultural context to another. This became an important consideration for all the participants because depending on where we found ourselves, we had to enact certain aspects of our identity and subvert others.

It was through the research journal that I brought my interactions with different sources of information together in order for me to begin the deciphering of the concepts, and reconstruction of the ideas that the participants and I encountered in this research project. It was in this journal where I developed questions to ask the participants to either follow up or begin a new conversation. It was also a place where I documented my own evolution during this project. It was in this journal where I noted the changes in thinking that my conversations with the participants had on me. The journal was a chronology of my conversations with myself and my responses to the conversations with the participants. It was also a place where I outlined my next steps. Whether profound or mundane, I saw it necessary to document my process of self-discovery that was occurring while I participated in this study. In the process, a path unfolded that was unique to my journey with these women. 


\section{Data Collection Methodology}

The research design was qualitative in nature. The Afro-Boricuas' experience in college were documented by engaging in hour-long conversations that resulted in testimonios about their lived experiences. Narrative inquiry informed the structure of this research project because it welcomes the participants into every aspect of the research, from the data collection, to the interpretation, and final analysis. As Schwandt (2007) outlines, narrative is "a form or genre of presentation organized in story form" (p. 201). It can also "include an examination of the methodology and aim of research in the form of personal narrative and autoethnography." (p. 204). Using narrative both as a theoretical framework and a methodology provided the conceptual space to take into account the cultural context as well as the cultural nuances that influenced the way interactions are enacted, as well as how one interpreted what is said and done by participants and researchers. This approach also aligns with the tenets of Critical Race Theory in that it allows for a recentering of the narrative of who is seen as an authority. Although the project was approved for one calendar year (July 2014 to July 2015), the timeframe and level of interaction were negatively impacted by the ability to consistently meet with the participants. As a result, the researcher requested and was granted an extension to the project to engage in conversations through June 2016.

Using narrative inquiry as a methodology allowed for the participants and researcher to co-create the structure of the research project, including developing the questions, and analyzing the data. The point was to develop a kind of cultural intuition with everyone involved in the project. Through self-disclosure and sincere engagement, the participants helped to create an environment where cultural intuition was fostered through interactions, conversations, readings, attending cultural events, and self- 
reflection. In so doing, "it extends one's personal experience to include collective experience and community memory..." (Bernal, 1998). In this project, the Afro-Boricuas were given an opportunity to contribute to the research project. Although I approached them with the initial interest of exploring their experiences in school, subsequent questions and themes emerged organically from our conversations and the parameters of the topic of the research project expanded to their experiences in the broader society. What mattered to them led the way as we learned together about how we experienced college, and by extension life, as Afro-Boricua women.

With each participant, the researcher had at least six conversations that were a minimum of one hour, but no longer than 90 minutes. This level and extent of discourse helped develop rapport, and provided a way to explore issues in depth and with time. It allowed for unique insights to come from the interplay of listener and speaker, and provided time for me and the participant to reconocernos [reacquaint ourselves with one another]. I say reconocernos because as the conversations progressed, it became clear that we had similar histories, and it was as if we had known one another, or at least our lives, from before. The conversations allowed us to continue the stories the women wanted to share with me. The conversations took place both in person and via electronic

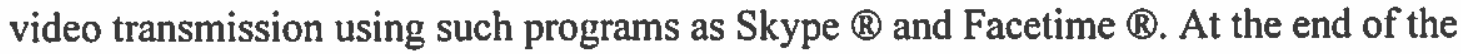
project, in separate conversations, all participants proposed having a round table discussion with the other participants utilizing Google Hangout $($. After proposing it to all the participants, they agreed that it would be a benefit to have a virtual round table discussion in order to see one another, speak with one another, and come together in a common space and time to continue to share our stories. The stories came to exist in what 
Beverley considers "a discursive space" (1991). There was only one round table that was included in this research project.

\section{Data Analysis Methodology}

Once the transcription was complete, the transcripts were coded using a variety of approaches. Open coding allowed the text to "open up", "exposing the thoughts, ideas and meaning contained therein" (Strauss \& Corbin, 1998, p. 102). It provided me with a way of letting the stories reveal themselves as I followed along. The next approach was in-vivo coding, which provided themes directly from the words the women used to describe their experiences. And finally, axial coding was used to "begin the process of reassembling data that were fractured during open coding (p. 127). It was through axial coding that the conversations were reassembled into what became our testimonios. The analysis was done by hand, without the use of any conventional software package. I did paragraph coding and looked for similarities and themes both within individual transcripts, and across the transcripts. This was done for each participant, and across all five participants. The resulting data was what informed the creation of themes and testimonios, and verified by the participants as important and common themes.

Critical Race Theory (CRT) was used as the overarching the theoretical framework for the study. This approach allows for the contextualization of the participants' and researcher's responses within a racial framework that included an intersectional analysis of such issues as gender and culture. It allowed a deeper understanding of the lives of these women through our testimonios. Within this context, the data was interpreted via interpretive research methods (Schwandt, 2007, p. 159). Interpretive methodology engages narratives to see how the individual makes meaning from their environment. Also known as hermeneutics "because they accept the premise 
that interpretation or understanding is the fundamental way human beings interpret their world" (Schwandt, 2007, p. 159). It aims to describe the quality of the experiences of Afro-Boricua women while also capturing the expressions of these experiences as they are presented by the Afro-Latina. This was the most appropriate form of analysis to capture the interaction of the participants among themselves and with me, the interaction with the participants and their college environment, and the interaction with the participant and other important people in their lives. It also allows the participants to describe their world and thus gives me an opportunity to view their world through their eyes.

Being in conversation with the women, and deciding to see myself as a participant in the research project, I developed in me what Strauss \& Corbin (1998) called "theoretical sensitivity" (p. 209). It helped me tap in to my "awareness of the subtleties of meaning of data" (p. 41). It helped me see myself as an insider, while reminding me that it was because of this project the women came forward; therefore I am also an outsider to their individual worlds. It drew in the ideas of Espiritismo, Womanism. African Womanism, and Mujerista Feminist Ideology discussed early to uncover a mutual understanding embedded our collective realities. I created an artificial structure through which we came together, and therefore I had a responsibility to ensure that the space was safe and open, and allowed for a co-creation of stories that stood alone but also intertwined to tell a new and unique story of the Afro-Boricuas in this research project. The conversations were recorded and those recordings were transcribed in order to have a written record of what was said, but also to have something with which to interpret themes and determine the possible testimonios that came out of our conversations. This 
documentation and interpretation happened throughout the data collection process in order to provide the researcher and the participants with the insight to adjust the project as it progressed. This level of flexibility provided a much broader space in which to cocreate testimonios.

\section{Issues of Trustworthiness}

\section{Validity and Trustworthiness}

Ensuring that the interpretation of the data maintained the authentic intention and meaning of the words shared by the participants, a set of criteria was agreed upon by the participants. Lincoln and Guba (1985) defined trustworthiness as "that quality of an investigation (and its findings) that made it noteworthy to audiences" (as cited in Schwandt, 2007, p. 299). Lincoln and Guba (1985) note that the following criteria should be considered with determining the trustworthiness of a study: credibility, transferability, dependability, and confirmability. (as cited in Schwandt, 2007, p. 299). After a thematic analysis was done of the conversations, a profile of the participants was developed that incorporating demographic information (age, where they went to school, size of the school, years attended, etc.), and salient quotes that captured for the researcher the essence of the individual participants' experiences. The profiles were then shared with the participants in order to confirm that the researcher accurately captured who they were, and allowed for them to read back their own words to see if they reflect their true sentiments. It provided for a certain amount of member checking and helped diminish the bias that is inherent in this form or research and provided increased credibility to the project and its findings.

Validity and trustworthiness are vital in order to ensure that the research was conducted in such a way that the results can be trusted by others to reflect what actually 
occurred in the project. Validity can be determined in a couple of ways, as summarized by Merriam \& Associates (2002)

a. Internal validity, which asks the question "how congruent are one's findings with reality?"' (p. 25)

b. External validity, looks at "the extent to which one's findings can be applied to other situations"; in other words, can your finding be generalized beyond the project (p. 28)

c. Reliability requires that valid methods be in place in order for you to trust the results. This refers to "the extent to which research findings can be replicated". (p. 27)

Validity and reliability requires that one has "confidence in one's statements or knowledge claims." (Schwandt, 2007, p. 309). Given the nature of this research project, one can attest that the findings were congruent with reality and can be trusted to be true because they reflect the realities of the women in the research project at that time. It has to be said that the findings reflected the realities of these particular women at this particular point in time. Afro-Boricuas are part of the Afro-Latin@ diaspora as well as the African and Latin@ diaspora more generally, so some of their experiences may have some predictive value for expressing the experiences of other Afro-Latinas.

\section{Confidentiality and Anonymity}

Protecting the privacy of all the participants was of paramount importance. All participants were given the opportunity to use a pseudonym for the project. Two of the five chose pseudonyms and the rest of us chose to use our real names. All participants were given a consent form with a description of the project, their rights, information on 
how the conversations were going to be recorded for analysis, and how all information was going to be secured for privacy and anonymity. All participants read and agreed to the details of the project. The first conversation took place in July 2014, and the last took place in July 2015.

\section{Assumptions, Limitations, Delimitations}

\section{Assumptions}

The nature of the project required that the participants identify and consider themselves Afro-Boricua women. As the researcher, I had to assume that the participants who came forward saw themselves as fitting this criterion. Because of the efforts taken to protect the identity and anonymity of the participants, I had to assume that the participants were being truthful during our conversations. At all points in the project, the participants were free to leave without consequence, therefore ensuring that their participation was informed by their willingness to be a part of it, and not by a feeling of coercion or obligation. I periodically checked in with the participants to ensure that their continued participation was done on their own volition, and not impacted by a sense of obligation to me or the other participants.

\section{Limitations}

Because the project focused exclusively on the experiences of Afro-Boricuas [women], the research project's methodology, findings, and implications may be limited in scope and applicability to just other Afro-Boricuas [women]. It is not clear how the methodology, findings, and implications would be directly applicable to any other Latinas, or other women in the African Diaspora. The number of participants is also a limitation in that the experiences of five Afro-Boricuas cannot be extrapolated to explain 
the experiences of other (or all) Afro-Boricuas. Some commonalities may emerge that highlight the common experiences of women, women of color (specifically Black women), women from the Caribbean, and women from Puerto Rico, but those commonalities must be seen contextually and not used to inform any conclusions about the lives of any women outside of the ones in this study. There was also a limitation of time. The research project needed to be completed within a year (as mandated by the IRB application), so there was a certain amount of urgency that influenced the recruitment efforts. Due to the small number of participants, the researcher felt it was important to gather more information in order to have depth from which to explore the issues that emerged from the conversations. This is part of the justification for extending the research project one more year from July 2015 to June 2016. The project is a reflection of a moment in time and reflects the social, political, psychological, social, and emotional conditions present during that time period as they manifested in the lives of the participants.

Due to these limitations, I worked with the participants to ensure that the research project reflected an honest account of our lives and that the themes that emerged were an authentic representation of the lives of the women as they engaged in conversations with one another. This was done through constant member-checking and speaking out loud any concerns the participants had about the outcome of the study. Through honest and consistent dialogue the participants were able to ensure that the limitations were not seen as such but part of the framework that informed our experiences. 


\section{Delimitation}

The first item to delimit this project was the choice of topic explored by this research project. Although looking at Afro-Latin@s in general would have been interesting, it was too broad a topic that required too much context and explanation.

Given also that the Afro-Latin@ experience is dependent on the cultural context in which it is found, it would have required an exploration of the historical and political framework of most of Latin America to do the topic justice.

The next level of delimitation would have been to look at the lives of AfroLatinas. More focused, this topic would have allowed me to explore the general issues of women of African descent in the Latin@ community. This still presented the problem of needing to provide too much context and explanation, as well as including the history of women in Latin America. It created a need to analyze an extensive amount of information, as well as an equally extensive literature review and historical context with which to frame it all.

These considerations then led me to the final level of delimitation, where I decided to explore the lives of women of African descent from Puerto Rico (or of Puerto Rican descent). The objective of the project became an exploration of the lives of AfroBoricuas. This delimitation created the framework within which the project was going to come to life. It contextualized the research agenda to the experiences of women of Puerto Rican descent who also were or saw themselves as part of the African Diaspora. This framework then informed the sorts of questions that would initiate the conversations. It informed the literature review, and finally the theoretical framework used to construct the project and analyze the findings. For instance, one of the first questions was: "How was 
your time in college?" This broad question led to more specific questions that related to types of interactions (i.e.; friendships vs. family), location (i.e.; inside the classroom vs. outside the classroom), timeframe (i.e.; during school vs. after graduation), contact with cultural groups (Puerto Ricans vs. other Latin@s vs. vs. African Americans) and context (i.e.; work vs. school).

Focusing on Afro-Boricuas allowed me to have conversations on issues that were specific to women in general to see if they were also issues for the Afro-Boricuas in the research project. It also allowed for a critical exploration of how intersection of race (not just ethnicity or national origin) and gender revealed itself in the lives of the women. Race is often not seen as a factor when considering the lives of those who make up the Latin@ community. To this point, Flores and Jiménez Román (2009) note that:

"Hispanic is a construct that is decidedly non-Black - and in significant ways discursively anti-Black. In census parlance, for example, it is significant that while we do hear ad nauseum the term 'non-Hispanic white'(thus signaling that there are Hispanic Whites, marked of course - what might be called 'off-White'but White nonetheless), nowhere and never do we hear 'non-Hispanic black." (p. 325)

Race in the Latin@ community is rarely explored, and as Flores and Jiménez Román (2010) speak to directly, this is because there may be a conscious or unconscious rejection of the Blackness that exists in our community. This research project moves directly into this discussion and brings light to it by showcasing those of us who are living examples of those who the Puerto Rican community may want to erase from the Boricua imaginary. 
By taking great care to acknowledge the small sample size, the methodology, findings, and implications of this project may be generalizable to other Afro-Latinas who (a) are from other Spanish-speaking Caribbean island nations, (b) now live in the United States, (c) see themselves as Afro-Latinas, (d) have encountered issues with the world around them seeing them as such, and (e) have had similar experiences both in college and in other social contexts. Being mindful of the impact that the intersection of gender and race may have, the results may also be generalizable to Afro-Boricua men (or AfroLatino men in general) in that they also live a racialized reality that informs almost all aspects of their lives. These generalizations must be done with caution in order to account for the small sample size, the paramount role gender plays in the lives of these men. We also must protect against falling prey to reducing our experiences to caricatures. We must proceed with an awareness of the inherent racism and sexism that is very much alive in our respective Latin@ cultures and the sources of such beliefs and resulting personal and social realities.

\section{Risks and Benefits}

The purpose of this project was to provide a forum to showcase the stories and lives of Afro-Boricuas. It was to give us a place and space to acknowledge us as full inhabitants of the Puerto Rican community, but realizing that we inhabit a unique space within that community. Some risks to the participants included that during the sharing of certain aspects of their lives, they may be reminded of difficult times in the past and induce sadness or anxiety. Given that two of the four other participants did not know me, so trust limited their ability to fully disclose the negative emotional effects of their participation. They may be hesitant to share these anxieties with me, and therefore 
consciously or unconsciously begin to limit the quantity and quality of the stories they share during our conversations. During the roundtable, they might have felt a greater sense of angst because now the sharing was occurring within a group, rather than with just the researcher. In full disclosure, I shared these same fears and anxieties as I prepared myself to engage in conversations with the participants. I needed to share just as much or more as the other participants in order to create a shared space where we both (and ultimately all five of us) felt safe and validated by the other. I had to model for them what I wanted and needed for them to share with me in order for our stories to come fully to life.

\section{Possible Ethical Considerations}

The research project followed the ethical guidelines set forth by the Institutional Review Board of Chapman University. Merriam \& Associates (2002) note that "ethical dilemmas are likely to emerge with regards to the collection of data and in the dissemination of the findings." (p. 29). As the researcher, I did everything in my power to protect the anonymity and privacy of the participants. I provided opportunities for participants to share to the extent they felt comfortable and during our conversations mentioned that they are only obligated to share what they wanted to share with me. All the participants knew that I was conducting this project as part of a dissertation in order to earn my doctoral degree. I sought their approval of the transcriptions and themes that emerged, and they independent of my asking, presented the option of collaborating on a paper continuing our conversations beyond the project. Every possible measure was taken to ensure that all ethical issues were addressed as they arose. As Merriam and Associates (2002) also note, "all possibilities cannot be anticipated, nor can one's reactions." (p. 30). 
They stress that the researcher must be away of the "assumptions one carries in the research process" in order to ensure that negative ethical issues are reduced or eliminated in the process.

\section{Subjectivity}

I am an Afro-Latina, a woman of the African Diaspora, with African features who was born into and acculturated by the Puerto Rican community. Specifically, I am an Afro-Boricua (Boricua is the indigenous Taíno name for Puerto Rico) woman born in Vieques and raised in Culebra and California. As an Afro-Boricua, I often wondered if other Afro-Boricuas women had similar experiences as mine while in college. I was curious about these women and wondered how their experiences in college were the same and/or similar to mine. I wondered what their migration stories were, and what sort of impact has the racial matrix of the United States had on their lives. I hoped that through my scholarship I was able to give them, and me, a voice in order to answer these questions. I believe this study accomplished some of this objective.

For me attending the university was an accomplishment that, in hindsight, required an incredible amount of courage and determination. It placed me in a position to have to tell my story; and therefore I had to figure out what that story was in the first place. Reflecting on this reality was the impetus for beginning the research project in college. The experience requires us to tell our story to those with whom we have not shared a past. It requires us to reflect on our past and determine what aspects of it will be placed in what order to tell the story we want (or are ready) to tell at that moment in time.

I transferred from the community college, making me two or three years older than the average first year student. Not having the typical first year college experience 
added to my feelings of alienation and isolation. My experiences at the university required adjustment and accommodation on many levels: adjustment to college; adjustment to the Latino community at the university; adjustment to the class differences that were apparent all around me; and adjustment to being a brown person attending a predominantly white institution.

My adjustment to the Latino community at the university was an unanticipated challenge. The welcoming nature of the Latino community that I had experienced during my early years in Puerto Rico, and then again in my hometown of Carson when we moved to California in 1976, was not reflected in the students I encountered at my undergraduate institution. During my time at the university, I encountered varying degrees of suspicion in the form of challenges to my claims of ethnic affiliation. These took the form of what I have come to name cultural litmus tests. Like the name implies, litmus tests are "used to make a judgment about whether someone or something is acceptable." (Merriam-Webster online, n.d.). I often encountered requests for demonstrations of language proficiency, dancing ability, food preferences, and questioning of historical knowledge of my home country. These were attempts to see if I was "acceptable" to the Latin@ students on the campus. As Duany (2002) noted, there is a "continuing perception that being black is foreign to national [Puerto Rican] identity" (p. 27).

Acceptability was one way that my blackness was being positioned outside of the Latin@ consciousness of the Latin@ community on campus. On more than one occasion, I would attend Latino-themed events, or Spanish language lectures, only to be approached to see if I was lost or looking for another event. This mirrored my 
experiences in elementary school where I first felt this feeling of being foreign, unacceptable as I was, and ultimately unwelcomed in school by the other children. Because of when we arrived to California, I began school in first grade. Many of the first grade children taunted me because I, a brown-skinned little girl who appeared African American, didn't speak English as they expected me to. I did not fit the expectation of the children at my school. This level of suspicion and rejection delayed my English language acquisition and proficiency. I did not become fully conscious of, and comfortable with, my ability to speak English until the fourth grade, and only at the constant encouragement of my ESL teacher. It took another year for me to be fully comfortable with my bilingualism.

Thinking back on my time in college, I came to believe that this lack of understanding by the various communities within the educational environment, and specifically the Latin@ community, of the historical influences of the African diaspora on Latin@s led to my initially withdrawing from campus life. Who I am was neither recognized nor welcomed; it seemed like I was failing the cultural litmus tests set before me. The cultural litmus tests were also used by the broader campus community. Depending on the context, whether it was the classroom or in line at the grocery store, I was treated as I now have come to understand as an African American: sometimes being asked to speak for the Black community in class, or followed in the store because my presence was deemed suspicious. These experiences helped me understand that my understanding of being Afro-Boricua was not contained within the Puerto Rican community, but extended to the broader African Diaspora. 
Eventually I made my own way in the various cultural milieus of the university (i.e., joining multicultural student organization such as PALS, Pan-American and Latino Society; and AMES, Association of Multi-Ethnic Students), ultimately graduating with a bachelor's degree. This withdrawal was in one sense a form of self-protection: from rejection, from further alienation, from ignorance, and from psychological and emotional injury. I now understand that the use of cultural litmus tests by other Latin@ students was a reflection of limited knowledge and a natural suspicion of the unfamiliar, lack of familiarity of within-group differences in the Latino community, and lack of understanding of the history of the African diaspora in the Americas. I am now learning that the other cultural litmus tests used by the broader society were also an attempt to understand and to determine the level of acceptability that would be bestowed upon me. It was my experiences in these contexts that informed my intent for the project. It was within these contexts that $\mathrm{I}$ asked my participants to begin reflecting upon and conversing with me about their experiences.

\section{Summary}

In this chapter, the research project's methodological approach was discussed in detail. Narrative inquiry was described and justified as a reasonable and appropriate approach to studying the lives of Latin@s in general, and Afro-Boricuas in particular, as well as a methodology. This chapter also provided a rationale for the research approach, a description of the research setting and context, the type of sampling and data sources that were used, methods used to collect the data, and the methodology that informed the data analysis. There was also discussion on the assumptions, limitations and delimitations that informed the project. We also learned about the ethical considerations and risks and 
benefits were being considered and impacted the execution of the project. And finally the researcher included a description of her own subjectivity in order to provide some context as to the motivations that lead to the creation of this research project.

What follows now in Chapter Four is a discussion of the findings. In Chapter Five is a more detailed description of the participants that includes a poem that provides more insight into who we are. And finally in Chapter Six is a discussion of the outcomes and implications of the research study. 


\section{Chapter 4: Lo que encontramos [Findings]}

This chapter documents the conversations of the four participants and me as the fifth person in the conversations. Through these conversations, a number of themes emerged that included, among other things, a sense of belonging within the Puerto Rican community; experiencing others using the framework of Mexican experiences as cultural point of reference to understand them; colorism within the Black and Latin@ communities; and the participants' role as agents of inclusion and change. We all shared our struggles to be believed when we tried to claim our Puerto Rican identity, and the sense of inclusion and exclusion that accompanied our varying levels of success.

Although we all had stories of being a minority within a minority living in a majority white culture, our comments and stories of struggle were primarily framed within our interaction with both the African American and Puerto Rican (or Latin@) communities. This mirrored in different and distinct ways how we lived within the BlackWhite binary that exists within the broader society, and was interpreted within each community. From our discussions, we all had experiences where we often had to brush aside, or engage with, comments that came from a misunderstanding of the diversity within the Puerto Rican community. The level of engagement depended on our mood, or the time we felt we had to fully engage in the conversation to bring about a heightened awareness in the other person of the nuanced experiences that exist within the Puerto Rican community. Oftentimes we heard comments that reflected a narrow understanding of what it meant to be Puerto Rican. This was informed by a perception of Puerto Rican being seen as a monolithic group devoid of any difference. Other times, we encountered those who were not aware of the location of Puerto Rico on a map and its historical 
colonial relationship with the United States. These interactions told us that Puerto Rico and it history and people are (intentionally?) being erased from the consciousness of people in the U.S. We all shared stories of being perceived as having the wrong pigmentation for the places and spaces we found ourselves in, and sensing feelings of alienation even when we were among those we considered our own. Colorism was something we all encountered both within the Black and Puerto Rican communities, and within the broader society. We shared incidents where we were characterized by archetypes and thus our multidimensionality was not allowed to manifest itself. We were reduced to cultural sound bites and measured against an abstract, distorted, and often false understanding of what it is to be Latina. We all had in common the embodiment of sobreviviendo (surviving and thriving), using these experiences to ensure that we helped others who found themselves in similar situations. All of these findings impacted what it meant for us to belong.

On occasion, some participants reflected on their time in K-12 to provide a picture of the changes in their experience over time. They frequently included their relationships with family and how those helped frame their perceptions of themselves and impacted their experiences. Throughout and across the conversations, I engaged and shared with the same level of intensity and depth as the participants. It allowed for an unspoken understanding to develop between us. An understanding that grew out of our shared experiences with what I call (and will later define as) cultural litmus tests, family interactions and took the form of criticisms, and our daily experiences of pushing back against both internalized and externally manifested racism. It was important to allow the linguistic and epistemological space for the Afro-Boricua women themselves to "tell 
[their] own stories, write [their] own versions, in [their] ways for [their] own purposes" (Smith 2009, p. 29). Therefore, sometimes it felt appropriate and necessary for our conversations to occur in whatever language the participants felt they/we needed to use to convey the intent of their/our message. As a result there are quotes that are both in English and in Spanish. The bilingual nature of our conversations allowed us to own and engage in a cultural instrument that helped up convey our deepest sentiments of what it meant to be an Afro-Boricua woman, and reflected our multinational and multiracial identity. What now follows is a summary of the conversations and the themes that emerged from them.

\section{Theme \#1: "You're Puerto Rican?" - Politics of Belonging}

For many, belonging or feeling a part of a cultural group is informed by one's family experience. It is informed by choices that you make to claim membership in a cultural group that is distinct from all others. It is based on the knowledge and level of comfort you have of the culture. It also is based on whether you perceive yourself as being a part of it. Through our conversations, it was clear that we all experienced varying degrees of feeling as if we belonged in the Puerto Rican community. These experiences varied and were influenced by what I have come to define as cultural litmus tests used by the Puerto Rican community (and sometimes the broader Latin@ community), as well as the participants' age, birth place, experience with the Puerto Rican community, and language ability. These cultural litmus tests involve insistences of demonstrations of language fluency, confirming birthplace, knowledge of history, food, music and dance. For Erica, the time of year (whether she had tanned skin or not) determined whether people saw her as Latina or not. For me, Taina, Erica, and Anastasia, it depended on our 
language ability. And for Marta, who spent the most time in Puerto Rico and received her all of her K-12 education on the island, language was used to determine what social class she was in by others within the Puerto Rican community.

The actions by the Puerto Rican community towards the Afro-Boricua women in the project constituted what I now term cultural litmus tests. For this study, I use the term cultural litmus tests to bring the scientific idea of litmus tests into the cultural realm. In the scientific community, a litmus test is "a test in which a single factor (as an attitude, event, or fact) is decisive" (Merriam-Webster.com). Therefore, I posit that cultural litmus tests are informed by stereotypes and essentialized notions of what it means to be Puerto Rican. Cultural litmus tests were (and still are) being used to determine whether we as Afro-Boricuas are believed by our community when we claim membership. As a result, the participants in this research project shared experiences that would be considered cultural litmus tests using single indicators of what it means to belong in a cultural group. Such tests included verifying whether we spoke the right dialect of Spanish (Puerto Rican), could cook Puerto Rican food, could dance Puerto Rican dances like bomba and plena, were familiar with the popular Puerto Rican cultural icons (musicians and other artists), knew the monetary value of things, if one or both parents were Puerto Rican, or were born on or off the island. This litany of litmus tests felt like attacks from within and was an affront to our sense of belonging to the Puerto Rican community.

We all had varying degrees of engagement with the Puerto Rican community. This level of engagement was largely determined by the decisions our parents initially made when they migrated stateside- where they moved (and if that move placed us in close proximity to the Puerto Rican community), if they chose to teach us Spanish, if they 
decided to educate us on the Puerto Rican culture, etc. Engagement was also mitigated by our own level of affinity with and desire to learn more about the Puerto Rican culture. Many of us took courses in college, read books, attended cultural events, worked in the Puerto Rican community, and intentionally took up the task of being proficient in the language. These efforts were in addition to the other concerns we had to deal with on a daily basis - finding work, attending college, maintaining relationships, etc. The constant effort to embody the cultural markers that made us "authentic" in order to be welcomed by our own community, because our own community does not see us as our own, informed many of the experiences of the Afro-Boricuas in this project.

Subtheme \#1: Language. Participants revealed how language issues were central to feeling a part of the community. We felt that language was instrumental in allowing us to understand another person in a symbolic way that connects you across time. For the Afro-Boricuas in this research project, the level of our language proficiency was used by others as a cultural litmus test to determine how authentic our claim of being Puerto Rican was. This was based on the understanding of the listener as to what a Puerto Rican was supposed to look and sound like. A seemingly important cultural litmus test, language was used by self-professed gatekeepers (family on the island, professors, other Puerto Ricans) to determine if the Afro-Boricuas were telling the truth. This test of authentication was a constant theme that crossed all participants and was a consistent issue that we all had to deal with.

As mentioned before, our language ability is initially determined by both our family, and then our own decision to prioritize Spanish language proficiency in our lives, both personal and internal motivations. As we interacted with the Puerto Rican 
community, at some level it became an external motivation to prove to other Puerto Ricans that we too are like them; that we too are Puerto Rican despite whatever preconceived notions they may hold of what a Puerto Rican is supposed to resemble. Anastacia speakers about her struggle with challenges to her language proficiency. This was something that she first experienced in her community, as she shares:

Growing up, I was always very self-conscious about how I spoke Spanish, and the fact that I didn't have a Puerto Rican accent. If I did speak it, especially in Chicago, we don't speak Puerto Rican Spanish, and you don't have that kind of Caribbean flair, everyone assumes you're Mexican. Whenever I spoke Spanish, everyone was like you're Mexican and black.

For Erica, language was used by other Latina students on campus to determine her level of membership in the general community, as she describes, Latino community ... they... at first they were like, "Oh, you're one of us because you're Puerto Rican, " but then because I don't speak Spanish, I wasn't really one of them. They're like, "Oh, well, I guess that doesn't count anymore." I said, "Oh, okay. That's cool."

Both Anastasia and Erica experienced different impacts of the use of language as a cultural litmus test. With Anastasia, because she didn't speak the sort of Puerto Rican Spanish that is commonly heard on the island or in her community, and she didn't appear to the observer as a Puerto Rican woman, she was seen as not part of the community. To the other person, she didn't speak the expected dialect of Spanish, and because her appearance was not within the expected range of who is Puerto Rican, she must not be "full" Puerto Rican. The observer concluded because of her linguistic ability, and her 
appearance, she must be a foreigner to our community. She must be Mexican and Black. She must be lying. With Erica, the fact that she is not proficient in Spanish was determined by the other person as no longer a requirement to claim cultural affiliation. Her appearance in this instance did not influence whether her claims of being Puerto Rican were genuine, only her linguistic ability was used as a determining factor. Because other aspects of whom she was fit within the realm of who is Puerto Rican, her inability to speak Spanish was determined by the observer to be unnecessary.

I often experienced such cultural litmus tests that included checking my language ability and fluency. I often was complemented on my level of Spanish proficiency and regularly asked where I learned it: These sorts of questions followed me into the classroom when I also took Spanish language classes in college. It still follows me to this day as I teach courses on cultural diversity. It even follows me into casual interactions like baby showers where I was consistently questioned as to where I learned to speak Spanish so well. One such conversation was with a fellow Boricua! For me it is a neverending experience that creates frustration and apprehension. It reinforces in my mind that I am an outsider, and must provide the proper cultural documents in order to be given entry into the only cultural identity that deeply informs who I am.

Erica experienced such frustration during her first year in college when she decided to major in Spanish:

Itried to major in Spanish when I first got to college. To get placed in certain classes, I had to take an oral test. I apologized a lot, because I was like, my language skills are not that great. I studied under a Romanian teacher [in high school]. My Spanish teacher in high school was Romanian, and then the other 
one was French, so I kept apologizing. He's like, "Oh, it's not that bad for a white person." I'm like, "I'm Puerto Rican." He was like, "Oh." I still made it to the... I wasn't in beginning Spanish, I still made it to Intermediate Spanish, and he was like, "I'm going to expect a lot from you." I was like, "Please don't." Yeah. He's like, "So, do your parents speak Spanish?" I said "Yes, they speak Spanish." He said, "Oh, okay, so you know what it should sound like, then." I felt like I was never really able to meet expectations, and it was a lot of while girls in my class who were doing a lot better than me.

The pressure that came from Erica's instructor once she made it be known that she was Puerto Rican added to the complexity of the position she found herself in. Prior to acknowledging her heritage, the expectations were that she was a white student who was doing "not bad". After mentioning that she was Puerto Rican, the instructor shifted his expectations and that added a level of apprehension to her experience of the language instruction in college. Her instructor enacted cultural litmus tests that he felt were appropriate to verify and validate Erica's identity. For Erica, this apprehension highlights the internalized racism many of us who are at the margins experience.

Through our conversations like the one I had with Erica, we see that AfroBoricuas are confronted with a complex set of rules of what it means to be Puerto Rican. In our attempts to meet those expectations, we sometimes fail both in our eyes and in the eyes of the cultural gatekeepers. Like anyone, we want to feel like we belong to the culture we are very proud to be a part of. Sometimes working towards belonging brings with it self-doubt and unrealistic expectations. We are not allowed to be authentic to the version of Puerto Rican that we chose to be, Afro-Boricua. 
Subtheme \#2: Archetypes and Expectations. Through the conversations, the participants shared stories that provided evidence of struggles to be seen by our own Puerto Rican community as one of their own. We at times felt like we belonged but were alienated by the knee-jerk reactions of our community that reinforced the fact we did not belong. The constant feeling of having to justify our claims for membership into a cultural group often resulted in frustration and using humor to cope. Taina shares her struggles with showing that Puerto Ricans can appear as she did, part of the African diaspora:

Sometimes people were like, "Oh ..." because I would actually say that, and they'd be like, "What are you talking about?" as if they'd never seen a black Puerto Rican before. I'm like, "Okay, you know some of the same people I know, and I know you know black Puerto Ricans who are $100 \%$ Puerto Rican and dark as night, and you're going to sit here and tell me that you don't know that Puerto Ricans are also black?"

Taina and I shared similar stories of constantly having to educate people on the existence of Black people in the Puerto Rican community, and in the Latin@ diaspora in general. Our very existence, and our insistence on being seen as part of the community, was proof of this fact. We both met with incredible resistance that manifested in looks of disbelief, or of comments stating as much. Blackness in the Latin@ community is not something that many are aware of, either within or outside of the Latin@ community. Anastasia also thought it was important to expand the definition of what Puerto Rican was when she spoke to friends in college: 
Whereas, I don't think I've ever had an explicil conversation like that with someone my age. It's just been like, "Oh, you're not black. You're Puerto Rican. That makes sense." Then I always have to be like, "Yeah, but there are pieces of me that are different like being Puerto Rican is not this one whole piece. There are all these other pieces that go with it. Yes, your original question wasn't completely wrong, but this is the appropriate label or this is what I have done if I asked. It just happens to be in an umbrella of all these other things."

In her work at a high school, Anastasia experienced a form of racial profiling from her co-workers. When it was time to assign advising or mentoring duties, her coworkers used a set of standards and preconceived notions of what Blackness and Latin@ness was in determining which students she was going to interact with. Based on her appearance and the meaning her coworkers placed on it what they saw, Anastasia was consistently placed to supervise or advise the Black students at the school. She shared this commentary during the roundtable discussion:

I work at a high school, and it was always, "what is she?" And what students should she work with based on what she looked like? So they always liked to give me the Black kids because they thought I could identify with them...I can but it was based off of appearance. So I always get to chaperone, or be assigned to, or they asstmed I was most comfortable with them. So that they could put a lighter Latina to work with the actual Latin@ students. And they would put me with the Black kids.

All the participants experienced a sense of sadness and disappointment because we were never fully accepted by those we saw as our community. This experience was 
complicated by our embodied intersectionality as Afro-Boricua. Our selves intersect blackness, Latin@ness, and womanness. We talked about existing in spaces where we (and maybe others like us) can only exist. Yet we can try to reach out and bring ourselves and others into the different realities in which we exist: Black, Boricua, and woman. We feel that our bodies are superimposed with archetypes, those ideas that are "impressed upon the unconscious" and were "exclusively the subjective fantasy-ideas aroused by the physical process." (Jung, 1917, p. 69). The quintessential Puerto Rican archetype of $e l$ jibaro [mountain person] refers to the person who lives in the heart of the island and therefore "[is] the backbone of the Puerto Rican culture" (ElBorica.com, n.d.). El jibaro was illiterate but not uneducated, as "he had natural wisdom". He is seen as "a true and genuine Puertorriqueno..." (ElBoricua.com, n.d.) Its literary parallel could be of the noble savage. Unfortunately, el jibaro is usually a male mestizo of European and indigenous ancestry. Nowhere in this archetype exists the African; therefore, to be a true and genuine Puerto Rican excludes being Black.

This sort of archetype (and others that will be discussed laters) are used by others to help them place us in contexts where they can more easily define us, accept us, or reject us. The participants and I shared with one another that we often feel that because of this sort of archetype, we are experienced viscerally by those around us and that experience tapped into an unconsciously understood idea of whom and what we represent. These archetypes served to bind both the viewer and the viewed in a symbolmaking process where the Afro-Boricua represents an unacknowledged or disowned past in the Puerto Rican consciousness. In our conversations about belonging, we mention that we feel forced to amplify those qualities understood to be uniquely Boricua in order help 
the viewer better see us. Some of us shared that we often feel that our dark skin sometimes makes our Boricua identity invisible. When the viewer is asked to acknowledge us as one of them, they are put in a position of cognitive dissonance where the perceived reality does not match the imaged reality.

To illustrate this, I want to focus on an incident that occurred to Anastasia. Her attendance at a private institution in the northeast put into question the level of sincerity of her commitment to and affiliation with the Puerto Rican community in the area. Since she attended a private institution, she was perceived as being of a higher socioeconomic class than the constituents she would be assisting through her volunteer work in a Puerto Rican cultural center. For those seeing Anastacia, she was not Puerto Rican because she did not fit the archetype of struggle, of poverty, of their definition of what a "real" Puerto Rican's life should be. Those who saw her could not see beyond what her education represented to them, and adding to this her Blackness, further created a reason for separating her from them. Unbeknownst to those looking at Anastasia, she did have a migration story, and a story of struggle that made her familiar with the struggles of the Puerto Rican community in which she wanted to serve. In this instance archetypes served to both inform and separate Anastasia from the community with which she felt such a strong connect to, and from which informed the essence of who she is.

\section{Subtheme \#3: Feeling Alone Among Your Own - Balancing a Sense of}

Belonging with Alienation. In some of our conversations, the issue of class was brought up as something we all experienced in a variety of ways. The consensus was that class was used to exclude, rather than include us, in the spaces where we felt we had a right to be. From a cultural center to an antique store, our presence was questioned and class was 
seen by the participants as one of the underlying causes for the behaviors of those trying to control our access to spaces and places where we felt we belonged. In the following section, the stories of Anastasia and Marta are shared as examples of this lived experience.

In sharing her experiences, Anastasia recounted the challenges she faced while volunteering in her community. She and a group of students decided to do their undergraduate volunteer experiences at a Puerto Rican cultural center. The fact that she attended a private post-secondary educational institution was used as a class marker by those in charge at the center. They used class as a sorting mechanism to separate her (as well as the other volunteers) from the common understanding of who belonged in the Puerto Rican community and who did not. This made her, according to her interpretation of the behavior of the center staff, the wrong class of Puerto Rican. She was therefore deemed by the center's staff as unable to adequately relate to and address the needs of the community. She shared with me her experiences during one of the first visits to the cultural center:

I think it was just the notion of you if you go to DePaul and you are Puerto Rican you are instantly bourgie. I had never in my life been called bourgie, so I didn't understand why that was happening. It got better. I think it was just a matter of people not understanding that you can still be rooted in your community and go to this prestigious very expensive school, but still be humble and know where you come from, and not think that you're better than anybody. It wasn't easy at first and I think a mumber of us were kind of taken back by the comments and just this assumption that we were all the same. All of these different things and that we 
came from very privileged backgrounds and our parents have money, and we grew up in this serene wonderful place. That isn't the case for any of us. We'd all had our struggles and we're trying to survive at DePaul. It wasn't like it was an easy journey for any of us.

Bourgie, being slang for bourgeoisie, referred to her perceived class as it was compared to those who were served or worked at the Puerto Rican cultural center. The administrators at the center used the class marker of "bourgie" to separate and alienate Anastasia from who they perceived to be the authentic Puerto Rican community. Her intentions were challenged, and from her subsequent remarks, she felt that the onus was on her to prove to the staff that she was authentic in her claims of cultural affiliation and authentic in her understanding and motivations to help in the Puerto Rican community. Over time, the administrators came to see her as someone who was indeed Puerto Rican and therefore worthy to be considered part of the community. The initiative, however, came from Anastasia to present herself in such a way as to allow a shift in the perception of others, and therefore their evaluation of who she was and where she belonged. Marta spent the majority of you young life in Puerto Rico and went back to live there during various times in her adult life. Of all the participants, she is the most acclimated to the Puerto Rican culture and is familiar with the cultural nuances. For Marta, her dark skin was assumed by others to be a mark of lower class and therefore not the appropriate type of Puerto Rican to be seen in certain spaces. Below are portions of our discussion that illustrate these points. Marta's story illustrates how in Puerto Rico distinctions in skin color are social markers used by other Puerto Ricans to determine admission into certain spaces: 
Es que yo tenia un apartamento de ricos. Nosotros eramos duenos. Entonces, las que iban a limpiar eran Dominicanas, eso asi como mexclaitas. Entonces un dia una mujer me dice "¿tienes llaves?" Es que yo tenia llaves para subir...dije "iSi, yo soy dueña!", le dije. Serre la puerta en la cara. Entonces, yo y Sonya fuimos a una tienda antiguedades al frente del edificio. $Y$ nosotras nos hemos quedado con la costubre de cargar una cartera bien grande o tn "backpack". ¿Y qué fue que te dijo la mujer? Te dijo "Ten quidado porque aqui ayi cosas muy caras." $Y$ Sonya y yo empezamos de hablar de Mozart. Nosotros empezamos de hablar de Shubert, de arte, de todas las bainas Europeas. Creia que eramos una prieta y un sirviente.

[It's that I had an apartment in a rich area. We were owners. Well, the ones who cleaned were the Dominican women, and others similarly mixed. Well, one day a women asked me "do you have keys". It was because I had my keys to go in. I told her "yes, I'm an owner!" And I gave her a look. And then, Sonya and I went to an antique store in front of the building. We came in with our stuff, a large purse and a backpack. And you know what the woman told us? She said "be careful because there are expensive things in this store". Then Sonya and I began talking about Mozart. We began talking about Schubert, of art, of all things European. The woman thought we were just a black woman and a servant.]

When she shared this story, I asked her if she had ever heard of a book called Whistling Vivaldi, by Claude Steele (2010). She had not, so I explained to her the major themes of the book and how they related to the story she just shared with me. The book discusses the concept of stereotype threat, the knowledge that if we behaved as the 
stereotype many hold in their minds about us, "anything we do that fits the stereotype could be taken as confirming it." (p. 5). The book gets its title from an experience shared by one of Mr. Steele's interviewees, Brent Staples, an African American man and a columnist for the New York Times. He recounted that when walking home through Chicago's Hyde Park, "at night I whistled popular tunes from the Beatles and Vivaldi's Four Seasons. The tension drained from peoples bodies when they heard me." (p. 6). Doing this, Mr. Staples "changed the situation he was dealing with" in order to reduce the tension of the people he encountered in the hope of changing their perceptions of him.

In his book, Steele (2010) discusses a concept called identity contingencies. These are "the things you have to deal with in a situation because you have a given social identity..." (p. 3). For Marta, she was aware that the store owner probably made the comment that she did because the owner, looking at their skin color and mode of dress, assessed Marta and her friend's placement in the social order on the island. The store owner saw Marta and her friend as having the social identity of someone from a lower class-because of their skin color and overall appearance. Having made this determination, the store owner then proceeded to interact with them as if they were living up to the stereotype. With this awareness of how the store owner was responding to their social identity, both women responded to the stereotype threat by discussing in loud voice things that would only be known by individuals who were of a higher social class than the one the store owner perceived them to be a part of. This was done in the hope of shifting the perceptions of the store owner and deflecting the deleterious emotional and social effects of the stereotyping and discrimination they were experiencing in the store. 
Differing from the intention of Brent Staples in Steele's story to diminish him in order to reduce the emotional response of others to see him as a threat, these women were using their knowledge of classical music to push back and shatter the preconceived notions that the store owner had of them. They used their privilege as women with advanced degrees to expand themselves in order to shift the dynamic. This was done independent of whether they were perceived as threatening by the store owner. Because they were women, their behavior was not received as threatening, and therefore probably just dismissed by the store owner. The response by Marta and her friend to this overtly discriminatory comment was an attempt to expand themselves and literally fill the space they were in with a different understanding of race, class, and gender. Although Marta's example is highlighted here, across the participants our response to such affronts is often not to shrink down and reduce our influence on our environment, but to expand and through our expansion initiate a shift in the perception and consciousness of others. This was a unique finding that came out of this research project that is not noted in any of the literature on Afro-Boricuas to date.

Intersectionality is a persistent reality in the lives of the women in this research project. Such efforts at trying to belong, and pushing back at efforts to exclude us, were one theme that the women and I shared in our conversations. We acknowledge that we faced these challenges almost on a daily basis. We all shared stories of having to prove our Puerto Ricanness to those who at times did not even speak the language as well as we did. For example, while I my undergraduate institution, I was attending a Latin@ student organization meeting and was immediately approached to see if I was lost. Once I was 
allowed in, I was met with a constant inquiry as to where I was from, if both my parents were Puerto Rican, where I learned to speak Spanish, if I was born on the island, etc.

Cultural litmus tests, archetypes, wanting to belong, alienation. All of these ideas complicate the life of the Afro-Boricuas in this research project. They are part and parcel of the intersectional existence that we inhabit. They are part of the microaggressions that attempt to wear away at our sense of who we are and where we belong. They inform our response of expansion rather than contraction. They contribute to the attempts at our cultural invisibility and push us into a defensive stance where we are screaming at the wind jsomos boricuas!

\section{Theme \#2: "I'm Not Mexican." More than a Monolith - Puerto Ricans Lost in the \\ Latin@ Other}

Through the experiences of the women in this project, we learn that those who consider themselves part of the dominant U.S. American culture use what is familiar to make sense of what is different. This comparison is often made by utilizing stereotypes or one-dimensional interpretations of a person or group of people. In so doing, the multifaceted nature of within-group difference is collapsed and the members are seen as similar variations of the same theme. This collapse is often done for convenience and can lead to frustration for everyone involved. Through the participants' experiences we see examples of how members of the dominant culture used their understanding of the Mexican culture in the U.S. to help them understand what it means for the participants to be Puerto Rican. The participants and I shared stories of being confused for Mexican, told that we speak "Mexican" Spanish, asked if we eat tacos, or if we were half Mexican. 
These experiences are often complicated by our assertion of being Afro-Boricuas, thus adding more complexity to the understanding of what it means to be Puerto Rican.

The use of Mexico as the cultural frame of reference and dominant narrative from which to understand Puerto Rican identity could be a function of the geographic location of the participants (three are from southwest, one is from the Midwest, and one is from the southeastern U.S.) as well as the ubiquitous nature of Mexican cultural iconography in the U.S. American landscape. For example, just over 20 years ago, salsa surpassed ketchup as the most popular condiment in the U.S. (Seitz-Wald, 2013, National Journal). People of Hispanic descent comprise approximately $20 \%$ of the total U.S. population, with those identifying as Mexican or of Mexican origin making up $64 \%$ of the total Hispanic population (Pew Research Center, 2015). And in July of 2015, California's Latin@ population officially outnumbered whites (Panzar, 2015, LATimes.com). With its close proximity to Mexico and central and South America, the largest groups within the U.S. Latin@ population are Mexicans and Guatemalans. From this backdrop it is not difficult to understand how Puerto Ricans and the Puerto Rican identity is usually interpreted and understood from the lens of what is understood by the dominant culture to be Mexican. Through our discussions, we learn how the participants try to insert some nuance into this interpretation and understanding. We share our own experiences with being confused for being Mexican, or our actions interpreted as being Mexican. We soon learn that a pastel is not always a pastel.

Subtheme \#1: Cataloguing Difference. In our conversations, we all shared stories of having to educate friends, fellow students, and faculty on what it means to be Puerto Rican, and how our language differed from Mexican or Spaniard Spanish. These 
two forms of Spanish were frequently referenced because one is associated with a geographical neighbor to the United States, and the other is seen as the source of the "mother tongue" and therefore the official form of Spanish. There were also times where we had to help others understand that Mexican culture is not a stand-in for all Latin@ cultures. We engaged in conversations that helped break down the inaccurate perception that being Latin@ was a monolithic experience. Here is an example provided by Erica of an exchange she had with a classmate during a Cinco de Mayo celebration:

Or on Cinco de Mayo, they would have Mexican food, and people would come up to me, they're like, "Does this offend you, having all this Mexican food for Cinco de Mayo?" I'm like, "No, because it's a Mexican holiday. It has nothing to do with me."

The lack of awareness we encountered from others that Puerto Ricans were not Mexicans made such situations frequent and awkward. It also forced us as participants to learn to frame our responses using the Mexican iconography in order to bring others to a different level of understanding about the diversity within the Latin@ community.

Taina grew up near the California-Mexico border and was very familiar with the Mexican community and culture found in the area. She expressed the same sentiment as Erica when she spoke about how she had to learn how to express her Puerto Ricanness in terms of Mexico:

I think I learned to talk about being Puerto Rican in terms of that Mexican-ness or the Mexican surrounding. It was always, "Our Spanish is different," or our Puerto Rican tamales [pasteles]. People are like, “What do you mean that's not cake?" 
And in the following comment, Taina notes that her familiarity with the Mexican culture allowed her to use discussions of food as a forum through which to help others understand the differences in the two cultures:

Having those conversations or when people are like, "You don't eat tortillas? What?" I'm like, "No. Tostones? Yeah. We do things with bananas. Not corn, no. " Having that conversation, I always found because I knew a lot about Mexican culture, it was easy for me to contextualize Puerto Rican culture for them. It made it more accessible to other people so they understood how it was similar, but also how it was different.

Like Taina, I have often needed to contextualize the foods that I eat during the winter holidays within the framework of Mexico. For example, it is tradition in the Puerto Rican community to make pasteles for Christmas. [Pasteles are a dish made of a root vegetable mash filled with meat, and then wrapped in butcher paper and/or banana leaves. It is then boiled and served with other traditional Puerto Rican side dishes like arroz con abichuelas (rice and beans), and platanos (green or yellow plantains).] In order for me to explain this holiday tradition to others, I often have to compare it to the Mexican tradition of making tamales for Christmas. Once I do this, I very quickly get acknowledgements of understanding from the other person. This use of Mexico as a point of reference is a testament to the extent that the Mexican culture has infused itself into the American consciousness. It is also a testament to the extent that it has influenced the narrative of other Latin@ groups, including Puerto Ricans, in certain parts of the United States.

Throughout our discussions, it was clear that Mexico, both as a country and an idea, has contributed significantly to the cultural milieu of the United States. The 
influence of Mexico was so profound in the lives of the participants that Taina, when sharing her story of taking an online quiz on "How Mexican Are You?" said the following:

Like those Facebook quizzes like "How Mexican are you?" I took one of those and I got a 100 percent! I'm like, "Well, I'm not Mexican at all" but because of my experience growing up around so many Mexicans and Mexican culture, I have a great understanding of what that means and what that is...

This experience that the participants have with the Mexican culture has also influenced personal relationships both at school and at home, as Anastasia recalls:

My boyfriend is Mexican.

It's so funny because my brother married a Mexican woman. And Erica notes that her friends describe her father as "a Mexican Santa Claus". It is difficult to remove or diminish the influence the Mexican culture has on the U.S. conceptualization of what it means to be Latin@. This influence often impacts our ability to connect with other Latin@ groups. Anastasia shared her story about having difficulty connecting with other Latino college students because of it:

The Puerto Rican's experience is very different so we felt like we didn't have somewhere to belong. I definitely didn't feel like I belonged in my dorm. I was the only Puerto Rican I think in the entire dorm and so I got a lot of ... There were other Latinas but they were Mexican.

Anastasia also found that the influence of the Mexican community in which she lived extended into the intonation of her Spanish language pronunciation. This created problems for her because she was, at the time, intent on embodying as much of a Puerto 
Rican identity as she could, and this included sounding Puerto Rican. In the following statement she shares this sentiment:

I've had a lot of people who were like, "Oh, you speak Spanish like a Mexican." For a while, I was like, "Oh, I just want to sound Puerto Rican." I had to break myself of that thinking because there's not one specific way that Puerto Rican should or should not sound. So many people had made me feel like I didn't sound authentic. I just strayed away from challenging that. It's just a matter of being confident with who I was, but it takes a lot when there's a lot of judgment." While attending college, I also felt a sense of alienation from the Latin@ community because there were moments, like the other participants noted already, where I had to explain where Puerto Rico was on the map, that I called a bus a guagua, and that I did indeed speak Spanish, just not the "Mexican" dialect. The extent to which cultural litmus tests were utilized with me as a way to authenticate my claims of Latin@ membership was a constant source of frustration during my time in college. It resulted in my self-segregating and limiting my access to the Latin@ students on campus. This left me feeling more alienated from the one community on campus with whom I had the most in common. It was important for me to feel a part of a campus, and not having that cultural connection impacted the quality of my educational experiences while in college.

This frustration extended beyond my time in college into my interactions with others in the work world. While at work, I was often met with surprised stares when I proclaimed that I am Puerto Rican and demonstrated that I could speak Spanish. The stairs and looks of apprehension came from both Latin@s and non-Latin@s. This usually occurred while advising a student and his/her parents on an academic issue. It also 
occurred when these conversations took place over the telephone and in an area where others could hear me speak. After my conversation with Taina on July 11, I wrote in my research journal the following:

We both saw ourselves as Latinas, but the world responded to us in different ways depending on who were with and where we were.

The participant conversations helped us all see that the context in which we found ourselves had a significant impact on our daily lives. The frame of Mexico as a place, idea, and dominant narrative mediated our conversations and interactions with others. It required us to not only linguistically but figuratively translate who we were and how we saw our reality from Puerto Rican to what was perceived as Mexican. The example of translating guineo to banana [banana being a word used in Mexican Spanish for the fruit of the same name] captures the interlinguistic challenges Afro-Boricuas face on a daily basis to help others understand that Puerto Rico and Puerto Ricans are real and have a distinct culture from what is understood to be Mexican culture. This constant act of reinterpretation extended into even explaining something as simple as the hair on our arms. Anastasia shared during our roundtable that she was often seen as Mexican, even among other Puerto Ricans, because of the amount of hair on her arms. She shares this story with the group:

I went to school with a lot of Puerto Ricans, so they said it [having a lot of hair] was a Mexican thing. I had Mexican arms. I would say "I don't know what that means".

This was a very salient example of how among Puerto Ricans, any difference that did not align with the conceptions of Puerto Rican identity that were informed by stereotypes and 
archetypes were relegated to another type of group, Latin@ or otherwise. In this case the group that the Puerto Ricans in Anastasia's environment used to interpret her arm hair was the Mexican culture. Because she was already seen as different and not fitting the conceptual understanding of what it meant to be Puerto Rican, any other difference was relegated to the next closest type of Latin@, which in her case was Mexican.

During many of our conversations, the participants shared that during their time in college, they experienced a dominant narrative in their academic courses of what a Latin@ identity, history, and culture was supposed to entail. The themes covered in the coursework and the issues addressed in class were primarily framed by Mexico and the Mexican or Mexican American narrative of experiences in the U.S. This included such things as the immigration narratives, language narratives, citizenship status, etc. This created the situation where the Puerto Rican experience was presented as tangential to those issues related to Mexico or Mexican Americans. Little to no mention was made of the continuing colonial relationship that Puerto Rico has with the United States and how that impacts the lives of Puerto Ricans both on the island and stateside. Of the participants, Anastasia was the most direct and insightful in juxtaposing her cultural awareness as an Afro-Boricua with the reality that Mexico and the Mexican experience had taken precedent in her college classroom:

I think one of the most profound things for me was growing up I was in a family that was very proud of being Puerto Rican and where we came from and all of those things. Then getting into a classroom with a combination of different Latinos and suddenly the Puerto Rican issues were not important and the bigger and the more dominant Latino group was Mexican so a lot of the things were very 
Mexican centered. Ilearned a lot because I didn't know enough about those things and I appreciated the knowledge that was being shared, but at the same time it would get very frustrating because there was this assumption that Puerto Ricans have it easy because we don't have to deal with the same issues. I grew up with a much easier past because my parents didn't have to deal with crossing the border or citizenship or any of those things, so my life was easier.

A lack of understanding by the academic community, specifically those who teach Latin@ studies, of the diversity within the community creates an environment where students like Anastasia feel lost in the dominant narrative that is put forth in the coursework.

\section{Subtheme \#2: The Unknown/Hidden Colony - Collapsing of Difference} within the Veil of Ignorance. Another issue that came up in our conversations was the lack of awareness that Puerto Ricans were in fact U.S. citizens. This included demonstrating to other that Puerto Rico was in fact on the map of the United States of America. Unfortunately, there is evidence that Puerto Rico actually is not on most maps of the U.S.A., and is usually left out of renderings. For example, Appendix 3 has three images: one from a children's coloring book purchased in Dubai in the summer of 2015, and two of map puzzles for children purchased during the fall of 2014. In all three images, Puerto Rico is missing. In both map images, inserts are included for Hawai'i and Alaska, but none is included for Puerto Rico. More than anything, these sentiments expose the inadequacies of the education systems in the United States in how (or if) the complete and accurate history of the United States and its relationship to the Latin@ 
diaspora is taught in schools. A more insidious interpretation is that Puerto Rico continues to be an unacknowledged and hidden colony of the United States.

Another example of this insidiousness can be found within the new Common Core Standards for U.S. History and World History. As Appendix 4 shows, the Standards books for grades 3-5 make no mention of Puerto Rico. Such an omission can only be interpreted as either an egregious oversight by the book publisher, or a deliberate attempt to diminish in importance the role of Puerto Rico in U.S. and World history. With this and other examples mentioned before, it appears that these are efforts to make the island disappear in the minds of both young domestic and international learners; the island is literally omitted from educational material and therefore deemed unnecessary. One is left to question the motives of those creating the educational material that is supposed to inform us of the world around us. This issue extends to political realm as well.

In a May 8, 2015, broadcast of the show Last Week Tonight, the host John Oliver lamented that, despite what is said in the media, Puerto Ricans are not immigrants. (Oliver, J., 2015) In the segment, he highlighted the national discussion regarding Judge Sonya Sotomayor being nominated for the U.S. Supreme Court. During a national discussion that occurred across all major news outlets, Justice Sotomayor was consistently referred to as a child of Puerto Rican immigrants. Oliver was adamant in his rebut that Puerto Ricans are not immigrants but in fact are U.S. citizens. As a result, Justice Sotomayor's parents migrated to New York from Puerto Rico. In another instance, I came across a children's biography book series called Women Who Broke the Rules. In this series was a book about Sonia Sotomayor called, Sonia Sotomayor: I'll Be The Judge of That! (Krull \& Dominguez, 2015) where it clearly noted on page 7 that her 
parents as immigrants. [See Appendix 5]. Prior to returning the book to the library, I corrected the misspelling, and contacted the book publisher to bring the error to their attention. [See my email in the Appendix 5]. I asked them to correct this error in future publications of the book. To date (the email was sent January 28, 2016) there has been no response from the publisher. This level omission places the Afro-Boricua in a position to have to educate her peers about the existence of the island, as well as about the complexities that are contained within it, and its relationship to the United States of America.

Dr. Sonia Nieto, a Puerto Rican professor emerita of Language, Literacy, and Culture in the School of Education at the University of Massachusetts at Amherst, has written about the experiences of Puerto Ricans and she describes our relationship with the United States as migrants having an immigrant experience. To explain this, she speaks about the circular migration patterns of many Puerto Ricans and says, "this circulatory migration, called vaivén ["coming and going"], has helped redefine immigration from the life-transforming experience that it was for most Europeans immigrants at the turn of the century to a "way of life"" (p. 134). Even she is not immune to the erroneous assumption in the academy that Puerto Ricans are immigrants. In a profile done on the Arizona State University website "Inside the Academy", the description repeatedly states that "Dr. Nieto recalls how hard her parents worked as immigrants from Puerto Rico to buy and successfully run their own bodega [a small grocery store]"; "As the daughter of Puerto Rican immigrants, Dr. Sonia Nieto describes her passion for writing about the experiences of Puerto Rican students in American schools" (Arizona State University: Inside the Academy, http://insidetheacademy.asu.edu/sonia-nieto). 
Anastasia summarizes this frustration in the following two quotes from a conversation she had with another student during freshman year in college:

In college, it was where people make these really weird statements and I was like,

"I don't even know how to have this conversation. You just asked me where

Puerto Rico is. I don't, I don't know. I don't know how to do this." I need to pull up a map and be like, "It's right there. Not that far from where we are. It's not this magical island that popped up." I had a lot of those freshman year and I wasn't as comfortable with myselfyet. I was very just taken aback and confused and I didn't know if this was like a one-time thing. Definitely, it was not. It happened a lot of times after that.

Because the first few times I was pretty offended. I was like everybody knows where Mexico is. No one ever asked me where that is, but for some reason Puerto Rico seems to be this like, "Oh, my God. I had no idea it existed."

Where then do we begin to identify and then deconstruct the tendency by the dominant culture to collapse the differences between and among the Latin@ population? This is a question that highlights the role that structures play in our lives and the responsibilities us as Latin@s in general, but Puerto Ricans specifically, have in that process. It highlights the impact that those structures have on our personal and political lives, and the confines in which we are left to navigate our world. It brings to light the ignorance that informs the everyday experiences of all the citizens of the United States. It leaves the Afro-Boricua woman both present and hidden from the consciousness of Latin@s and non-Latin@s alike. This presence is further complicated by the fact that the 
most immutable aspects of who we are (our phenotypical features) are met with suspicion and used by others to justify our exclusion us from our community.

\section{Theme \#3: "But You Look Black..." - Colorism and the Role of Phenotypes}

Colorism is defined as "the allocation of privilege and disadvantage according to the lightness or darkness of one's skin" (Darity, 2007). It differs from racism in that it occurs within groups to confer privilege and differentiate by skin color. According to Darity (2007), "most studies have found that gender interacts with the effect of skin tone, making lighter skin a form of social capital for both Black and Latinas" (p. 17). This phenomenon then puts Afro-Boricuas at a double disadvantage in that, depending on the shading of our skin, we are excluded culturally and socially. This creates the context where Afro-Boricuas are evaluated downward based on superficial factors such as skin tone, hair texture, facial features, and so on. The intersectionality of this existence is often stifling to the mind and the spirit.

This phenomenon is different from racism in that with colorism "discrimination is not based on racial categorization but rather on assumptions about the meaning associated with one's skin color." (Hollinger, 2007). The related concept of hypodescent is the relegating to the less dominant group those who are not perceived as white (Hollinger, 2007). From the experiences shared by the participants in this project, it seems like hypodescent and colorism are ideas are persistent within the Latin@ community that we have come in contact with. The participants and I have found this practice to be in full effect during our interactions with our community. A uniquely state-side phenomenon, hypodescent assigns you to the Black group regardless of skin tone, so long as you have Black or African heritage (Hollinger, 2007). In Puerto Rico, racial assignment is more 
fluid and the shading of the skin allows the Afro-Boricua to at times "emphasize the Indian or European heritage" (Jorge, 2010, as cited in Jiménez Román \& Flores, 2010). Words like mulata [mixed with African and European ancestry], jabá [person with light skin and kinky curly Afro-like hair], trigueña [tan-skinned person], grifa [light-skinned, light-haired Black person], negra [black person], and prieta [dark black person] represent progressively darker representations of Blackness on the island. This gradation also determines how people treat you and behave themselves around you.

The participants, to varying degrees, experienced colorism in a variety of settings, including within their family and friends. For Taina, the treatment she received was dependent upon the context in which she found herself:

Some places in Southern California, the assumption is that you're Black and. The assumption is never Puerto Rican first. It's always Black first. Are you Black and White? Are you Black and Asian? Are you Black and something?

For Taina, she found this belief to be an attempt to exclude her from the Latin@ community while simultaneously confirming her place on the dark end of the racial binary system of the United States.

Subtheme \#1: Being Latina in the Black Community. The racial binary that exists in the United States was something that all the participants found themselves experiencing to some degree or another. Latin@s for the most part challenge this racial binary, not only by the variety of ways we appear in the world phenotypically, but how we perceive ourselves. When talking specifically about her college experience, Taina spoke about her interactions with the black community as being tenuous: 
They [Black student organization leaders] already had an idea of what a Black woman was supposed to be and I didn't fit that. At the time it's not like there was a mixed student organization or center so it was like, "Well, you don't belong here so you should probably go away." It was the feeling that I got even though that was never directly said or communicated. That was the feeling that I was left with in trying to access those spaces.

She struggled with living up to the expectations of the Black community, and experienced rejection of her efforts when she tried to insert diversity in that paradigm: With the Black students, the assumption was that we all grew up on soul food and it was a very Southern Black Baptist tradition as opposed to within the Brown community on campus, it was much more diverse.

When interacting with members of the Black community on campus, she felt like she was not given the space to define for herself what Blackness meant to her. This left Taina feeling like an outsider looking in at a community that she felt a deep connection to, but that she was not welcomed to join. Anastasia was a member of a PanHellenic organization, but it was specific to Latinas. She had a positive experience with the Black community on her campus:

I think that most of the time the way I looked, the way I spoke and the comfortability I had with the black people made them assume that I had to have been black in some way they assumed. "You couldn't be this comfortable with us if you were not us." So I think there was a lot of, "well what are you? Where do you come from? Oh Puerto Rican's are basically black." I guess... 
Anastasia attributes her level of comfort with the Black community on the positive worldview her family had towards the Blackness present in their family history. This is not to say that Taina's different experiences were a result of a negative experience with the Black community in her personal life. This is just an example of the differences that exist in the quality of our interactions with the communities of color around us. For instance, in the following sentiment, Anastasia speaks of her grandmother and how she was the main source of African cultural pride in the family:

My grandmother is very proud of being African. She always tells us that she knows what tribe we're from in Africa and not to forget that that's a very big part of who we are. When I started learning about the three blood lines I always felt closest to that African part, because of her and because she has always made us very proud of who we are and what we look like. I felt comfortable in the center and I think I came from a family who is was very outspoken and comfortable with their blackness.

Anastasia was included in the Black community in her area and this inclusion was seen as a positive by her and incorporated into a component of her ethnic and racial identity that was reinforced in the home. It allowed her to engage with the Black community to the extent that some believed her to be only Black. Because of how she conducted herself with them, others came to the conclusion that Puerto Ricans were "basically Black"...a comment she heard repeated many times in her personal and professional life.

For Marta, colorism was used to both include and exclude her from the Black community. She made a clear distinction between being Black and being African American. For her being Black was a more global concept, but she was aware that to 
many people in the U.S., being Black meant being African American. To quote her, "They didn't understand that being Black is not the same as being Afro-American." She goes on to say that "Yes, I have black heritage and I'm black, but not the same black". It was important to Marta to acknowledge the diversity within the African diaspora. She was adamant about acknowledging her African heritage and shared an exchange she had with some of her students in a Spanish class she taught. At the time, Marta taught at a historically Black college. During a lecture, Marta used the collective "we" when speaking about enslaved peoples and the outcomes that the slave trade had on our people. One student challenged her and said that she was not one of them:

I said, "what do you mean I'm not one of you?? I am as black as you are the last time Ilooked in the mirror." They said, "No, no you're not one of us" I said "why because I speak Spanish, that's the language of my colonizer. Your language of your colonizer is English, that is not your language either." They freaked out, there was incredible silence in the classroom. I said "you have no idea what your own language or your heritage is". They just like... I mean there was like a long silence for a long time. I said "you don't know what tribe you come from in Africa. You don't know what slave ship you came in. You don't even know if you came from the Caribbean. "From that moment on they eased up on me, because it was like "you're not one of us, you are just a Spanish teacher. Come from another country, you might look a little bit more refined here or there. You're not really one of us" and at that point, I made it clear to them, "I'm one of you and you're one of mine. We are one family", but of course I didn't get there overnight either. 
Marta was insisting that the students see and acknowledge her as being part of the Black community and used her position as teacher to advance the conversation in the minds of her students as to who is included in that community. She clearly saw herself as one of them, despite some external differences ("I had an accent, because I was not really Black"). She also saw them as part of her, and she was determined to help the students understand that they must see her as one of them as well. This collectivist idea of community was brought up in our conversations. It may be a result of our Latinaness, our Africanness, or the result of our interactions with the people in our world. Regardless of the source, we all saw ourselves as a part of a larger community, a diaspora that bridged the Black and Latin@ communities. From the conversations, we all agreed that this was the only reality we knew and were often surprised to find others in the two communities did not see the world as we did, or see the world with us in it.

Subtheme \#2: Being Black in the Latin@ Community. From the shared stories, the participants often mentioned colorism, or some derivation of it, when discussing preference and privilege. Colorism provided a context with which to explore the different levels of privilege among the participants. To understand colorism within the Latin@ community, Telzer \& Garcia (2009) note "the value of skin color and stigmatization of darker skinned Latinos may be reinforced by Latinos themselves because of internalized racism and subconscious acceptance and/or incorporation of negative stereotypes from the media, society, and history." (p. 369). The presence of such racialized frames of reference within the Latin@ community requires us to acknowledge that the interactions Afro-Boricuas engaged in are informed by a race-based ideology that is inescapable for both the Afro-Boricua and the other person. Within the Puerto Rican community (and the 
Latin@ community in general) there is the idea of adelantar la raza [advancing the race]. This advancement is accomplished by a dark-skinned or Afro-Puerto Rican marrying or reproducing with someone who is light-skinned or European. As Cruz-Jansen (2001) asserts, "for Latinos, to be Black in the United States is a perceived liability." (p. 172). As a result all efforts to lighten and "refine" are made in order to create a distance from the Africanness that is perceived as a liability and what is coveted, whiteness. To exemplify this, Taina and I spoke extensively about her family friendships with other Puerto Ricans. In social gatherings, skin color was made an issue:

Yeah. I remember when we would go over to the Gonzales's, so that's Denise, Carlos and Vanessa, the three of them; they're siblings, and they had a pool. We would all be over there in the pool. Sometimes the parents would remark, "Oh, come out of the water. Come inside for a little bit. You're going to get too dark" For me, I could be outside for five minutes, I'm going to tan versus some of the other kids, they'd be outside for that long and they could burn. Is that really necessary? Do you have to say that?

Although the comments were not directed at her, she experienced them to be degrading and emotionally charged. She shared another story about the family mentioned above and articulated her concern for the emotional damage such comments were having on her friends and ultimately her:

Actually, that mostly would come from Carmina, so that would be Jose and Cecile's mom, who had the one dark kid and the one light kid. Carmina was very fair-skinned, and then her husband was very dark, which is why they had one dark kid and one light kid. But she would always tell Cecile...Actually, it would be 
directed at her and kind of all of us, "Come inside before you get too dark." To say that in front of your other child who is already dark, you're doing not-kind of things to their self-esteem and their mentality about themselves. But that was something that I heard. Even when we're in Hawaii, it was like, the word that they use there is paele. Don't stay outside too long, you're going to get too paele, like, "Come inside," or, "Don't stay at the beach too long," or those types of things, because even there it's still about color, where the darker you were, that was bad. Taina's concern for the psychological damage such comments could cause are wellfounded. Jorge (2010) notes that without properly integrating "the parts of herselfblack, Puerto Rican, and woman - into a meaningful whole", the Afro-Boricua is "susceptible to all types of psychological pressures that force her to play an active role in her own genocide, eventually leading to a total disappearance of people like her from the Puerto Rican group." (p. 274). These are strong statements, but ones that are supported by the experiences and opinions of the women in this research project.

Erica shares with me conversations she has with her cousins about skin color privilege. They are African American and Puerto Rican. Erica was born in Puerto Rico of Puerto Rican parents. Her cousins challenged Erica's claims to being Afro-Boricua like them. They reminded her that she had skin color privilege, as the she shares:

So I didn't really say stuff like that in class that much but I do talk about it with my cousins here who are half black and half Puerto Rican. And depending on...I would say overall it's not received very well. They're like, "you're not really black. You have skin privilege. You can't say that you're this. Nobody will believe you when you're Puerto Rican anyway". Just a lot of stuff like that. It's very 
physical to them, visual to them. I just don't see it like that most of the time. Yeah. For them it stands all or nothing on the physical level and then when I try to throw it back like, "well nobody, everybody thinks you're black just because of the way you look, nobody's gonna thinks you're Puerto Rican". They're like, "that's not fair, Erica."

Because of her genetic make-up Erica fades and becomes lighter in the colder months, and then is distinctively much darker in the warmer months. This noticeable shift in her skin color creates situations where the perception of others shifts along with her change in skin tone:

She was like, "You don't look Puerto Rican. No, you're white, you're white." Then a few weeks later, she was like, "Oh, you look your color!" I was like, "Oh, Lord have mercy, you can't say that to real people."

Marta experienced a different form of color privilege. The resistance Marta experienced to her claims of her Blackness began when she was in Puerto Rico. She experienced individuals trying to assign more favorable racial/ethnic qualities to the tone of her skin. For instance when she was in a restaurant in Puerto Rico someone made the following comments:

There is when immediately they started to say but you're olive or you're this or you're that. What the hell is that, with the color of your skin. I said well the last time Ilooked I was brown of some sort. They said, "No, no you're olive, oh but your hair and your nose".

The insistent and persistent dismissal by others of her Blackness put Marta in a defensive stance. She felt she must acknowledge vociferously the fact that she rejected their 
attempts to ignore her Blackness, something she valued and saw as integral part of her identity. This diminishing of Blackness by Puerto Ricans is often an intentional act. In another example shared in a discussion with me, Marta mentioned being denied access to her Blackness as a young person growing up in Puerto Rico. As a child she was colored with burned cork for her to sufficiently resemble a character in a play at school:

Cuando yo era chiquita, yo era la tembandumba y mira la ridicula de la escuela de mi mai, a mi me pintaban con cocho negro para que yo sera negra. Si pues eso nos hacian en Puerto Rico para que fuera sufficiente negro. So that I could be in character. For me to be in character, I have to be black on my skin. [When I was small, I was tembandumba and look how ridiculous was my mother's school, they painted me with burned cork so that I was more black. Yes, so they did this to us in Puerto Rico so that we were sufficiently Black] What could only be considered a subconscious denial of Marta's already present Blackness, the adults put her in "blackface" in order for her to sufficiently represent the Black character in the play. This insistence that Marta was not Black but "olive" appeared to limit, or at least create issues, in her search for a more integrated cultural identity informed by what she knew to be our history and racial heritage. The insistence by the Puerto Rican community to ignore, suppress, and eliminate the apparent Blackness of our culture, beginning with what is done to our children, speaks volumes as to the inherent and internalized racism within the community. As Taina mentioned during one of our roundtable discussions, it is "colorism on steroids." She confirmed that there is a negation of Blackness "in the Mexican American community", and there is a lack of awareness and acknowledgement that there are Black people within the Latin@, 
community writ large. This structural and seemingly intentional eraser of Blackness in the Puerto Rican community is ultimately detrimental to us all.

Subtheme \#3: Hair - "pelo bueno, pelo malo" [Good hair, bad hair]. In my conversations with the participants, one issue situated within the concept of colorism became a recurring topic: pelo [hair]. I was not expecting it to be a major topic of discussion, but the participants were consistent in sharing how their hair influenced their experiences both within the Puerto Rican community and in the broader society. Hair color and texture, like skin color and eye color, is the product of genes. As such it is a bellwether of our genetic past. It is a visible representation of the colonial past of the Americas, and can instantly render you by the observer a member of one or other particular group. It was an unexpected subtheme with very little academic literature speaking specifically to the experiences of Afro-Latin@s in general, and Afro-Boricuas specifically, with regards to their hair. When expanding into the arts, I found poetry, paintings, and online references to the experiences of Afro-Latin@s and their hair. Within the Latin@ community in general, comments like pelo malo [bad hair] or pelo bueno [good hair] are commonplace and reference the value placed on the diminishing of African heritage as displayed in the curl of the hair. Poet Mariposa (2010) states in her work, Poem for My Grifa-Rican Sistah, or Broken Ends Broken Promises:

Chemical relaxers to melt away the shame until new growth reminds us that it is time once again for the ritual and the fear of scalp burns and hair loss 
and the welcoming

of broken ends

and broken

promises (p.280)

I personally know all too well the struggles with chemical relaxers because I was subjected to them starting at the age of about nine. Being the only sibling (and the only member of my immediate family) with kinky curly hair, I was the only one who had to endure the burns that came with the chemical relaxers. My experiences were shared by the other participants in the project as they lamented over the fights with family members (usually mothers, grandmothers, and sisters) over their hair. We were all subjected to acts of self-policing by family members to ensure that our hair was "presentable". It was important that we presented to the world a respectable image of a Latina, and that any vestiges of Africanness were diminished as much as possible.

In the past couple of years, there have appeared articles in online platforms such as Ebony Magazine, BlackLatinaMovement.com, Belleza Afro Latina, and Latino USA discussing the issue of hair in the Afro-Latin@ community. In a podcast posted on the LatinoUSA.com website, Brenda Salinas (2014) interviewed a couple of Afro-Latinas regarding their hair. One person she featured was named Carolina Contreras. Ms. Contreras, an Afro-Dominican and owner of the blog MissRizo.com, shared her experience when returning to the Dominican Republic for a visit: "If you work for a bank in the Dominican Republic, you're most likely going to get a weekly stipend to go to the salon, they just feel like it's not professional." She goes on to say that "It's frustrating to 
have to deal with that today, our hair has nothing to do with our productivity, our intelligence or with our knowledge about a particular subject or anything."

The importance of hair in the Black community and the Latin@ community differ in how hair is seen and interpreted, regulated and deemed acceptable, both within and outside of the communities. These concepts break apart and reemerge to create a different reality on the bodies of Afro-Boricua women. For instance, Taina in the following comment spoke about how if she had her hair styled a certain way, the world would interact with her differently:

Initially when I walk around with my hair straight, if I'm wearing sunglasses, people who I interact with on a daily basis would not recognize me. I always feel like it kind of gives me this invisibility cloak where I can walk around like a ninja and no one notices me. My brother refers to it as "incognegro".

Her hair literally gave her the ability to be invisible, to be an "incognegro" among the general population. In reflecting on what she meant by that assertion, she said that her straightened hair gave her the ability to "walk around like a ninja and no one notices [her]". To Taina, her hair allowed her to disappear out of the perceptual frame of others into a space where she was so undefinable and racially ambiguous that she was left to just be who she was by the broader society. Hair for Taina acted like a cloak of invisibility that gave her the opportunity to come and go in the consciousness of others. She was able to side step stereotypes that others would otherwise use to define who she was before they chose to interact with her or maybe pass judgement about her. During our roundtable, Taina shared that "if I wanted to be left alone, I just straightened my hair, put 
some glasses on, and no one would even know it's me." The other participants had similar experiences with their hair and nodded in affirmation of her experiences.

Similar to Taina, I also have been in situations where when I straighten my hair using a flat-iron, I disappear from the gaze of others into a place where I become racially ambiguous. With my hair in its natural kinky curly state, it is undeniable that I am Black, part of the African diaspora, and the world around me perceives me and reacts to me as it would any Black woman. That changes when my hair is straightened. When this happens, my hair injects uncertainty in how African Americas and Latin@s perceive me. I recently was at a garden store and the man helping me to my car with my purchases said, "you look Latina, but you are not Mexican. What are you?" At this point, I began speaking to him in Spanish. I said, " $i m e$ descubristes!" [you found me out!]. We then continued our conversation in Spanish, where I shared that I was Puerto Rican. He commented that he had a friend who was Puerto Rican, showing some familiarity with the culture and a justification for how he knew I was Latina.

Such conversations do not happen when my hair is in its natural state, nor do they occur when I am around African American people. The diversity within the African American community that manifests itself in variations of skin tone, hair texture, etc., make my appearances fall within the reasonable expectations for how a Black woman would present herself to the world. In the Puerto Rican community, on the other hand, there is a conscribed and expected appearance for Puerto Ricans and for African Americans. From the experiences shared by the participants, we seem to think that the Puerto Rican community has adopted the state-side concept of the black-white binary to assess those who are part of the community. When my hair is straight, I am no longer 
perceived as just a Black woman. I no longer neatly fit into the Black-White binary and therefore, a shift in perception occurs and I am assumed to be of some Latin@ descent. For Taina and me, the texture of our hair has the effect of shifting the perception of others, placing us into a space of racial and cultural ambiguity but away from blackness, and we experience different treatment by each racio-ethnic group.

Hair touching is often perceived as an invasion of personal space that ignores the right of an individual to privacy and ownership over her own body. The experiences of the participants support this and can be also seen as different between the African American and Latin@ communities. The movie, Dear White People, addressed the issue of hair touching as an undercurrent storyline in the film. In the film, Sam (played by Tessa Thompson) on her radio program, says the following "Dear white people, please stop touching my hair. Does this look like a petting zoo to you?" Marta will share later how in the Puerto Rican community, the idea of personal space is different than that in the states among African Americas. To her hair touching was part of the act of creating connection while engaging in conversations. It encompassed touching of other body parts (such as arms, hands, face, etc.) during conversations.

In the Black community, this act of intruding upon personal space harkens back to the times of slavery when Black bodies, especially Black female bodies, were put on display and examined for either the purposes of sale or for study by White people. This lack of respect for the Black body is still felt today so many centuries later, as the reference to "petting zoo" mentioned in the movie Dear White People. All the women in the study have had the experience of someone touching their hair without permission. Taina shares one incident of hair touching: 
Being like, "Your hair's so soft." I'm like, "I didn't give you permission to touch my hair. Why are you touching me?" When my hair is straightened, again, people feel that they have the license to just touch my hair. Even if they're someone that I have known for a long time, it's something new and different and they're like, "How do you get those curls out?"

There was a difference in the quality of the interactions surrounding hair if the AfroBoricua was with Black friends versus Latina friends in college. Across the conversations, the participants found more in common with their Black friends or students in the residence halls, than with Latin@ friends and students. For instance, Taina shares this story of her experiences in the residence halls at her college:

I had students, particularly women living on the black floors lof the residence hallsJ who talked a lot about hair, and all that experience. Before their first year when they lived in a predominantly white hall, when they would be straightening their hair or washing out a perm, or they were going natural, whatever it is what they were doing with their hair, they would literally have white girls sitting there staring at them, asking them like...Like "Does that hurt?" or "Are you going to burn yourself?" "Like, aren't you scared to do that?" Like, "I've never seen a hot comb before. Tell me about that." Then, they [Black female students] talked about moving from that environment to living on the Black floors, and when they'd be putting the hot comb through their hair, they might have someone run in and be like "Let me take that and fix my bangs. Here you go," and I'm going to run out and leave. 
Feeling like our life was on display was something that Taina and Anastasia shared while they lived in the residence halls at their colleges. Being around other Black students reduced the sense of being on display and provided a space to share a common experience without it being made into learning opportunity for non-Black students. Anastasia shared this comment with me during one of our conversations:

I went through a lot of questioning by white students. Ilived in a dorm with predominantly white students and was frustrated the majority of the time because they ask things like "can I touch your hair."

The participant shared with me that when they had conversations with Black women living in the residence halls, they felt that taking care of their hair was like an aspect of their life was on display for the world. They were placed in a position where they were questioned and felt compelled to answer questions in order for others to understand and move on. Their personal space was not honored and others would cross personal boundaries in order to touch their hair. Anastasia shared a story that exemplified a shared experience with other Black women in her residence hall. It involved having to care for her straightened hair in a similar way as that of another Black student, I can say that one of the funniest experiences I had with one of the girls was that at night they wrap their hair and I have to wrap my hair too when I am straightening because I didn't do all that work to wake up in the morning looking crazy.

Once it was clear that hair was a major aspect of the Afro-Boricua's experience, I waited to see if the theme materialized in my conversations with the last two participants. After I 
asked Erica to reflect on her time in the residence halls, both as a resident and as part of the residence staff, Erica shared what she thought was an obscure and trivial fact,

This sounds kind of trivial, but a lot of the times it would be things like, "Oh, your hair is so different! Can I touch it?" I'm like, "What? No, you can't touch my hair." "Il's so curly, I just want to touch it."

Erica attended a small, private women's college of about 700 students. Her experience in this unique educational space speaks volumes as to the persistent nature of how Blackness is disconnected from its owner and put in a common space for others to observe, dissect, and inquire without the consent of the person.

While in college, Marta also experienced people touching her hair. This experience was unique in how it impacted her ability to engage in rapport-building with Black women: El pelo mio no se desarroya...pero cuando yo estaba estudiando, me tocaban el pelo. Y las negras, tú no te puedo tocar el pelo. [My hair doesn't get messy, but when I was studying, my hair was touched a lot. And with the Black women, I was not allowed to touch their hair?]. Marta thought it was odd that Black women touched her hair, but she was not allowed to touch theirs. It was as if Marta was not seen as part of the Black community in a significant way that would allow her the right to engage in similar hair-touching behavior as the Black women. This presented a disconnect between what was acceptable in the Black community and what was acceptable in the Puerto Rican community, who belonged and who didn't, and how those differences in cultural cues were not understood by Marta. This inability to negotiate and reciprocate limited Marta's ability to fully engage and bond with Black women at her college over something as intimate as hair. 
When discussing hair and its role in the lives of Latinas, the concept takes on multiple purposes. Marta explained in one of our conversations that with Puerto Rican women, touching hair is normal:

Y para nosotras... ayi muchacha. Eso no es ningun "issue". Yo tengo una amiga que se puso en fugu porque "me tocaron el pelo". Yyo, "y que?" Si ella era Puertorriquena, forget about it. Nosotros tocamos el pelo." [And for us (Puerto Rican) women, oh girl, that is not an issue. I have a friend that got very upset because someone touched my hair. And I said, "so what?" If she was Puerto Rican, forget about it. We touch our hair.]

To her, sharing personal space was a cultural trait among Puerto Ricans that encompassed touching hair, in addition to touching of the hands, arms and face, and that was acceptable to and expected by Marta. I concur with her because I find the concept of personal space to still be a bit foreign. I am most comfortable siting in close proximity to others and extending a hand to touch someone while we are talking. I have encountered non-Latin@s who find these actions odd and at time uncomfortable. This may be because of the possible dissonance created because what I look like and my actions do not align with the expectations the other person has of Black people. This may have served to further alienate me from others. Speaking with Marta, I have learned that it is a cultural trait among Puerto Ricans to have a very small area of personal space. Not having others reciprocate, or at least feel comfortable with our way of interacting with others, reinforces the alienation I personally feel, and others in the group feel at times. Marta is the one, of all the participants, who has lived the longest in Puerto Rico and has a recent and deep connection and familiarity with the culture. This level of 
familiarity with the nuances of the Puerto Rican culture is not present in the other participants, including me. Because of this culturally informed understanding of personal space, Marta found it difficult to understand why if both Blacks and Puerto Ricans touched hair, why was it seen as unacceptable for her to touch a Black woman's hair, but a Black woman could touch her hair. From Marta's perspective, there existed a double standard with regards to touching hair that she perceived as confusing and unacceptable. During our roundtable discussion, Marta shared that a Puerto Rican female friend of hers had a set of keys thrown at her head by an African American woman to determine "if that was her real hair". This shocked the entire group to hear the treatment that those of us who live in the liminal spaces of the Latin@ and Black community must endure, even by the Black community.

Taina's experiences with the Latinas in the residence halls were similar in that those students also touched her hair, but the motivation for touching was different from the motivations of the Black women. The Latinas she came in contact with saw curly hair as just another type of hair rather than some marker of mixed ancestry. In our conversations we postulated that this may reflect a generational perspective where: (a) there is sufficient familiarity with the existence of African features in the Latin@ community; or (b) there could be a lack of awareness of African history, and therefore individuals chose ignore the reason behind the difference in hair texture and attribute it to a difference that is reasonably expected in the Latin@ community. This perspective provided a glimpse into how the Latinas who lived in the dorms performed self-care differently and in compliance with Western standards of beauty, as Taina shared: 
Part of it was still about hair, just like having curly hair in an environment where people have mostly straight hair, where people are like, "Oh, is your hair really that curly? Did you get a perm? Can I touch it? " or just touching it, so those, similar experiences. It wasn't in the same way, but it was just an understanding that people have different types of hair, and they're like, "Well, my mom has straight hair. I just happen to have curly hair. Why is it that big of a deal to you?" was sort of their reaction, so even the similarities of experiences of hair...

For many Latinas, they articulated their preference for the dominant culture's standard of beauty by how they styled their hair. Taina shared this statement as an example of her observing this preference:

Right, but a lot of them [Latinas] would straighten their hair and... It was sort of that idea of "Oh, well if my hair is straight, then that's considered prettier," so conforming to western ideas of beauty as opposed to just letting their hair be naturally what it is.

The participants experienced a distinct difference in how and why Black and Latino women engaged in hair touching with them. We proposed that this difference may be based on historical factors that provide a framework for understanding where the Afro-Boricuas is positioned along that spectrum. Gilmarie Brioso mentioned in her January 2014 article entitled Kinky Hair and the Pursuit of Latin-ness, that "all 'real' Latinas have straight hair". This understanding is deeply embedded in the consciousness of the Latin@ community. She goes on to say "It was a no-brainer: if kinky equaled Black, straight equaled Latina and Latina equaled beautiful, I could straighten my hair and become a beautiful Latina." This sort of accommodation to the White standard of 
beauty has detrimental effects on all of us. All of the participants in this study have heard some version of this statement said to them, or about them. The struggle for the AfroBoricua, as it relates to her hair and its representation of colorism in the respective communities she interacts with, is the one of integrating all aspects of who she is into a beautiful whole.

\section{Theme \#4: "You Can Make It!" - Transforming the Politics of Exclusion}

Four of the five participants work in education, with one contemplating returning to school to complete her law degree. All expressed a deep desire to help others like them succeed in school. It was important for us to reach out and provide assistance in the form of information, access to resources, and guidance in deciphering the bureaucracy of the educational institution. Many of us struggled with navigating the bureaucratic structures of post-secondary education. Having someone available to answer questions and provide advice on best practices makes the process much easier. This sort of cultural capital is often missing in the Latin@ community as we are underrepresented in post-secondary educational institutions on the whole, and particularly in administrative and teaching positions. Anastasia speaks to what motivates her to help the students at her high school to succeed:

Never would I ever thought I was going to end up in education, let alone in a high school. Let alone working for a college prep organization. Within a few months the whole direction of where I was going, it changed. The kids inspired me and motivaled me and I think gave me purpose in my work. You can do your work but if there's no purpose and there's no meaningful action laking place, then what are you doing and who are you doing it for? I felt like I made a difference. It wasn't 
this egotistical like I came in and I fixed everything. It was like a, they need people and they need more of us who come in with this genuine open mindedness and care for them. They have so many other people who look at them in such a negative light and they don't need that. They've gotten that all their lives. They need people who believe in them and are going to push them and motivate them and hold their hand through rough stuff because high school is hard. It's so much harder than I think people really understand. These kids are going through things I didn't have to experience until I went to college. They're experiencing it their freshman and sophomore year in high school. The world is requiring them to grow up so much faster than it did me. That stuport system is so necessary. Anastasia saw her work as providing a path to college attendance for a population of students who are ordinarily overlooked, discouraged, or marginalized as they attempt to pursue post-secondary educational opportunities. Anastasia believed by being present in the lives of the young people with which she worked, she could wield the resources she had to help focus their efforts so that they could reach their educational goals.

Taina shared a conversation she had with her high school counselor who did not see her as someone who could succeed in college, despite the fact that her grade point average and extra-curricular activities would have made her a competitive candidate for admission into a four-year institution. She spoke of professors and staff who supported her as she matriculated through college to graduation, and on to graduate school. She also relied on the support of fellow students. Her experiences informed her commitment to being a resource for others in order to ensure that they did not encounter similar obstacles on their way to meeting their educational goals. 
One resource Taina spoke about as a source of support for her outside the classroom were the "sister friends". This was a group of African American women who met regularly at a women's resource center at the college where she was completing her doctoral degree. She tells of her initial encounter with the group:

At the institution where I was going to school. I was interning there. They happened to meet every Wednesday at the same time, and I was there. Before me, previously, because it's a closed group, so if the staff members didn't identify as Black, they actually close the space and would leave. This was the first time they had a Black woman working there, and so they were like "Oh!" like "Staff can actually attend. Great, we can keep the center open. That's great..."

Taina was aware that she was seen as an African American woman in this space. She was receptive to this inclusion and felt welcomed by the other African America women to stay and participate in the group discussion. Her perspective as a Black Latina was not seen as foreign and allowed everyone in the group gain a better understanding of the experiences of women of color on the campus. Inside the classroom, Taina spoke about an informal mentoring relationship she fostered with a professor who was like her in many ways, as her testimonio accounts:

Ithink in particular some of those conversations I had with one professor who was mixed and it wasn't until junior year of college. Her name was Jayna Brown and she was an English professor at UC Riverside. She was the first professor I ever had who looked like me. Brown skin, curly hair. It was like, “Oh, my people." We exist in an academic setting. I'm not the only one. She was someone 
who I sought out, went to office hours, and had some great conversations with about representation, about looking at our backgrounds.

This relationship helped Taina see herself in academia and belonging in college. It fostered in her as belief that she could succeed in college. She feels strongly that it is vital to have mentors in a student's life that reinforce the narrative of success. This reinforcement can come in the form of being a racial or ethnic minority in a space where one is not expected to be, or providing access to resources and information to help the Afro-Boricua woman succeed.

Erica was aware that at her small, liberal arts, all-female private college, students of color were an extreme minority and as a result struggled to stay engaged and matriculate successfully to graduation. She shared this awareness in this conversation:

I know just because of the kind of educational system I came from, I just assumed that... Which may have been a poor assumption on my part. But I was like, you know what? If you're black, you probably had a really terrible time in the education system. Let me take you under my wing, show you the tricks, and show you how to... Because that was one of the issues that I saw, but wasn't necessarily brought up enough in my opinion. A lot of African-American students, a lot of Latino students, they were more likely to drop out of college than the white students. I know that's an overall trend, but particularly at Converse, when it's just all white people all the time. They were more likely to drop out, and I was like, "You guys, that's not happening to you. Come on." So I would take them under my wing and kind of show them, "You should get involved in this, this is 
what to avoid. Don't get sidetracked by people being stupid, or people being racist, this is what you need to do."

For Erica, providing guidance and mentoring to the Black and Latina students on campus was a way for her to assure that others like her "made it through". She took this responsibility on as a personal task because she saw so many African American women transfer, primarily to historically Black colleges and universities, because they did not find a place for themselves at that institution.

Marta experienced such mentoring relationships during her time in college. She speaks of a specific professor who helped her develop her identity as a political being. She states in her conversation:

Well, actually I had a Political Science class with an incredible man who continues to be my mentor, my friend, and he was my professor. He was called, "The Resident Marxist." His name is Victor Wallis. He's retired but he currently teaches at Berkeley, Boston. He said, "Marta, I really want you to meet this guy who is one of the leaders of the Puerto Rican Movement in Chicago. "So I said, "Sture!" I met him. His name is Jose Lopez. He's an icon and I would say the father of the Puerto Rican Movement in Chicago, at least from the '80s on. Although she shared with me that professor Wallis was a Jewish man, she felt he helped her by providing mentoring and access to political thought and action that she would not have had access to otherwise. She gives credit to her cultural heritage, and the insistence on respect, humility, and valuing education, for the quality of interactions she had with her professors. One case in point is the following: 
Ilearned a lot of that from some of my professors who are very interested in Puerto Rico and my background because they saw that I was a different student. First, I was respectful. I saw them as people who had something for me that I could learn from, I could grow from. While the other students took it as a commodity. That was also one of the situations, as not only as a woman of color and as a woman, but also in terms of how I grew up in Puerto Rico.

This idea of respect was something that Marta valued and took seriously. She felt it was this cultural trait that differentiated her from the other students in her classes. Her cultural heritage informed her codes of conduct with the faculty, and she noted that the teachers were receptive to her way of interacting with them. As a result, Marta now teaches and mentors other students as they pursue their educational goals at the college level. During the roundtable discussion, Marta shared that "we must put ourselves in these spaces where others are not expecting us to be in order to show the world we exist". This idea that acknowledges that we belong, and we must insist that others see us in the same way, was a consistent theme across participants.

\section{Summary}

In this chapter, the themes were outlined as follows: "You're Puerto Rican?", "I’m Not Mexican...", "But You Look Black...", and finally, "You Can Make It!" Throughout the chapter, I wove the stories told me across the participants in order to create an image in the mind of the read of what the theme represents for the participants. I incorporate the elements of the conceptual frameworks outlined in Chapter Four (Espiritismo, Womanism, African Womanism, and Mujerita Theory of Justice) to retell 
our stories. Chapter Four provided a description of who we are as a collective. Here is a summary of the findings thematically conceptualize:

For the first theme, "You're Puerto Rican?", the idea of belonging reoccurred throughout and across the conversations. Without exception, all of the participants shared stories of needing to insist on membership in our culture by engaging with those who saw themselves as gatekeepers. From home, to work, to school, the Afro-Boricuas pushed back against the resistance of the Latin@ community to admit to the existence of Blackness.

The second theme, "I'm Not Mexican...", speaks to the frame used in the United States to identify all that is non-white, non-Asian, and non-Black. All that is Latin@ is understood through the lens of the Mexican culture as understood within the United States. The women all shared stories of having to use Mexican Spanish words to describe Puerto Rican cuisine, or being told that they had "Mexican arms" (as was the case for Anastasia). Educating about linguistic differences, geographic location of Puerto Rico, and educating within education were subthemes that emerged in the conversations.

The third theme, "But You Look Black...", the participants shared in their constant engagement with the Black community, Latin@ community, and society to not place them in a space they felt they did not belong. Our phenotype does not dictate our preferences or our identity. It does however dictate how all of society interacts with us. Colorism both within the Black and Latin@ communities played a significant role in the stories shared within this theme. Hair was the primary source of discussion when others were attempting to identify the Afro-Boricua and place her in a social, historical, and political context. 
And finally, the forth theme, "You Can Make It!", was the place where their college-going experiences were informed by who they were and how they saw themselves. It was in this space - school - where the women felt, as Marta expressed so eloquently, "we must put ourselves in these spaces where others are not expecting us to be in order to show the world we exist" It is proof that college is a place where we learn about ourselves in relationship to others, and where we find the resources to make meaning out of our experiences. We see it as a place to learn and grow and to help others do the same. We also see college as a place where we live as political selves engaged in the world around us, advocating for not only our rights, but the rights of others to be in school, to thrive, and to succeed.

Chapter Five will provide a sense of who we are individually. The participants and I decided to provide a snapshot of our most important memories that connects us to our culture and identity as Afro-Boricuas. Chapter Six will have a summary of the unique findings that I call the testimonios, implications of the study, questions that can be explored through further studies, and my final reflections of this project. 


\section{Chapter 5: La Historia detra del Cuento [The Story Behind the Story]}

To get a sense of who we are collectively, you can read the findings. To get a sense of who we are individually, the participants and I decided to provide a snapshot of our most important memories that connects us to our culture and identity as AfroBoricuas. In addition to the biography the participants were given the option to write a poem written in the style of George Ella Lyon's (1999) poem, Where I'm From. The participants were also given the option to provide an artistic representation that could take the form of anything they chose. Only one thought this option would be worthwhile, so she submitted a photo of herself to accompany her poem. Four of us just chose to write a poem along with our biographies. One participant decided to provide a brief biography. The stories and artistic representations provide some insight into what informs our individual stories, and gives you a hint of how we come together to tell different aspects of the same story. I will begin with my story.

\section{Marie - Merita}

I was named after my maternal grandmother: Maria Isabela Feliciano. The English translation became Marie Elizabeth. My nickname was Merita, or little Maria. This has been, and always will be, the way many people know me. It represents me, my essence as an Afro-Boricua, and my connection to the history of the women in my family. It connects me to the person I considered my mother twice. Abuelita Maria died ten years ago, but all the women in my family carry a part of her in us. My mother and I look a lot like her, and so does my daughter. The genes are strong, and so is the disposition that comes with them. She lived with my mother in Southern California until her death at age 86. During those times she caught snakes in the front yard, climbed ladders to clean gutters, and trimmed fruit trees with the family machete (most Puerto 
Ricans have one). She helped my mother when her home became the first Spanish bilingual foster home in the county. She was a force of Puerto Ricanness. I will forever be a part of her and do my best to honor her memory. It was her family home in Culebra where I started my life and began forming my identity. It was through her instruction that I learned all of my multiplication tables, colors, letters, and cursive writing before the age of six. It is in her home where my story begins...

Part of the charm, and difficulty, of living on an island off of an island (Vieques and Culebra) is that there was no electricity or running water. It was a hard life for the adults, but a charmed life for a child. My brother and I were closest in age (20 months apart) so we played together. I had two older sisters who were four and nine years older than me. Being too young to attend school, my grandmother taught me and my brother at home. By the time I arrived in stateside in 1976, I was able to write in cursive, knew all my numbers, letters, shapes and colors, could count to 100 , and knew my multiplication tables to 12 . The only thing I did not know was English. My grandmother helped me accomplish all of this despite the fact that she only had a $3^{\text {rd }}$ grade education herself. Despite this ability, my elementary school in southern California tried to keep me back a grade because I did not speak English. My mother, knowing how to fight for what she believed, fought for me and I was placed in the first grade where I belonged and assigned an ESL (English as a Second Language) teacher to assist me. As a result of the educational support I received by the teachers and administrators, I thrived in school.

Back in Culebra where I grew up, my brother and I at a very young age often walked down the street to my great-uncle's store to by soda and any essentials that my grandmother needed for preparing the afternoon meal. Everyone knew who we were and 
to whom we belonged. We were safe. My memories of our walks are lit in light brown sepia, the color of the dirt on the road we traveled to and from the store. On our way back we would pass the Catholic Church that was down the road from our home. Our home was made of cement and wood built by my grandfather and older relatives. We washed our clothes in a tub with soap chips, water, and a clean plunger. My brother and I sometimes were allowed to run across the clothes to create suds. The hard work of manually cleaning dirt and spots came afterwards. This is how I learned to clean with my hands. We were bathed in the same tub with warm water was heated on the stove. The same stove that boiled the crabs, conch, and other seafood that my uncles brought home from a day at sea.

As a child, it was my job to feed the pigs in the sty in the back of the house. I have distinct memories of walking to the pig sty with the bucket of leftovers. The sty was about 100 feet away from the back door of the house. The pigs seemed huge given that I was only about four years old at the time of my memory. I can still sense their bodies bumping up against mind as I made my way in between them to the trough to pour the food in. The smell of the pigs, the food, and the sty has stayed with me to this day. During one of the times of festival, one of the pigs was pulled out of the sty and tied in between two coconut trees that grew in the backyard. A family member took a bat and bashed it across its head. The next memory I have is holding open an intestine while an aunt pours a liquid mix into it, ties the ends, and sets it aside. I later learned that I was helping make budin [blood sausage]... and yes, it was delicious. These types of memories remind me that I am from an island people. I am from a place where sobreviviendo [surviving and thriving] is a way of life; where you value family, community and home; 
where you do not need a lot to be happy. It is these life experiences that inform the essence of who I am. It is these memories that I hold on to as evidence that, although I live stateside, and have done so for nearly 40 years, I am from somewhere else. I see photos of myself during this time in Culebra and I had a perpetual smile on my face. I can only remember happiness when I think of my home.

Although I have never gone back because of financial constraints, I hope to do so someday soon. This time I want to bring my children so that they can see where they also came from in the spiritual and cultural sense. They can learn and understand where their mamá's priorities and worldview were formed. They can learn where they have family and community and people who look just like them. They can learn to recognize themselves in the faces and ways of the people to which they will forever be connected to. It will be important for me as well to go in order to remember. Since I left at such a young age, my memories are a collage of firsthand experiences, viewing photographs, and stories others have told me. For example, my sister Janet was the one who corrected me when I said that we grew up in Vieques. I was wrong...I was born there, but we grew up in Culebra, a neighboring island that is also part of the Puerto Rican archipelago. Speaking to family has helped me get my story straight. What follows is a poem I wrote to help me understand what has informed my story, and help me sense where I need to continue going in order to complete it:

\section{Where I'm From $\subset$}

I'm from Vieques and Culebra, islands off of the big island of Puerto Rico.

From strong women with strong arms and backs and minds who know what's right and know how to fight for what they believe. 
I am from pig sties and blood sausage, single parenthood and alcoholism.

I am from school, school, and more school....I'm in grade 25!

I am from arroz con gandules, caña, y pasteles.

From machetes, correas, y chancletas.

From tropical breezes, lovely humidity, and swaying hammocks.

From struggle, struggle, and more struggle.

I am from Isabela, Maria, Gladys, Janet and Debbie, and Tymen and Tayla.

From a late summer love affair that ended with me.

I am from all of what was and what will be.

I am from a legacy of sacrifice that must be carried on in my heart-mind.

I am from Africa, Italy, and Taino...trenzas que me hacen quien soy.

I am from hope.

Erica

If there is one thing I fail miserably at, it's writing the "tell me about yourself" section of an online dating site. Most of the descriptors I have about myself are sarcastic, mildly self-deprecating, and do not capture what I truly want to say about myself. So the idea of going back and trying to condense where I am from and how I view myself as an Afro-Puerto Rican in the South is a mildly daunting task. I can only hope that this does not turn into a written version of my nervous ramblings.

I spent the first five years of my life in Puerto Rico, but I have almost no memory of what life was like on the island. Any experiences I had that might define my cultural identity are watered down as stories or home movies if my parents are in a nostalgic mood. My academic experiences and social life are largely defined by the values and 
culture of Southern society (minus the extreme conservativism, odd racial stereotypes, and the underlying sexism). Often as the only Latino in my class, I overachieved in my academic life and tried to overachieve in my social life. I am not sure if other kids would avoid me because they couldn't necessarily tell what race I was or if there was something programmed in them to actively dislike "nerds". No matter what it was, I felt an increasing sense of isolation along with this need to be the model Puerto Rican representative among my classmates.

In middle school and high school, I tried to be "spicy", I tried to speak Spanish, and I tried very frequently to swivel my hips in order to alert everyone while simultaneously conform to the expectations of what a Latino should look and act like. Unfortunately, while I still passed Spanish on the simple fact that I'm Puerto Rican (sadly that is not a joke), I can't speak any Spanish beyond "Hello. How are you? Please leave me alone.". I couldn't figure out what exactly it meant to be the "spicy" Latino beyond being loud and busty (at least according to the media's standards). And as far as the hip swiveling is concerned? I realized attempting to conform to that stereotype was simply slowing me down when I had much more important things to do.

When I wasn't trying to contort my personality into the media's portrayals of Puerto Ricans and fit into my classmates' expectations of how my behavior should mirror "my people" (which looking back on it, most of it seems like everyone thinks Puerto Ricans are wild and out of control), I became hyper aware of my skin color and how it could be perceived by others. From spring to the first day the temperature drops below seventy degrees, my skin would be tanned, bronzy, and clearly stamped to others that I am an Afro-Puerto Rican. Once the temperature dropped, I fled to the warmth of the 
indoors and my skin color shifted to pale beige with yellow undertones. For whatever reason, this would confuse others to the point I was told "you don't look your color." Since I lived in the South, race seemed to be more important than it would be in other places. I wanted my skin color to constantly be tanned and bronzy so it could tell others what I am. Now I realize that's entirely too much to ask one organ of my body.

I come from an amalgamation of cultures, values, and stereotypes. While none of my family is originaily from the South, it would be a dishonor to me and my world view to deny that growing up here has a profound effect. It originally forced me constantly think about my cultural identity and what stereotypes other people attempt to box me into. I cannot think about who am I or where I came from without thinking about my race and how other people treated me as a result. However, I cannot talk about these things without any type of humor or without dissolving into a loose narrative that resembles rambling. If I couldn't laugh at any of this, I would certainly be curled up in a ball and watching Amy Schumer while hoping I could one day morph into a blonde white woman. I would much rather be the sarcastic, mildly self-deprecating, non-Spanish speaking Puerto Rican woman 1 am.

\section{Finding the Sosa in the Southern (C)}

Taken from the island

Molded in the South

Trying to blend in

While being told to represent

Which stereotypes to follow

And what expectations to live up to 
My story becomes as muddled

As my identity

Accepting l'll never be

Dark enough, "spicy" enough,

Puerto Rican enough

For others

Ultimately accepting there is no

Enough.

There is only what a Sosa is

In the South

Smart.

Funny.

Outspoken.

Other.

Puerto Rican.

\section{Anastasia}

\section{Where I'm From $\mathbb{C}$}

I'm from the busy streets of Chicago

Raised in a vibrant Puerto Rican neighborhood

From both the traditions of Roman Catholicism and non-domination spirituality

I am the Puerto Rican Shirley Temple

Curls that cannot be controlled

From hamburgers and arroz con gandules 
I put ketchup on my pasteles

I have skin that is a combination of cafe and leche

I'm equal parts Afro and Boriqua

I continue the legacy of strong and beautiful women

I am proud of where I have been and where I am going

\section{Marta}

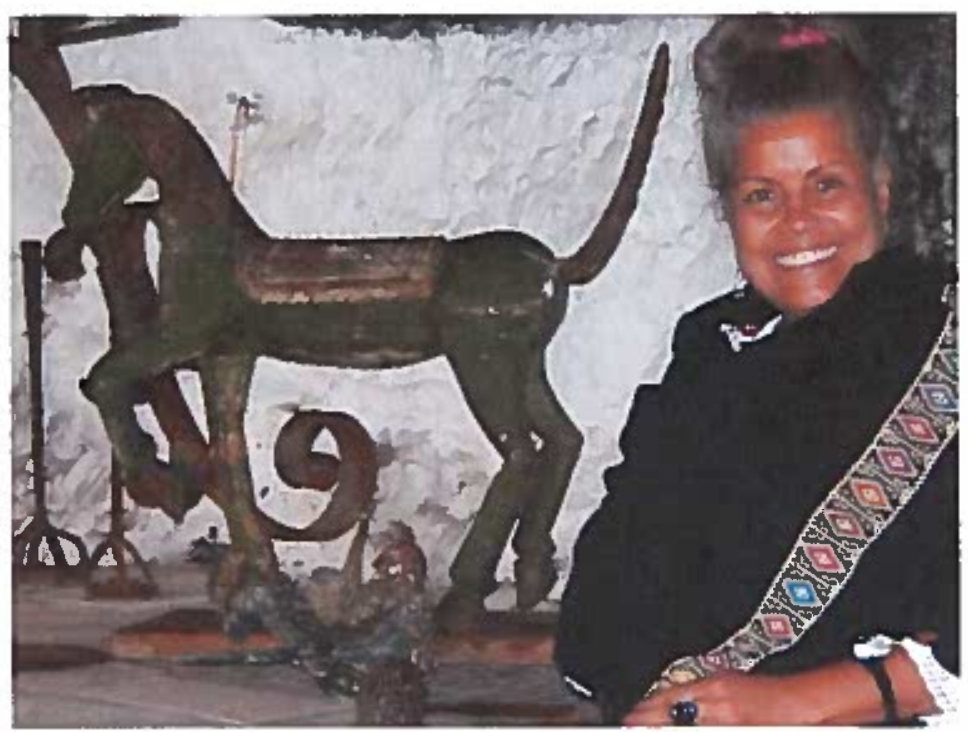

Marta's personal photo submitted for inclusion in this research project. 
Marta's Poem

The height of your note $(C)$ by Marta Cruz-Concepción

Only those of us

who have grown

in the heat of the noon hour

lost in the waves of the sea

can travel so far on a note.

I close my eyes and see it all, taste it all... as I feel the cutting salt into my toasted skin at the noon hour at the moment when everything and everyone

is possessed by the estio, the lethargic magic

in the sound of sedating altar bells.

I drift into waves that lose me in the longing for all that makes my being.

\section{¡Abuelita!}

I see you in the eternal and distant dream.

I see you yesterday.

But all that I feel are

the cold hands, once a warm touch

over my innocent head.

How far is the noon hour

from silent pelican flights?

Flights indifferent to these memories

days gone in a flight, on a note...

This is a place

as far as I can imagine

where waves do not play, do not sing, do not warm up

the essence of dreams.

Survival is within, it is the memory...

of playful moments

looking at the immensity

of the blue horizon.
Take me to the sights that agitated my young passion the endless curiosity and the fears of falling through clouds.

Let me feel the salty taste

of sour beach grapes

and the sweat of joy

in Caribbean dance.

¡Banda de acero! Steel band!

Take me into the height of your note!

Move me and stir all my senses!

Make me tremble in the euphoria of a dance!

Let the salty and sour flavors tingle on the tongue!

Caribbean Sea! Inundate me!

I plead on this beach of devotion.

Just let me be in the stupor of the noon hour!

The hour when the sand pounds

on the drum of eternity...

Caribbean Sea! Inundate me!

Caribbean Sea! Inundate me!

Only your rage on sandy shores

can carry the note to travel

so far into the essence of dreams.

The loose sand of the drum

at the noon hour

moves me into a silent flight.

Only those of us

who have grown

in the heat of the noon hour

lost in the waves of the sea

can travel so far on a note. 


\section{Taina}

As an identical twin, Taina had a very interesting life. Her and her sibling and older brother were Afro-Boricuas born and raised in south San Diego, in Chula Vista. In this place and space, her life became the epitome of a borderland experience. To quote her, "a borderland perfectly situated between a laid back American dream and Tijuana, the land of the best tacos you've ever tasted. Like my home stuck between American and Mexican, I was always stuck. Too black to be Latina and too Latina to be black." During our conversations, she often spoke about this in-between space that she occupied being present when she went to school and when she was part of other social situations.

She spoke about the realization that being Puerto Rican meant many things to many people... which also meant that she often did not fit the description or expectation of what a Puerto Rican was supposed to look like. Taina and I spoke about how cultural litmus tests manifested in her everyday life and impacted her sense of who she was in relationship to the Puerto Rican and Latin@ community. She experienced this level of awareness when she encountered a young woman talking on the payphone at school in a type of Spanish that was familiar to her. She realized that this girl was speaking Puerto Rican Spanish... but she looked different. This young woman had blond hair and blue eyes...the complete opposite phenotype of Taina. After later becoming friends with this girl, Taina realized that she was also imprinted with the social stereolype of what a Puerto Rican looked like. Together Taina and her friend explored the various ways Puerto Rican identity shifted and adjusted, but also asserted itself and demanded recognition, across

contexts. For instance, while visiting Puerto Rico, Taina and her friend often encountered people assuming Taina was the native Puerto Rican and her friend was the "white" 
visitor. The truth was the opposite. They were there visiting her friend's family in San Juan.

As a child, Taina came to learn there were three kinds of Puerto Ricans: islanders from Puerto Rico, Nuyoricans from New York, and Hawaiian Puerto Ricans from Hawaii. Each is similar but distinct from each other. Puerto Rico is like Hawaii, but in Spanish. Familia (or Ohana) is the center of life and food is vital to that. Taina's experience and understanding of the Puerto Rican diaspora is important because it reflects her understanding of the cultural centers of Puerto Rican identity as they manifest both on the Island and stateside. This understanding is part of who she is, and reflects an unacknowledged lack of Puerto Rican community in California. This is in contrast to the reality the one of the oldest Puerto Rican communities is in San Francisco, CA. The oldest Puerto Rican social club, the Club Social Pucrtorriqueño, formed in 1906 and is still in existence today. (U.S. Commission on Civil Rights, 1980, p. 5) As of 2010, there is approximately 190,000 Puerto Ricans living in California, making up only $0.5 \%$ of the total populations of Puerto Ricans living stateside. (U.S. Census 2010). Where we grow up, and what we see around us shape our reality of the world and of ourselves. Taina's story is exemplary of that fact. 


\section{Chapter 6: Discussion and Implications}

\section{Coming Home}

It has been nearly 40 years since I left Vieques and Culebra, Puerto Rico with my mother, grandmother, and siblings. I remember only the loving environment into which I was born and grew up: the dirt floor and farm animals in the backyard. We didn't have running water or electricity, and it was my job to feed the pigs in the sty in the far end of the yard. These memories stay with my all of these years later. They have influenced who I am both as a woman and as a Boricua. Coming to the United States was a necessary journey in order for my family to have more opportunities. It was necessary because of health reasons, as well as to have more economic and educational opportunities not present on the Island. Due to personal and financial circumstances, I never returned to Vieques or Culebra to visit family.

In reflecting on the process I underwent to develop and bring to life this research project, I see that this was my way of going home. In hearing the stories of these women, and sharing my own, I am attempting to reconnect to a Puerto Rico that I left behind. It is my attempt to make sense of what has informed the identity that I have claimed all of these years. It is my attempt at understanding what it means to be me. My life in the United States is different from what it would have been had we stayed in Culebra. The racial matrix of the United State that informs the everyday lives of people of color had, and continues to have, a profound impact on my and my family's life. When we arrived, we were forced to transform our perception of ourselves as Puerto Ricans to being perceived as Black, White, and "Italian". These labels permeated not just our conversations with others, but how we saw ourselves. It created discord in our family to 
the point that, during a very heated argument, one of my sisters called me the $\mathrm{N}$-word. It informed my mother's decision to have my bottom lip reduced slightly during orthodontic surgery in an attempt to reduce the negative experiences that I might have to endure in the United States because of my African features. As I went along in school, I worked to integrate the two selves that I was becoming, what I saw myself as (Boricua) and what the world saw me as (Black). This splintering and reintegration into a new identity happened primarily in college. That is why I chose to begin the research project by asking the participants what their experiences were in college. This was the place that put me in the position to have to tell my story. It allowed me to explore the different questions and write and read about others exploring similar issues. I was hoping that this would be a place from which the participants could also begin telling me their stories as well.

This research project initially began as a way for me to connect with other AfroBoricuas solely around our college-going experiences. The first effort to uncover these stories was done as part of a course assignment on qualitative methodology. I began by looking at all Afro-Latinas. From this preliminary study, I then decided to narrow down my subject to look at experiences of just Afro-Boricuas. Now that I delved deeper into the notions of testimonios and what they represent in the lives of Afro-Boricuas, it is clear that we are more than college students, and college is not the only place where who we are must exist. For all of us, college was a place to explore in an academic and semistructured way the issues of Black Latino identity and concepts of belonging. It provided a space to interrogate assumptions and look at who we are from a historical, political, psychological, and social context. It was also a place where we were put in the position to 
tell our story. It this educating-informing-telling process, we learned about who we were in relationship to our families, friends, and those around us who were just beginning to know who or what an Afro-Boricua is.

To this end, the results and discussion will be framed using Critical Race Theory (CRT). My use of narrative analysis involved situating my research project centrally in the theoretical framework of critical race. Narrative analysis "redirects the dominant gaze, to make it see from a new point of new what has been there all along." (Taylor, 2009, p. 8; cited in Taylor, Gillborn \& Ladson-Billings, 2009). Narratives are important for providing the stories behind the facts, the reality behind the assumptions, the truth behind the perceptions. It is an important vehicle with which we will tell our stories and remind the world that we are here and to see us how we want to be seen. CRT centers the notion of race and allows for exploring its many aspects of the Afro-Boricua's lie through this lens. It allows for the Afro-Boricua woman to be moved from the shadows, and helps to answer the question posed by the Vizcarrondo poem, "¿Y $Y$ i agüela, aonde ejtá?". [See Appendix 5 for the complete poem in its original Spanish, and the English language translation.] We are right here, and we demand to be seen.

CRT also provides for a way to examine what I have concluded to be a liminal existence of the Afro-Boricua. Liminal is defined as either "of or relating to a sensory threshold", "barely perceptible", or "of, relating to, or being an intermediate state, phase, or condition." (Merriam-Webster online). The Afro-Boricua's experiences as documented in this project fit the second and third definitions best. Historically, people of African descent were not necessarily acknowledged, and relegated to being part of the distant past of Puerto Rico. Duany (2000) noted that race was a complex issue to discuss within the 
context of Puerto Rican identity. He notes that "it is still difficult to break through the conspiracy of silence that surrounds racial politics in Puerto Rico" (p. 8-9). Even as recent as the 2010 U.S. Census, almost $76 \%$ of the population identified as White, and nearly 13\% identified as Black or African American (2010 Census: Puerto Rico Profile). Duany (2000) calls Puerto Rico the "Whitest of the Antilles" (p. 13). Afro-Boricuas are also in a phase marked by social and political change. We are coming out of the shadows, proclaiming our identities and demanding to be included in the Puerto Rican imaginary. We demand that this conspiracy of silence be broken, and those engaging in this conspiracy be called out into the open. I don't know if it would be fair to say that we are individually are in transition, but I think we are shifting the understanding of what it means to be Puerto Rican.

\section{Revisiting the Research Question}

This study sought to document the testimonios of Afro-Boricuas as they explored their lives. The research question asked them to reflect on their college going experiences in order to frame the narratives within the post-secondary educational experience. From the very first conversations, it was clear that the testimonios the women wanted to share might have begun in college, but went beyond their time in school. The study therefore shifted from one wishing to contain the women to their college experience, to one providing opportunity for the women to share all of who they were both within and outside of the college environment. This resulted in my reflecting on the conversations, reexamining the themes and coming up with an alternative title as well as alternative research question that more closely reflects what the women shared. The shift in the research question resulted my asking a different question: what are the experiences of 
Afro-Boricua women? This question allowed me to still initiate the conversation with their time in school, but provided a space in which to expand the conversations and bring in other life experiences that grew out of, or were influenced by, their time in school. Dillard (2000), in her discussion on endarkened epistemologies, states that from this way of knowing come "research as responsibility, answerable and obligated to the very persons and communities being engaged in inquiry." (p. 663). My engagement in this research project was informed by a personal obligation to tell our stories in the most respectful and truthful manner. It was also an attempt to bring to light the experiences of a group of women who the Puerto Rican community has relegated to a past that is no longer relevant to the present realities of Puerto Rican identity.

\section{Testimonios}

From the conversations and themes outlined in Chapter Four, it is evident that Afro-Boricuas live in the in-between spaces, the liminal spaces, of the Black and Latina experience. At times we found ourselves experiencing a sort of cultural double bind in which the participant is confronted with a choice between two undesirable courses of action (Bateson, 1972). Flores and Jiménez Román (2009) speak also of a triple consciousness that Afro-Latinos experience as is defined by "Latino, Black and US American dimensions of lived social reality." (p. 321) They go on to say that "in their quest for a full and appropriate sense of social identity, Afro-Latinos are thus typically pulled in three directions at once, and share a complex, multi-dimensional optic on contemporary society." (p. 321). Afro-Boricuas, therefore, have a unique perspective on what it means to be our particular type of person of color. 
From our conversations, a few unique experiences emerged that could only be demonstrated because of the Afro-Boricua's unique positionality. These findings include being seen as the "angry Black Latina", the concept of "incognegro", the idea of "combing out / coming out", and experiencing "cultural litmus tests". I have designated these experiences as our testimonios. They reflect the uniqueness of our position within and outside of many spheres (cultural, social, racial, educational, etc.). They also reflect our understanding of our experiences as they relate to us as participants in this research project. This politically charged and historically informed concept is appropriate for these unique findings because the findings serve to recenter the experiences of this Latina subgroup and provide an insight into the world in which we live. They are a declaration that our lives matter and are inextricably linked to the historical and present day realities of the Puerto Rican community. As Dillard (2000) states, "all research is social construction and cultural endeavor", so it is important that we as Afro-Boricua women engage in the co-construction of this research that is so personal and such a reflection of who we are. (p.662) I am also changing the voice from the past tense to the present because these unique findings are still present in our lives today and remain important influences on how we live our lives. In the end, we are telling our story in our own way through our own testimonios.

\section{Diagram of Testimonios}

The themes come together to inform and define the social reality of the AfroBoricua women in this project. They represent the challenges to our identity (Cultural Litmus Tests), how we are perceived when trying to live authentic lives (Angry Black Latina), and how we chose to engage or withdraw from our present realities (Combing 
Out / Coming Out and Incognegro), and how we declare that we belong everywhere (Declaiming Voice). They are in constant flow interacting with one another and provide a psychic backdrop that helps us make meaning of our world. They integrated into who we are and inform the lens through which we see, and are seen by, the world.

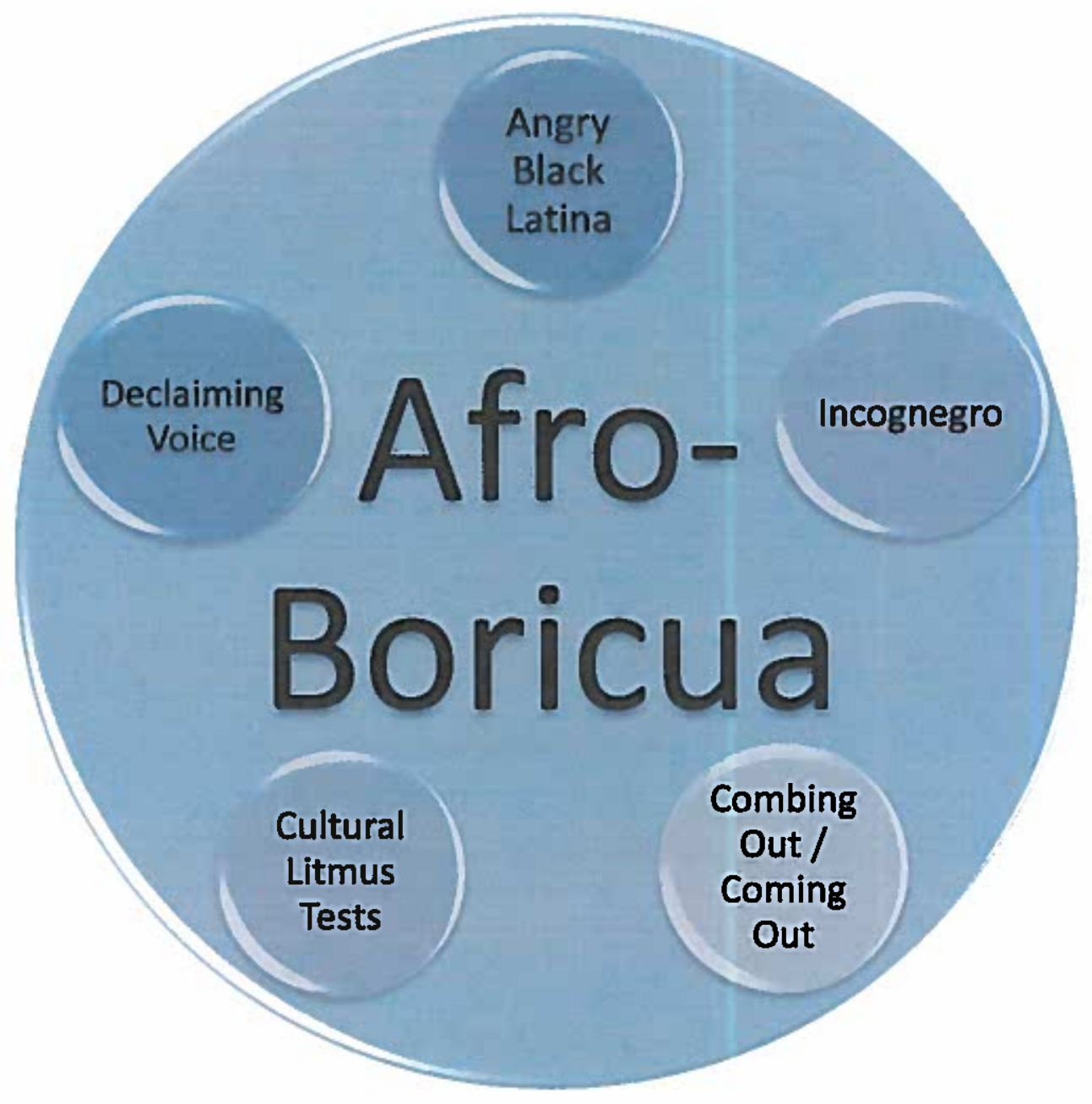

Diagram 2: The Testimonios as New Definitions of Self 


\section{Angry Black Latina}

In this collection of testimonios, the participants presented a particular aspect of our lived experience. This unique experience involves dealing with conflicting or overlapping stereotypes that exist in our location at the intersections of Latin@ness and Blackness. The stereotypical Latina behaviors (i.e., hot-blooded), if performed by the Afro-Boricua, were interpreted as stereotypical Black woman traits (i.e., hot-headed). This leaves us in a sort of cultural double bind where we face two conflicting and negative messages about our conduct. This results in a circumstance where if we succeed in embodying the stereotype of the Latina, we will fail to live up to the societal expectations of us performing the stereotypes of the Black woman. But, if we perform the behaviors expected of Black women, we then participate in our own alienation from the Latin@ community, thus confirming in the hearts and minds of those watching that we are truly not Latinas. However, in either case, we are seen as less than able to maintain a rational position and dismissed for both being a woman and being an ethnic and racial minority. For example, Taina spoke of feeling this pressure that exists because of her position at the intersection of being Black and being Latina at two points during a conversation:

Again, it's that, depending on the context or the setting, some people will see that as like, "Oh, you're being the fiery Latina or you're the angry black woman," but no one is ever, "You're the angry, fiery woman." No one ever says that. You're either one or the other depending on whoever's perception it is. 
Oh, definitely, where l've literally said to myself, "Take a breath. Don't be the angry black woman today," like, walk away. That's unfortunate that that's happened repeatedly in life as opposed to being like an isolated incident. Anastasia expressed the same sentiment of not being allowed to respond to situations authentically without being told to go back to a more familiar performance of self: When I get upset for some reason, they say that this blackness comes out. They'll say. "Go back to your calm Puerto Rican self." I've had student tell me this. Which is really funny and ironic, because they always say, "Puerto Ricans are spicy." According to them, when I get mad, it's this whole other Black issue. I hate to go back to my docile, calm Puerto Rican self.

I can't control what everyone says or thinks or any of that. I got comfortable calling people out, but it took a while. It took a very long time to figure out how to do it, because you also don't want to completely make everyone around you feel uncomfortable. I would have been the angry Puerto Rican black lady. There would have been a whole different set of labels.

Anastasia felt bound by the expectations of others to inform how she was supposed to behave. Both options were perceived as less than adequate, and possibly unprofessional depending on the context. She felt that being seen as the angry Black Latina constrained her to a performance of self that was less than authentic, and an inadequate vehicle through which to express all of who she was.

Although here is nothing in the literature that speaks to this unique experience, Cruz-Janzen (2001) can speak to the perception within the Latin@ community about this 
phenomenon as characteristic of racism within the Latin@ community. She states that "Latino racism, throughout Latin America, Spain and the United States, begins with the negation of the Black presence in history." (p. 2001) This negation requires an acceptance and belief that there is no Blackness in the Puerto Rican culture and therefore anyone who appears Black is not Puerto Rican. As a result, Afro-Boricuas whose behaviors are informed by a cultural knowledge of Puerto Rican ways of knowing, are not seen as Puerto Rican and therefore are perceived through another stereotypical lens. This lens of Blackness as understood by the Puerto Rican community is then used to interpret and judge the behaviors of Afro-Boricuas. This lens of Blackness is used to separate and demean and thereby remove from the Latin@ consciousness the Blackness that many of us represent.

This racism within the Latin@ community in general, and the Puerto Rican community specifically can be seen as a remnant of the colonial past that has manifested in a form of internalized racism. The categorical reduction and systematic desire to eliminate Blackness through such sentiments as "mejorar la raza" harken back to a colonial past where Blackness was seen as a blemish to extinguish from our genetic make-up. That said Blackness was considered undesirable in a moral context, while simultaneously seen as desirable in an immoral context. Black women were not seen as those with whom one married, but those with whom you had affairs. As a result, AfroBoricuas are relegated as Other, as Angry Black Women, with all the negative social stigma this stereotype brings to the circumstance. It is this warped gaze that is used to interpret the actions of Afro-Boricuas. It is this warped gaze that determined the confines of who is and is not Puerto Rican. 
King (1995) discusses the notions of "conceptual whiteness" and "conceptual blackness" as ways of understanding the gaze used by the dominant culture to try and define the Afro-Boricua. Critical race theory informs this analysis by "redirecting the dominant gaze, to make it see from a new point of view what has been there all along" (Taylor, 2009, p. 8; cited in Taylor, Gillborn \& Ladson-Billings, 2009). These notions of whiteness and blackness cannot fully explain the genetic, cultural, or social realities of Afro-Boricuas. This inability to understand further alienates the Afro-Boricua and relegates her to marginal status within society, regardless of whether she is seen as a hotheaded black woman or a hot-blooded Latina.

Recentering the notions of what it means to be Latina to have blackness as the center of that identity speaks to the notions discussed in womanism. As stated before, in womanism, the experiences of Black women are placed at the center and used to understand our world. Harris (2007) reinforces the importance of recentering Blackness as a way to validate "epistemologies and use these epistemologies as sources from which to uncover strategies of resistance and survival." (p. 393). At the center of Latinidad is the notion of struggle, so why not view this struggle from the perspective of AfroBoricuas. This perspective is a valid one to understand the Afro-Boricua experience. Incognegro

This concept was introduced by only one of the participants, Taina. Her brother used this name for her because of how she was able to move in and out of the Black and Latin@ community seemingly unnoticed, as she discusses in this testimonio regarding hair: 
Initially when I walk around with my hair straight, if I'm wearing sunglasses, people who I interact with on a daily basis would not recognize me. I always feel like it kind of gives me this invisibility cloak where I can walk around like a ninja and no one notices me. My brother refers to it as "incognegro". I can just walk around and I could be anyone I want to be that day becatse my hair is so recognizable now, which is funny to me. As a kid, in high school and early in college, I never wore my hair curly. I straightened my hair almost every single day.

I shared with her that I experienced the same type of social disappearance when I flatironed my hair. Depending on the state of my hair, I am able to position myself in an ambiguous space that makes it difficult for people to quickly pass judgment and make assertions about who or what I am. My hair imposes a cognitive pause on the conclusions people may make about who they think I am. In essence, I go undercover within both the Latin@ and Black communities.

Incognegro, a similar concept to "passing" in the African American community, was a term first written about by Matt Johnson (2008) in his graphic novel, Incognegro. In this novel, the protagonist, Zane Pinchback, a light-skinned Black man, passes as a White newspaper reporter during his travels in the southern United States during the 1930s. Pinchback uses his whiteness to maneuver the political, legal, and sociological dimensions of an antebellum south where lynchings were common. He used his ability to pass to witness and document the lynchings that were occurring and write about them in newspapers in the northeastern U.S. Early in the graphic novel, Pinchback states, "My camouflage is provided by my genes; the product of the southern tradition nobody likes 
to talk about. Slavery. Rape. Hypocrisy." (p. 18). In much the same way the Latinoness of the Afro-Boricuas was camouflaged by our Blackness. It covers up the need to acknowledge the same history of slavery, rape, and hypocrisy. This experience allowed us to maneuver into and out of the Black community, but made our Boricuaness nearly invisible to the Puerto Rican community. We are incognita, the feminine form of the Roman word incognito. Merriam-Webster defines incognito as "a word that describes someone or something unknown; with one's identity concealed" (n.d.). Our Blackness concealed our Boricuaness from the Puerto Rican community.

In this research project, although incognita is a term that can apply to the experiences of Afro-Boricuas, the participants used the term "incognegro" to refer to a different sort of passing; a passing that uniquely captures the everyday reality of the Afro-Boricuas in this research project. For instance, "incognegro" was not used to denote passing into the White community, but a shifting and blurring of the perceived reality of what it meant to be Black and Puerto Rican. There was no escaping our Blackness, but through our actions we blurred the interpretations of that Blackness. When specifically speaking about hair, the women saw their hair as one way of distorting the perceptions of others about us, and the conclusions drawn from those perceptions, to create a space of ambiguity. This space was a place where presumptions were suspended for a moment and the women presented a new reality for the viewer to have to contend with.

Another way that "incognegro" differed from passing in this research project was that the women were coming into and out of the Black community, not the White community. With this alternative understanding of passing, by adopting the term "incognegro", the women were redefining the notions of desired directional affiliation. 
We did not want to pass into the White community. We cannot escape our Blackness. On the contrary, we want bring our Blackness into the Puerto Rican community and be seen, still, as an integral part of the community. We represent a different way to be Black as well as Puerto Rican; one that strives to infuse Blackness with a Boricua essence. We do not want to remain concealed, or camouflaged, or ignored. Pinchback says that "since white America refuses to see its past, they can't really see me too well, either." (Johnson \& Pleece, 2008, p. 18). We no longer want the Puerto Rican community to ignore its past, and by extension ignore us. We want to be seen fully for who we are and where we belong. We want to ask the Puerto Rican community to acknowledge our collective history and see us in themselves.

In looking across participants, the concepts outlined above central to the idea of "incognegro" was seen in the testimonios of the other three participants. For example, Anastasia felt a certain amount of what she called "comfortability" with the Black community because of the discussions she had with her maternal grandmother, her abuela. The comfortability comes from her familiarity with Black ways of knowing and behaving, as well as pride in her culture and appearance. She spoke of her abuela as someone who instilled pride in their family's African heritage:

I think this comes back to my abuela on my mom's side. She's probably one of the proudest black Puerto Rican women I've ever met. I grew up, and I acted like a sixty year old Puerto Rican woman the first twelve years of my life, because I spent so much time with her. She was so proud of that side. So proud of who she was, what she looked like, what her family look like, and the color of her skin; and was so very vocal about it that growing up, I just thought she was the most 
beautiful person ever. I wanted to be darker. I was always in pursuit of being her color and being darker. I thought that she was just model-beautiful.

Because of this relationship, Anastasia felt a pride in acknowledging her Blackness, and kinship with the Black community that informed her sense of comfortability, and allows her to easily move in and out of the community without creating difficulty for her sense of identity. When in college, she learned about what Anastasia called "the three blood lines" that informed the Puerto Rican identity and culture. Through this academic and personal knowledge, Anastasia began understanding that she was a dynamic individual informed by a collective and personal history and understanding of Puerto Rican culture.

Erica, because of how her skin tanned or faded during the year, was able to move into and out of the Latina and White community. This was independent of whether she also considered herself an Afro-Boricua woman. She acknowledged that her ability to blend in was a function of how she was perceived by others during certain times of the year. Despite her attempts at inclusion, Marta was less able to blend with the Black community and was often placed in the India [Native American] category. This was a cultural in-between space where she was definitely not seen as white, but was not perceived as negatively as if she was Black. Her Spanish-accented English also provided an undeniable connection to the Puerto Rican community. For her, she was able to move within the constraints of Latina and India without raising much suspicion. Where she encountered difficulty is when she ventured out of the socially prescribed cultural and class expectations of the spaces she found herself in to claim her African heritage, as she shared during her discussions with her students. 
Again, this idea of being able to disappear into a blurred cognitive space that renders you uncategorizable is something that is not discussed in the literature. Critical Race Theory may help shed some light on how this concept creates a reality for AfroBoricuas that is unique to them. CRT "focuses on the intersectionality of subordination, including gender, class, and other forms of oppression." (Taylor, 2009, p.9; cited in Taylor, Gillborn \& Ladson-Billings, 2009). This intersection highlights a space where some live, using all means at their disposal to carve out spaces where they can sobrevivir [survive and thrive]. Within this discussion, Anzaldúa's notion of borderland can be useful to understand the cognitive space Afro-Boricuas enter. Anzaldủa (1987) states that "a borderland is a vague and undetermined place created by the emotional residue of an unnatural boundary" (p. 3). This place is where Afro-Boricuas can go and disappear from the prying eyes of a society struggling to make sense of who we are within a White and Black imaginary. It is a counterhegemonic stance that challenges the notions of the Black-White binary, a place where we define the outlines of our reality and our being and place society in the position to have to adjust to us, rather than the other way around.

\section{Coming Out / Combing Out}

Because of our perceived racial ambiguity, all of the participants were in a constant state of coming out of our Blackness, and voluntarily displaying our Puerto Rican identity through the use of language, behavior, skin shading, and hair appearance. Our revelation was optional, similar to the revelation of a person for being gay, and therefore under our control. For me and other participants, my hair particularly allowed me to move into a space where my racial and cultural affiliation was uncertain. It became a point from which to begin the conversation of whether I was Puerto Rican. The Puerto 
Rican community was then able to temporarily suspend their preconceived notions of my Blackness in order to consider me part of their community. This prompted some to ask me if I was Latina, or Puerto Rican specifically.

The other participants also experienced this sort of response from the public, but it was particular to when they spoke Spanish. Through language, one of the most personal forms of communication, we influenced the perception of others about who we were. Anastasia's testimonio is an example of this:

I think that they thought I was biracial. I know that that was the first thing. They were always trying to figure me out and where I was from. Once I came out and said I was Puerto Rican they were oh, I guess that makes sense. I'm not really sure what that means.

Our appearance (our hair specifically) and the social interpretations that it evokes necessitated us using cultural markers of difference like language as a way of acknowledging our Puerto Rican identity, and insisting that we be seen as part of that community.

Because of our position, we are compelled to come out to the world and claim our cultural legacy and affiliation. This may not be a reasonable or desirable option for others who are similarly placed in society. It is also cannot be an expectation for all AfroBoricuas because language ability differs, but should not exclude one from claiming our cultural heritage. Through our coming out, we transform both ourselves and the reality around us. Freire (2000) speaks of praxis as "reflection and action upon the world in order to transform it." (p. 51). Afro-Boricuas, by using language, force an engagement 
with a society trying to define who we are, and in this engagement transform ourselves and society in the process.

\section{Cultural Litmus Tests}

The challenges to, and questions about, our affiliation and/or claims to our Puerto Rican identity have come to be defined by this researcher as cultural litmus tests. Cultural litmus tests are informed by the concept of a litmus test in science. Like the name implies, litmus tests are "used to make a judgment about whether someone or something is acceptable." (Merriam-Webster online, n.d.). Cultural litmus tests are similar to microaggressions, in their intent to denigrate and exclude, but are more directly informed by a cultural outline than a racial one. Across all the participants, we all experienced some form of cultural litmus tests. Others we came in contact with used them to verify and validate our claims to the cultural identity of Latina, and specifically Afro-Boricua. All of us present to the world as women of African or mixed African descent, and have had to endure cultural tests administered by the Latin@ and African American community (and society at large) in order for our claims to our cultural identity to be believed by others. These tests usually involve checks for language proficiency, birthplace, dancing ability, cooking ability, and parentage. It is a nearly daily occurrence that our claims of affiliation with the Puerto Rican community are challenged. Sometimes the challenges are overt, with comments like "no you're not", or "are you 'full' Puerto Rican?" Sometimes they are subtle...a facial twitch or raised eyebrow, a quizzical look as you speak Spanish unaccented, or gawks when you dance salsa. These can be considered microaggressions as Solórzano (1998) have posited in his research. These can also be seen as ways Afro-Boricuas continue to confront challenges to our attempts to live full 
authentic lives. These microaggressions not only come from the larger society, but from the Latin@, Puerto Rican, and African American community as well. This then compels me to ask ¿Donde pertenecemos? Where do we belong?

\section{Declaiming Voice}

Drawing on the experiences shared by Marta and comparing them to those written about in Steele's book Whistling Vivaldi, it is clear that Afro-Boricuas are more than what has been said or written about them. We enter spaces and declare ourselves there; we speak up for ourselves and others; we expand the space we are in so that it is more inclusive, and accommodate diversity. We require such shifts in space and place in order to exist, in order to manifest ourselves, in order to be agents of change, and for others to finally hear us. Freire (2002) speaks to this notion of transformation by saying that "the solution is not to 'integrate' them into the structure of oppression, but to transform that structure so that they can become 'beings for themselves'. (Freire, 2002, 74)

We as Afro-Boricuas have to manage what Steele (2010) calls identity contingencies. These are "the things you have to deal with in a situation because you have a given social identity..." (p. 3). Afro-Boricuas must acknowledge that the Puerto Rican community places contingencies on who is seen as Boricua and who falls outside of that consideration. We are also aware that the racial matrix that exists stateside also places contingencies on who is allowed to claim a Black or Latin@ identity. AfroBoricuas often fall outside of these boundaries because we are not one or the other, but both. In the Puerto Rican community, racial discourse in subsumed within the fervor of expressing a national identity. The archetype of el jibaro excludes Blackness. AfroBoricuas often reflect aspects of the colonial past that many would like to forget: "los 
negros $y$ los perros" [the blacks and the dogs]. Fortunately, it is also part of being Puerto Rican to not be silent; therefore we use our voice to speak back to the world somos Boricuas!

\section{Implications}

This research project was an attempt to understand the lived experiences of AfroBoricuas like myself. It was an attempt to reach out to others who identified like me to see if there was some commonality to our realities. This research project forces us to think beyond stereotypes. It forces society to take off the glasses that imposes a binary perspective of what is meant by "White" and what is meant by "Black". It forces us to move into a cognitive space where reality is shifted in order to accommodate the liminal space in which the Afro-Boricua occupies with our body and mind. It forces both the Puerto Rican community and society at large to acknowledge that racism is "normal, not aberrant, in American society" (Delgado, 1995, p. xiv). The Puerto Rican community has inherited a legacy of white supremacy from the United States the moment it became a commonwealth in 1898 . This legacy has influenced the social order of the island so that the outcomes of colorism on the Island mirror the outcomes of race discrimination stateside. Solorzano \& Yosso (2009) challenge us to not "rely on stock stereotypes that covertly and overtly link people of color, women of color, and poverty with "bad" while emphasizing the White, middle- and upper-class people embody all that is 'good"' (p. 136).

In their study on skin color and self-perception, Telzer \& Garcia (2009) found that "the association between skin color and self-perception depend, in part, on both the message youth receive from their parents to overcome racial barriers and how connected 
participants feel with their ethnic group." (p. 370). They discovered that familial emphasis on "equality for all" and engaging in discussions and activities to prepare them to "overcome discrimination" had a buffering effect from "all the negative associations of dark skin" (p. 370). From the conversations and testimonios, the women in this research project felt the sting of racism and discrimination inside and outside the classroom. It may very well be the case that their experiences could have been much worse if their families did not play such a central and mostly positive role in their lives.

This research project strove to recenter the experiences of Afro-Boricuas so that our stories take others to our world. Our world is a place where the norm is a blended reality that allows for shifts in identity and affiliation, linguistic ability, and hair style. A world where there is no standard of cultural beauty based on archetypes that exclude us, but a deeply held commitment to the cultural heritage of Puerto Rico that lives within the hearts and minds of all Puerto Ricans regardless of where they live on the planet. This project has the capacity to engage the Puerto Rican community in a dialogue with itself on how colonialism is still alive and well and having a negative impact on all of its members, some more than others. It has the potential to revisit the notion of the "onedrop" rule and how it has been turned on its head by the Latin@ community so that a drop of European blood actually provides an avenue with which to claim white privilege.

Regarding the impact it may have to post-secondary education, this research project provides both a source for solutions and further questions regarding diversity on campus. As issues of diversity become part of almost daily conversations had by all constituencies on college campuses, it is important to understand that complexity must be seen as normal. All students must be seen as full and complex beings in order to feel like 
they belong. There is a science to belonging that speaks about the position of the "outgroup" as one where "we use our mental energies to monitor for threats, leaving fewer resources for higher cognitive processes." (Laldin, 2016). Post-secondary educational institutions need to make more of an effort to ensure that there are no students who feel they are part of the "out-group". Afro-Boricuas insist on being seen, but are often ignored or assigned a contingent identity in order to accommodate a particular narrative. We can be seen as bridges to two communities of students who often struggle to find common ground. That said, we also insist on being seen as having a unique identity that is informed by history, migration, and location; a history that goes beyond the black-white racial binary that is such a part of the diversity conversation. Our stories provide a glimpse into the realities of other students who are there because of history, migration, immigration (forced or voluntary), and location: Asian Latin@s, Afro-Asians, ArabLatin@, just to name a few. Given the location of the Dutch consulate on the big island of Puerto Rico, the experiences of Dutch Puerto Ricans (or Nedericans as I call them) would be worth exploring as well as a reflection of the impact that an existing colonial presence has on the whole of the Caribbean. Latinas of African descent insist that our claim of membership to both a diaspora and a cultural community be honored in order for us to feel like we belong anywhere, both on and off the campuses of this nation's postsecondary educational institutions. Our claim must be acknowledged in order for the mission of any university to truly come to fruition.

Another implication of this study is that it informs the development of Ethnic Studies curricula in the K-12. As I wrote in my blog just recently: 
"Our children also need to understand where they came from, and how they contribute to this social experiment that is the United States of America. Their existence is the result of cultures, nationalities, races, and religions coming together in the most intimate way possible. They are the hope that our future will be brighter than our past. With that hope comes responsibility to do what they can to move society forward.

"In order to live up to this responsibility, they need to be informed, educated, and ultimately motivated to act for the good of all. This can best be addressed in the classroom, and it should involve more than learning about heroes and holidays. Should be about learning the history of all the people of this land, the contributions they made, and the hurt some of them caused to others in the quest for "progress". Yes, this includes learning about the less glorious events of our past such as the attempt to eliminate Native Americans, the forced enslavement over 11 million people from Africa, the sordid history of lynchings of Mexicans (not just African Americans), and the use of Chinese immigrants as near-slave labor to build our railroads... all in the name of progress. These are just a few examples." (Personal website: marienubiafeliciano.com, 4 August 2016). Our students must be prepared during the compulsory years of their educational experience with the language to speak about the issues impacting our society. They must learn to interrogate their world in order to become the critical thinkers that know how to, as Freire notes "read the world in which words exist" (Freire, 2002). Doing so truly constitutes being career and college ready. 


\section{For Further Study}

Afro-Latinas live a racialized experience within the Latin@ community. Further study would help explore the lives of others women of African descent who are from other areas of the Spanish speaking diaspora. It has been posited that the racialization of Latin@s is just an U.S. phenomenon. Unfortunately, when one looks at the economic and social outcomes of other Latin@s of African descent, regardless of where they are in the Americas, the outcomes are the same. They are relegated to the lower socioeconomic levels of the society. It is important to explore the social, economic, political, and psychological impact that intersectionality has on the lives of other Afro-Latinas. This analysis can extend beyond women to include men who live in the liminal spaces of race and ethnicity.

The concept of Combing Out / Coming Out reminds us that the LGBT community is also part of the Afro-Latinx community and their stories that document the even more complex intersectionality of their reality is vitally important. We also must include those in the disability community as they are often also marked by difference depending on their level of impairment (visible and invisible). Also ignoring their claims of cultural affiliation only adds to the cultural litmus tests they must endure just be recognized by their community. Exploring how limited Spanish language proficiency, often used as a cultural litmus test to exclude, complicates things for the Afro-Boricua would also be an interesting area of research. Since language carries with it the history of a people, it would be of vital importance to document how lacking language proficiency impacts the affiliation process of Afro-Boricuas. It is often included in the cultural litmus tests that Afro-Boricuas have to endure, therefore exploring it as an often closed doorway into the 
Latin@ community would help understand how this population of Latin@s come to own their cultural identity. In the end, the more stories we share with the world about our realities, the fuller a picture comes into full relief of the lives of Afro-Latin@s. In so doing we impact the institutions in which we live: school, employment, marriage, etc.

The media places a crucial role in how the world makes meaning of the images we see. It helps define what is beautiful and who belongs in what context. Connecting the experiences of Afro-Boricuas to this narrative allows us to explore the reasons why we are always required to justify our claims of cultural belonging. This is not the same experience for all women, especially those who do not appear how cultural groups have determined their members should look like. Countless testimonios, both in this research project and in blogs and magazine article from other Afro-Latina women, attest to the countless times that Afro-Latinas are questioned about their language ability, cultural affiliation, and familiarity with Latino cultural. In the beginning of my paper, I recount the story of Jakyla who was not seen as Dominican enough to win the Miss Young Latina competition. She is Dominican, but the Dominican community did not want to see her as their own.

Both online and in hardcopy print publications, the Afro-Boricua is either nonexistent, or has created a niche existence where others like us come together to share stories and reclaim our identities as Afro-Boricuas. In magazines like Latina, features about the readership are beginning to include Afro-Latinas. In the October 2013 issue of Latina magazine, Dominican-American Eileen Fuentes was featured with photos of her family prominently displayed on the pages. In the same issue, Pauline Campos in her advice column named "Dimelo", responded to a letter from an African American and 
Puerto Rican reader asking about how to fully embrace her mixed heritage because she does not "look the part of the typical mixed girl" (p. 42). Campos responded by telling her to tell those asking her of her heritage that "l'm human, what about you?" This response dismisses the fact that Afro-Boricuas cannot get away from the racialized undertones of such question as "what are you", or "why are celebrating a quince" [quince is short of quinceñera, a celebration of a young woman's 15th birthday]. Ms. Campos misses the underlying issue that the reader is living in a world where she is not allowed to be an Afro-Boricua, and experiences questions about her cultural and racial identity on a daily basis.

This research project does not settle the notion of race in the Puerto Rican community. It presents an argument for a more complex understanding of this social construction. It reinforces the idea that the Latin@ community is not and cannot be seen as a racial group. This is despite the February 162016 appeals court decision in favor of Christopher Barrella in a race discrimination case against the town of Freeport, Long Island for "being passed over for the position of chief of police", losing the position to Miguel Burmudez, a "white Hispanic man". (Iafolla, February 16, 2016, Yahoo! News). The town of Freeport argued that there was no race discrimination because "Hispanic is not a distinct race". In Freeport v. Barrella, the three-court panel noting that "Hispanic has long been considered a separate race in civil rights cases." Despite this recent legal decision, the "Hispanic" or Latin@ community in general, and the Puerto Rican community specifically cannot be perceived as a monolithic group. Within it lie a diversity informed by the intersections of history and positionality. Diminishing in 
importance these elements of who we are as a people only works to reinforce the very stereotypes we are working to dismantle.

\section{My Responsibility as a Researcher}

In doing this research project, I took on the responsibility of providing a safe space in which Afro-Boricuas could share our truth. It was a responsibility that I did not take lightly and worked tirelessly to ensure the integrity of the process. I worked closely with the participants to highlight the "relationship between knowledge construction, naming and power" (Taylor, 2009, p. 4; cited in Taylor, Gillborn \& Ladson-Billings, 2009). I worked to promote the idea that positionality "is a perspective that must be disclosed" and that telling our stories "refutes notions of merit and colorblindness" (Taylor, 2009, p. 4; cited in Taylor, Gillborn \& Ladson-Billings, 2009). This "use of voice" informed my conceptualization of Declaiming Voice, and is how using Critical Race Theory "links form and substance in scholarship" (Ladson-Billings, 2009, p. 23; cited in Taylor, Gillborn \& Ladson-Billings, 2009). It is how my research project became more than a collection of stories. In the end, I hope that my efforts have provided some insight into how Afro-Boricuas experience our world. By extension, I hope that this research project expands the definition of what it means to be Puerto Rican. Finally, I hope I have provided a guide with which to examine other Afro-Latin@s, and by extension others who live at the intersections of many identities. 


\section{REFERENCES}

Allen, Q. (2013). Balancing school and cool: Tactics of resistance and accommodation among black middle-class males. Race, Ethnicity, and Education, 16(2), 203-224.

Allen, V.C., Lachance, C., Rios-Ellis, B., Kaphingst, K.A. (2011). Issues in the assessment of 'race' among Latinos: Implications for research and policy. Hispanic Joturnal of Behavioral Sciences, 33(4), 411-424.

Altschul, I., Oyserman, D., Bybee, D. (2008). Racial-ethnic self-schemas and segmented assimilation: Identity and the academic achievement of Hispanic youth. Social Psychology Quarterly, 71(3), 302-320.

Amaro, H., Zambrana, R.E. (2000). Criollo, mestizo, mulato, latinegra, indigena, white or black? The US Hispanic/Latino population and multiple responses in the 2000 census. American Journal of Public Health, 90(11), 1724-1727.

Anzaldúa, G. (1987) Borderlands/La frontera: The new mestiza. San Francisco, CA: Spinsters/Aunt Lute press.

Anzaldúa, G. (1990). Making faces, making soul: Haciendo caras: Creative and critical perspectives by feminists of color. San Francisco, CA: Aunt Lute Books

Anzaldúa, G., Keating, A. (2002). This bridge we call home: Radical visions for transformation. New York, NY: Routledge.

Astin, A.W. (1993). What matters in college?: Four critical years revisited. Liberal Education, 79(4), 4-15.

Bailey, B. (2001). Dominican-American ethnic/racial identities and the United States social categories. International Migration Review, 35(3), 677-708. 
Bailey, C.A. (2007). A guide to qualitative field research, $2^{\text {nd }}$ ed. Thousand Oaks, CA Pine Forge Press.

Banks, Cerri (2009). Black women undergraduates, cultural capital, and college success. NY: Peter Lang Publishing, Inc.

Bateson, G. (1972) Steps to an ecology of mind: A revolutionary approach to man's understanding of himself. Chicago: University of Chicago Press.

Bell, D.A. (1995). Who's Afraid of Critical Race Theory? University of Illinois Law Review 893-910.

Bernal, D.D. (1998). Using a Chicana feminist epistemology in educational research. Harvard Educational Review, 68(4).

Beverley, J. (1991). "Through all things modern": Second thoughts on testimonios. boundaries 2, 18(2), 1-21.

Beverly, J. (2004). Testimonio: On the politics of truth. Minneapolis: MN: University of Minnesota Press.

Blum, D. (1998). Face it! Psychology Today. Retrieved from http://www.psychologytoday.com/articles/200909/face-it

Bourdieu, P., Passeron, J.-C. (2000) Reproduction in education, society and culture. 2. Ed. CA: Sage Publications. As cited in I. Goodson (2007). Curriculum, narrative and the social future. Journal of Education: Review of Brasilian Education, 12(5).

Brisoso, G. (2014). Kinky hair and the pursuit of Latin-ness. Ebony. Retrieved from http://www.ebony.com/news-views/kinky-hair-and-the-pursuit-of-latin-ness978\#axzz3guZth3IM 
Cahill, D. (1994). Colour by numbers: Racial and ethnic categories in the Viceroyalty of Peru, 1532-1824. Journal of Latin American Studies, 26(2), 325-346.

Carter, P. (2006). Straddling boundaries: Identity, culture, and school. Sociology of Education, 79, 304-328.

Cole, A.L., Knowles, J.G. (2001). Lives in context: The art of life history research. NY: AltaMira Press.

Collins, P.H. (1986). Learning from the outsider within: The sociological significance of Black Feminist thought. Social Problems, 33(6), S14-S32.

Comas-Diaz, L. (1994). LatiNegra: Mental health issues of African Latinas. Journal of Feminist Family Therapy, 5(3/4)

Connelly, F.M., Clandinin, D.J. (1990). Stories of experience and narrative inquiry. Educational Researcher, 19(5), 2-14.

Cruz, C. (2001). Toward an epistemology of a brown body. Qualitative Studies in Education, 14(5), 657-669.

Cruz-Janzen, M.I. (2000). Y tu abuela a'onde esta?. Sage Race Relations Series.

Cruz-Janzen, M.I. (2001). LatiNegras: Desired women - undesirable mothers, daughters, sisters, wives. Frontiers, $12(3), 168-183$

Darity, W., Hamilton, D., Dietrich, J. (2002). Passing on blackness: Latinos, race and earnings in the USA. Applied Economics Letters, 9, 847-853.

Darity, W.A. Dietrich, J., Hamilton, D. (2005). Bleach in the rainbow: Latin ethnicity and the preference for whiteness. Transforming Anthropology, 13(2), 103-109.

Darity, W.A., Goldsmith, A.H., Hamilton, D. (2007). From dark to light: Skin color and wages among African-Americas. Journal of Human Resources, 42(4), 701-738. 
Darity, W.A., Dietrich, J., Hamilton, D. (2010). Bleach in the rainbow: Latino ethnicity and preference for whiteness. In M.J. Roman and J. Flores (Eds.). (2010). The Afro-Latino reader: History and culture in the United States. Durham, NC: Duke University Press. (485-498).

Davis, F.J. (1991). The one-drop rule defined. In Who is black? One nation's definition. PA: Pennsylvania State University Press.

Dear While People, directed by Justin Simien (2014; Co-produced by Code Red, Duly Noted, Homegrown Pictures), DVD.

Deegan, M.J., Hill, M.R. (1991). Doctoral dissertations as liminal journeys of the self: Betwixt and between in graduate sociology programs. Teaching Sociology, 19(3). 322-332.

DeGruy, J.A. (2009). Post tralmatic slave syndrome: America's legacy of enduring injury and healing. Portland, OR: Uptone Press.

Delgado, R. Stefancic, J. (1993). Critical race theory: An annotated bibliography. Virginia Law Review, 79(2), 461-516.

Delgado, R. (Ed.) (1995). Critical race theory: The cutting edge. Philadelphia, PA: Temple University Press.

Delgado, R., Stefancic, J. (2012). Critical race theory: An introduction. New York: New York University Press.

Dillard, C.B. (2000). The substance of things hoped for, the evidence of things not seen: Examining an endarkened feminist epistemology in educational research and leadership. Qualitative Studies in Education, 13(6), 661-681. 
Duany, J. (1998). Reconstructing racial identity: Ethnicity, color and class among Dominicans in the United States and Puerto Rico. Latin American Perspectives, 25(3), 147-172.

Duany, J. (2002). The Puerto Rican nation on the move: Identities on the island and in the United States. Chapel Hill, NC: The University of North Carolina Press.

Dubois, W.E.B. (1994/1903). The souls of black folks. Chicago, IL: Dover Press.

El Boricua: Un poquito de todo... (n.d.) What is a jibaro? Retrieved from http://www.elboricua.com/jibaro.html

Elenes, C.A. (2001). Transformando fronteras: Chicana feminist transformative pedagogies. Qualitative Studies in Education, 14(5), 689-703.

Erving Goffman. (n.d.) In The Sociology Hub. Retrieved from http://sociology.wetpaint.com/page/Erving+Goffman

Feliciano, C., Lee, R., Robnett, B. (2011). Racial boundaries among Latinos: Evidence from internet daters' racial preferences. Social Problems, 58(2), 189-212

Flores, J., Jiménez Román, M. (2009). Triple-consciousness? Approaches to Afro-Latino culture in the United States. Latin American and Caribbean Ethnic Studies, 4(3), 319-328.

Fordham, S. (1988). Racelessness as a factor in Black students' school success: Pragmatic strategy or Pyrrhic victory? Harvard Educational Review, 58(1), 54-84.

Fordham, S. (1993). "Those loud black girls": (Black) women, silence, and the gender "passing" in the academy. Anthropology and Education Quarterly, 24(1), 3-32.

Freire, P. (2002). Pedagogy of the oppressed. New York, NY: Continuum Books. 
Gándara, P., Contreras, F. (2009). The Latino education crisis: The consequences of failed social policies. Cambridge, MA: Harvard University Press.

Garcia, A. (2008). Situating race, navigating belongings: Mapping Afro-Cuban identities in the United States. Latino(a) Research Review, 7(1/2), 59-90.

Geertz, C. (1975). Common sense as a cultural system. The Antioch Review, 33(1), 5-26. Goffman, E. (1959). The presentation of self in everyday life. New York: Anchor Books.

Golnaz-Boza, T., Darity, W. (2008). Latino racial choices: The effects of skin colour and discrimination of Latinos' and Latinas' racial self-identifications. Ethnic and Racial Studies, 31, 89-934. As cited in Stokes-Brown, A.K. (2012). America's shifting color line? Reexamining determinants of Latino racial self-identification. Social Science Quarterly, 93(2), 309-332

Gonzalez, R.G. (2013). Same and different: Latino college students' perceptions of themselves and others on campus. Journal of Hispanic Higher Education, 12(1), 3-22.

Goodson, I. (n.d.) Key idea: Narrative capital. Retrieved 8/19/2013: http://www.ivorgoodson.com/narrative_capital

Goodson, I. (2006). The rise of the life narrative. Teacher Education Quarterly, 33(4), 721.

Goodson, I. (2007). Curriculum, narrative and the social future. Journal of Education: Review of Brasilian Education, 12(5).

Graff, C.S., McCain, T., Gomez-Vilchis, V. (2013). Latina resilience in higher education: Contributing factors including seasonal farmworker experiences. Journal of Hispanic Higher Education, 12(4), 334-344. 
Hannifan, L. J. (1916). The rural school community center. In A. L. Suhrie (Ed.), New possibilities in education. Philadelphia, PA: The American Academy of Political and Social Science. As cited in M. Kikuch and C-L. Coleman. (2012). Explicating and measuring social relationships in social capital research. Communication Theory, 22, 187-203.

Harris, M.L. (2007). Womanist humanist. Crosscurrent, 391-403.

Harris, P. (2003). Gatekeeping and remaking: The politics of respectability in African American women's history and black feminism. (Book Review). Project Muse, $15(1), 212-220$.

Harrison, J., MacGibbon, L., Morton, M. (2001). Regimes of trustworthiness in qualitative research: The rigors of reciprocity. Qualitalive Inquiry, 7(3), 323-345.

Hispanic Americans by the Numbers. (n.d.). Infoplease.com: A Pearson Education Online Publication. Retrieved from http://www.infoplease.com/spot/hhmcensus 1.html

Hogg, L. (2011). Funds of knowledge: An investigation of coherence within the literature. Teaching and Teacher Education, 27, 666-677.

Hollinger, D.A. (2007). Amalgamation and hypodescent: The question of ethnoracial mixture in the history of the United States. The American Historical Review, $108(5), 1-24$

Holloway, J. (2010). Crack capitalism. New York, NY: Pluto Press.

Hubbard, L.N. (2012). Frances Ellen Watkins Harper: A proto-African Womanist. The Western Journal of Black Studies, 36(1), 68-75. 
Hughes, D. (2003). Correlates of African American and Latino Parents' messages to children about ethnicity and race: A comparative study of racial socialization. American Journal of Community Psychology, 3I(1/2), 15-33.

Hungerford-Kresser, H., Vetter, A. (2012). Positioning and the discourse of urban education: A Latino student's university experience. Urban Review, 44, 219-238.

Hurtado, A. (2003). Theory in the flesh: Toward an endarkened epistemology. Qualitative Studies in Education, 16(2), 215-225.

Iafolla, R. (16 February 2016). 'Hispanic' is a race under U.S. anti-bias laws, court rules. Yahoo! News. Retrieved from https://www.yahoo.com/news/hispanic-raceunder-u-anti-bias-laws-court-221334178.html?ref $=$ gs

Incognito. Merriam-Webster Online. (n.d.). Retrieved from http://www.merriamwebster.com/dictionary/incognito.

Inside the Academy. Sonia Nieto. Retrieved from http://insidetheacademy.asu.edu/sonianieto.

Instituto Nacional de Estadística y Geografia (2015). Retrieved from http://www.inegi.org.mx/saladeprensa/boletines/2015/especiales/especiales2015_ 12_3.pdf.

Isasi-Díaz, A.M. (2010). Justice as reconciliatory praxis: A decolonial mujerista move. International Journal of Public Theology, 4, 37-50.

Isensee, L. (2016, May 30). More Latino students enroll at historically Black colleges and universities. Retrieved from http://www.houstonpublicmedia.org/articles/news/2016/05/30/154512/morelatino-students-enroll-at-historically-black-colleges-and-universities/ 
Jennings, J. (2010). Afro-Latinism in United States society. In M.J. Roman and J. Flores (Eds.). (2010). The Afro-Latino reader: History and culture in the United States. Durham, NC: Duke University Press. (p. 540-546)

Jiménez Román, M., Flores, J. (2010). The Afro-Latin@ reader: History and culture in the United States. North Caroline: Duke University Press.

John-Steiner, V.J., Mahn, H. (1996). Sociocultural approaches to learning and development: A Vygotskian framework. Educational Psychologist, 31, 3-4, 191206.

Johnson, M., Pleece, W. (2008). Incognegro: A graphic mystery. NY: DC Comics, Vertigo Press.

Julia, M. (2000). Constructing gender: Multicultural perspectives in women with women. Belmont, CA: Brooks/Cole Thomas Learning. As cited in Zamani, E.M. (2003). African American women in higher education. New Directions for Student Services, 104, 5-18.

Jung, C. (1917). Two essays on analytical psychology. In Vol 7 of the Collected Works of C.G. Jung. Princeton, NJ: Princeton University Press, 1953 \& 1956.

Keating, A. (2006). From borderlands and new mestizas to nepantlas and nepantleras: Anzaldúan theories for social change. Journal of the Sociology of Self Knowledge, IV, 5-16.

Keating, A. (Ed.) (2009). The Gloria Anzaldua reader. Durham, NC: Duke University Press. 
King, J. (1995). Culture-centered knowledge: Black studies, curriculum transformation, and social action. In J. Banks, \& C.M. Banks (Eds.), Handbook of research on multicultural education (pp. 265-290). New York, NY: Macmillan Press.

Krull, K., Dominguez, A. (2015). Women who broke the rules: Sonia Sotomayor. New York, NY: Bloomsbury USA Childrens.

Kumashiro, K.K. (2004). Against common sense: Teaching and learning toward social justice. New York, NY: Routledge Falmer Press. As cited in Mintz, A.I (2010). Common beliefs and common sense in educational policy and practice. Philosophy of Education, 1-3.

Ladson-Billings, G. (2009). Just what is critical race theory and what's it doing in a nice field like education? In E. Taylor, D. Gillborn \& G. Ladson-Billings (Eds.) Foundations of critical race theory in education. New York, NY: Routledge Press. 18-36.

Laldin, M. (11 February 2016). The psychology of belonging (and why it matters). Learning and the Brain: Connecting Educators to Neuroscience. Retrieved from http://www.learningandthebrain.com/blog/psychology-of-belonging/

Liminal. (n.d.) In Merriam-Webster online. Retrieved from http://www.merriamwebster.com/dictionary/liminal.

Litmus test. (n.d.) In Merriam-Webster online. Retrieved from http://www.merriamwebster.com/dictionary/litmus\%20test.

Llorens, H. (2005). Fugitive blackness: Representations of race, art, and memory in Arroyo, Puerto Rico. Retrieved from ProQuest Digital Dissertations. (AAI3180227) 
Logan, J.R. (2000). How race counts for Hispanic Americans. Retrieved on 8/27/2013 from http://mumford1.dyndns.org/cen2000/BlackLatinoReport/BlackLatino01.htm

Logan, J.R. (2000). How race counts for Hispanic Americans. As cited in Stokes-Brown, A.K. (2012). America's shifting color line? Reexamining determinants of Latino racial self-identification. Social Science Quarterly, 93(2), 309-332. Retrieved on $8 / 27 / 2013$ from http://mumford1.dyndns.org/cen2000/BlackLatinoReport/BlackLatino01.htm.

Lopez, I. (2008). Puerto Rican phenotype: Understanding its historical underpinnings and psychological associations. Hispanic Journal of Behavioral Science, 30(2), 161180.

Lynn, M., Dixson, A.D. (Eds.) (2013). Handbook of critical race theory in education. New York: Routledge Press.

Lyon, G.E. (1999). Where I'm from, where poems come from. New York: Absey \& Co MacDonald, V.-M., Botti, J.M., Clark, L.H. (2007). From visibility to autonomy: Latinos and higher education in the U.S., 1965-2005. Harvard Educational Review, 77(4), 474-504.

Martinez, M.E. (2008). Genealogical fictions: Limpieza de sangre, religion, and gender in colonial Mexico. CA: Stanford University Press.

Martinez, M., Fernandez, E. (2004). Latinos at community colleges. New Directions for Student Services, 105, 51-62. 
McAdams, D.P. (2008). Personal narratives and the life story. In O.P. John, R.W. Robins and L.A. Pervin (Eds.), Handbook of personality: Theory and research, $3^{\text {rd }}$ Ed. NY: Guilford Press, 242-264.

McCoy, D.L., Rodricks, D.J. (2015). Critical race theory in higher education: 20 years of theoretical and research innovation. ASHE Higher Education Report, 4I(3), 1117.

McCracken, E. (1999). New Latina narrative: The feminine space of postmodern ethnicity. Tucson, AZ: The University of Arizona Press.

Mehan, H., Hubbard, L., Villanueva, I. (1994). Forming academic identities: Accommodation without assimilation among involuntary minorities. Anthropology and Education Quarter, 25(2), 91-117.

Merriam, S. \& Associates (2002). Qualitative research in practice: Examples for discussion and analysis. San Francisco, CA: Jossey-Bass.

Meyer, M.A. (2013), Holographic epistemology: Native common sense. China Media Research, 9(2), 94-101.

Miller, D.B., Maclntosh, R. (1999). Promoting resilience in urban African American adolescents: Racial socialization and identity as protective factors. Social Work Research, 23(3), 159-169.

Mintz, A.I (2010). Common beliefs and common sense in educational policy and practice. Philosophy of Education, 1-3.

Mirabal, N.R. (2002). Scripting race, finding place: African Americans, Afro-Cubans, and the diasporic imaginary in the United States. In A. Dzidziendyo and S. 
Oberloer (Eds.), Neither enemies nor friends: Latinos, black, afro-Latinos (189207). New York, NY: Palgrave MacMillan.

Mirara, T.D., Mitra, P. (2013). Colorism: Ubiquitous yet understudied. Industrial and Organizational Psychology: Perspectives on Science and Practice, 6(1), 103-107.

Modestin, Y. (2010). An Afro-Latina's quest for inclusion. In M.J. Roman and J. Flores (Eds.). (2010). The Afro-Latino reader: History and culture in the United States. Durham, NC: Duke University Press. (417-421).

Moen, T. (2006). Reflections on the narrative research approach. International Journal of Qualitative Methods, 5(4), 1-11.

Moll, L.C., Amanti, C., Neff, D. Gonzalez, N. (1992). Funds of knowledge for teaching: Using a qualitative approach to connect homes and classrooms. Theory into Practice, 31(2), 132-141.

Monzo, L. (2009). Fostering Academic Identities Among Latino Immigrant Students: Contextualizing Parents' Roles. In M.L. Dantas \& P. Manyak (Eds.), HomeSchool Connections in a Multicultural Society: Learning from and with Culturally and Linguistically Diverse Families.

Where black is brown: The African diaspora in Mexico. Museum of African American Art. Baldwin Hills Crenshaw Plaza, Macy's Third floor, 4005 Crenshaw Boulevard, Los Angeles, CA 90008. June 5-September 18, 2016. Retrieved from http://www.maaala.org/exhibits.html

Nasir, N.S., Saxe, G.B. (2003). Ethnic and academic identities: A cultural practice perspective and emerging tensions and their management in the lives of minority students. Educational Researcher, 32, 14-18. 
National Center for Education Statistics (2010). Enrollment rates of 18- to 24-year-olds in degree-granting institutions, by level of institution and sex and race/ethnicity of student: 1967 through 2010. Retrieved from http://nces.ed.gov/programs/digest/d11/tables/dt11 213.asp

National Center for Education Statistics (2010). Status and Trends in the Education of Racial and Ethnic Groups. http://nces.ed.gov/pubs2010/2010015.pdf. Retrieved $8 / 29 / 2013$

Native Heritage Project (15 June 2013). Las Castas - Spanish Racial Classifications. Retrieved from http://nativeheritageproject.com/2013/06/15/las-castas-spanishracial-classifications/

Nieto, S. (1998). Fact and fiction: Stories of Puerto Ricans in U.S. schools. Harvard Educational Review, 68 (2), Summer. Retrieved from http://hepgjournals.org.libproxy.chapman.edu/doi/pdf/10.17763/haer.68.2.d54668 $22 \mathrm{~h} 645 \mathrm{t} 087$.

Nubia-Feliciano, M. (4 August 2016). The Case for Ethnic Studies. Personal website: http://www.marienubiafeliciano.com/blog/2016/8/4/the-case-for-ethnic-studiesin-the-k-12.

Oliver, J. (2015). Last Week Tonight: Puerto Rico. Broadcast on May 8, 2015.

Oyserman, D., Brickman, D., Rhodes, M. (2007) Racial-ethnic identity in adolescences: Content and consequences for African American and Latino and Latina youth. (p. 91-114). In A. Fuligni (ed), Contesting Stereotypes and creating identities: Social categories, identities and educational participation. NY: Russell-Sage. 
Panzar, J. (July 8, 2015). It's official: Latinos now outnumber whites in California. Los Angeles Times. Retrieved from http://www.latimes.com/local/california/la-mecensus-latinos-20150708-story.html

Pew Research Center (n.d.) Statistical portrait of Hispanics in the United States: 19802013. Via http://www.pewhispanic.org/2015/05/12/statistical-portrait-ofhispanics-in-the-united-states-1980-2013/.

Pugo, K. (2013). Little Miss Hispanic Delaware stripped of her crown for not being "Latina enough". NBCLatino.com. Retrieved from http://nbclatino.com/2013/09/26/little-miss-hispanic-delaware-stripped-of-hercrown-for-not-being-latina-enough/

Quiñones Rivera, M. (2006). From trigueñita to Afro-Puerto Rican: Intersections of the racialized, gendered, and sexualized body in Puerto Rico and the U.S. mainland. Meridians: Feminism, Race, Transnationalism, 7(1), 162-183.

Quiñones Rivera, M. (2011). Mediating blackness: Afro Puerto Rican women and popular culture. Retrieved from ProQuest Digital Dissertations. (3483478) Quiros, L., Dawson, B.A. (2013). The color paradigm: The impact of colorism on the racial identity and identification of Latinas. Journal of Human Behavior in the Social Environment, 23(3), 287-297.

Raymondi, M.D. (2005). Latino students explore racial and ethnic identity in a global context. (Doctoral Dissertation). Retrieved from ProQuest. UMI \#3153765

Rendón, L.I. (1994). Validating culturally diverse students: Toward a new model of learning and student development. Innovative Higher Education, 19, 33-51. 
Riessman, C.K. (2008) Narrative methods for the human sciences. Thousand Oaks, CA: Sage Publication.

Rivas-Drake, D. (2011). Ethnic-racial socialization and adjustment among Latino college students: The mediating roles of ethnic centrality, public regard and perceived barriers to opportunity. Jotrnal of Youth Adolescence, 40, 606-619.

Rivera, D.P., Forquer, E.E., \& Rangel, R. (2010). Microaggressions and the life experience of Latina/o Americans. In D.W. Sue (Ed.) Microaggressions and marginality: Manifestation, dynamics and impact (p. 59-83). New York, NY: Wiley Press.

Rivera, E.T. (2005). Espiritismo: The flywheel of the Puerto Rican spiritual traditions. Revista Internamericana de Psicologia/Interamerican Journal of Psychology, $39(2), 295-300$.

Rivera, M.Q. (2006). From Trigueñita to Afro-Puerto Rican: Intersections of the racialized, gendered, and sexualized body in Puerto Rico and the U.S. mainland. Meridians: feminism, race, transnationalism, 7(1), 162-182.

Rosenthal, D.J. (2004). Race mixture in nineteenth-century U.S. and Spanish American fictions: Gender, culture, and nation building. Chapel Hill, NC: The University of North Carolina Press.

Russell, K., Wilson, M. Hall, R. (2013). The color complex: The politics of skin color in a new millennium. New York: Anchor Press.

Saenz, T.A. (2013). Mendez and the legacy of Brown: A Latino civil rights lawyer's assessment. Berkeley Journal of African American Law \& Policy, 6(2), 1-9. 
Salinas, B. (May 16, 2014). Afro-Latinas and "Good Hair". Latino USA. Retrieved from http:/latinousa.org/2014/05/16/afro-latinas-hair/.

Sanchez, G.R. (2008). Latino group consciousness and perceptions of commonality with African Americans. Social Science Quarterly, 89(2), 428-444).

Schwandt, T.A. (2007). The Sage dictionary of qualitative inquiry ( $3^{\text {rd }}$ ed.). Los Angeles, CA: Sage Publications.

Seitz-Wald, A. (2013). Salsa overtakes ketchup 20 years ago. National Journal. Retrieved from http://www.nationaljournal.com/politics/salsa-overtook-ketchup20-years-ago-20131017.

Smith, L.T. (2012). Decolonizing methodologies $2^{\text {nd }}$ ed: Research and indigenous peoples. New York: Zed Books.

Solórzano, D. G. (1998). Critical race theory, race and gender microaggressions, and the experience of Chicana and Chicano scholars. Qualitative Studies in Education, II(1), 121-136. Cited in Hungerford-Kresser, H., Vetter, A. (2012). Positioning and the discourse of urban education: A Latino student's university experience. Urban Review, 44, 219-238.

Solórzano, D.G., Ceja, M., Yosso, T. (2000). Critical race theory, racial microaggressions, and campus racial climate: The experiences of African American college students. The Journal of Negro Education, 69, 1/2, 60-73.

Solórzano, D. G., Yosso, T.J. (2001). Critical race and LatCrit theory and method: Counterstorytelling Chicana and Chicano graduate school experiences. International Journal of Qualitative Studies in Education, 4, 471-495. 
Sokol, J.T. (2009). Identity development through the lifetime: An examination of Eriksonian theory. Graduate Journal of Counseling Psychology, 1(2). 1-14.

Somers, M.R. (1994). The narrative constitution of identity: A relational and network approach. Theory and Society, 23, 605-649.

Steele, C. (2010). Whistling Vivaldi and other clues to how stereotypes affect us. New York: W.W. Norton \& Company.

Stokes-Brown, A.K. (2006). Racial identity and Latino vote choice. American Politics Research, 34(5), 627-652. As cited in Gonzalez, R.G. (2013). Same and different: Latino college students' perceptions of themselves and others on campus. Journal of Hispanic Higher Education, 12(1), 3-22.

Stokes-Brown, A.K. (2012). America's shifting color line? Reexamining determinants of Latino racial self-identification. Social Science Quarterly, 93(2), 309-332

Strauss, A., Corbin, J. (1998). Basics of qualitative research: Grounded theory procedures and techniques. Newbury Park, CA: Sage.

Syed, M., Azmitia, M., Cooper, C.R. (2011) Identity and academic success among underrepresented ethnic minorities: An interdisciplinary review and integration. Journal of Social Issues, 67, 442-468.

Taylor, E. (2009). The foundations of critical race theory in education: An introduction. In E. Taylor, D. Gillborn, \& G. Ladson-Billings (Eds.), Foundations of critical race theory in education (1-13). New York, NY: Routledge.

Taylor, E., Gillborn, D., Ladson-Billings, G. (Eds.). (2009). Foundations of critical race theory in education. New York, NY: Routledge. 
Telzer, E.H., Garcia, H.A. (2009). Skin color and self-perceptions of immigrant and U.S.born Latinas: The moderating role of racial socialization and ethnic identity. Hispanic Journal of Behavioral Sciences, 3I(3), 357-374.

The American Heritage Dictionary of the English Language. (1976). Boston, MA: Houghton Mifflin Company

Torres, V. (2004).The diversity among us: Puerto Ricans, Cuban Americans, Caribbean Americans, and Central and South Americans. New Directions for Student Services, 105, 5-16. As cited in Gonzalez, R.G. (2013). Same and different: Latino college students' perceptions of themselves and others on campus. Journal of Hispanic Higher Education, 12(1), 3-22.

Torres, V. (2004).The diversity among us: Puerto Ricans, Cuban Americans, Caribbean Americans, and Central and South Americans. New Directions for Student Services, 105, 5-16.

Torres-Saillant, S. (2007). Divisible Blackness: Reflections on heterogeneity and racial identity. In M. Jiménez Román \& J. Flores (2010) The Afro-Latin@ reader: History and culture in the United States. (p. 453-466) Durham, NC: Duke University Press, 2010

Trueba, E., Takaki, R., Munoz, V.I., Nieto, S. (1997). Ethnicity and education form: What difference does difference make? Harvard Educational Review, 67(2), 169 187

Turner, V.W. (1969). The ritual process. Chicago, IL: Aldine Publishing Company. Tye, B.B. (2000). Hard truths: Uncovering the deep structure of schooling. New York, NY: Teachers' College Press. 
United States Census Bureau (2012). 2010 Census shows multiple-race population grew faster than single-race population. Retrieved from http://www.census.gov/newsroom/releases/archives/race/cb12-182.html United States Census Bureau. (2010). The Hispanic population: 2010. (PDF) Retrieved from http://www.census.gov/prod/cen2010/briefs/c2010br-04.pdf

United States Census Bureau. (2010). The Two or More Races Population: 2010. (PDF). Retrieved from http://www.census.gov/prod/cen2010/briefs/c2010br-13.pdf United States Commission on Civil Rights. (1980). A Staff Report of the Western Regional Office. (PDF), Retrieved from http://www.law.umaryland.edu/marshall/usccr/documents/cr12p96r3.pdf. Vélez-Ibáñez, C.G. (1988). Networks of exchange among Mexicans in the U.S. and Mexico: Local level mediating responses to national and international transformations. Urban Anthropology and Studies of Cultural Systems and World Economic Development, 17(1), 27-51.

Villenas, S.A. (2007). Diaspora and the anthropology of Latino education: Challenges, affinities and intersections. Anthropology and Education Quarterly, 38(4), 419425.

White, E.F. (2001). Dark continent of our bodies: Black feminism and the politics of respectability. Philadelphia, PA: Temple University Press.

Williams, C.B., Wiggins, M.I. (2010). Womanist spirituality as a response to the racismsexism double bind in African American women. American Counseling Association, 54, 175-186. 
Wise, T. (n.d.). Hear no evil: The amazing obluseness and ignorance of campus conservatives. Retrieved 8/20/2013: http://www.timwise.org/2013/02/hearing-noevil-the-amazing-obtuseness-and-ignorance-of-campus-conservatives/

Wolf, E. (1966). Peasants. Engelwood Cliff, NJ: Prentice-Hall; As cited in Hogg, L. (2011). Funds of knowledge: An investigation of coherence within the literature. Teaching and Teacher Education, 27, 666-677.

Wright, B.L. (2009). Racial-ethnic identity, academic achievement, and African American males: A review of the literature. Journal of Negro Education, 78(2), $123-134$.

Zamani, E.M. (2003). African American women in higher education. New Directions for Student Services, 104, 5-18.

Zamudio, M.M., Russell, C., Rios, F.A., Bridgeman, J.L. (2011). Critical race theory matters: Education and ideology. New York, NY: Routledge Press.3

Zinn, H. (2003). A people's history of the United States: 1492-present. New York: Harper Collins 


\section{APPENDICES}

Appendix 1: List of Terms

Appendix 2: Participants Chart

Appendix 3: Map Images

Appendix 4: Common Core History Standards Books for Grades 3-5

Appendix 5: Sonia Sotomayor

Appendix 6: Poem - ¿Y tu agüela, aonde ejtá? [And Yo Granma, Where She At?] 
Appendix 1: List of Terms

1. Afro-Boricua: This project was limited to Afro-Boricua women only. As a result, the gender neutral nature of Afro-Boricua will be changed and used in this research project to refer to women only. Even the term Afro-Boricua is an adjustment to the racialized ideology that exists in the United States. Many Puerto Ricans, both on and off the island, do not have a racial identity. The strong sense of nationalism supersedes the necessity to have a racial identity.

2. Angry Black Latina: This unique experience involves dealing with conflicting or overlapping stereotypes that exist in our location at the intersections of Latin@ness and Blackness. The stereotypical Latina behaviors (i.e., hot-blooded), if performed by the Afro-Boricua, were interpreted as stereotypical Black woman traits (i.e., hotheaded). This leaves us in a sort of cultural double bind where we face two conflicting and negative messages about our conduct.

3. Cultural Litmus Test: are informed by the concept of a litmus test in science. Like the name implies, litmus tests are "used to make a judgment about whether someone or something is acceptable." (Merriam-Webster online, n.d.). Cultural litmus tests are similar to microaggressions, in their intent to denigrate and exclude, but are more directly informed by a cultural outline than a racial one. Examples include requests for demonstrations of language proficiency, dancing ability, food preferences, and questioning of historical knowledge of my home country. These were attempts to see if I was "acceptable" to the Latin@ students on the campus.

4. Incognegro: a similar concept to "passing" in the African American community, was a term first written about by Matt Johnson (2008) in his graphic novel, Incognegro. In much the same way the Latinoness of the Afro-Boricuas was camouflaged by our 
Blackness. The participants used the term "incognegro" to refer to a different sort of passing; a passing that uniquely captures the everyday reality of the Afro-Boricuas in this research project. For instance, "incognegro" was not used to denote passing into the White community, but a shifting and blurring of the perceived reality of what it meant to be Black and Puerto Rican. Another way that "incognegro" differed from passing in this research project was that the women were coming into and out of the Black community, not the White community. With this alternative understanding of passing, by adopting the term "incognegro", the women were redefining the notions of desired directional affiliation.

5. Litmus Test: "used to make a judgment about whether someone or something is acceptable." (Merriam-Webster online, n.d.) 
Appendix 2: Participant Chart

\begin{tabular}{|c|c|c|c|c|c|}
\hline & Taina & Anastasia & Marta & Erica & Marie \\
\hline $\begin{array}{l}\text { Demographic } \\
\text { Information }\end{array}$ & $\begin{array}{l}\text { In her 30s; } \\
\text { Graduated } \\
\text { with her Ed.D. } \\
(2014) ; \text { Bom } \\
\text { in Hawaii of } \\
\text { Puerto Rican } \\
\text { and African } \\
\text { American } \\
\text { parents; } \\
\text { Attended } \\
\text { public colleges } \\
\text { for B.A. \& } \\
\text { Ed.D., private } \\
\text { college for } \\
\text { M.A.; Works } \\
\text { as an } \\
\text { administrator } \\
\text { at a CSU in } \\
\text { California }\end{array}$ & $\begin{array}{l}\text { In her 20s; } \\
\text { Graduated } \\
\text { with her B.A. } \\
\text { (May 2012); } \\
\text { Attended } \\
\text { private } \\
\text { college for } \\
\text { B.A.; Born in } \\
\text { U.S. } \\
\text { (mainland) of } \\
\text { Puerto Rican } \\
\text { parents; } \\
\text { Works as a } \\
\text { school } \\
\text { counselor at a } \\
\text { historically } \\
\text { PR high } \\
\text { school in } \\
\text { Chicago }\end{array}$ & $\begin{array}{l}\text { In her 50s; } \\
\text { Withdrew } \\
\text { from Ph.D. } \\
\text { program in } \\
2013 ; \text { Born } \\
\text { in Puerto } \\
\text { Rico of } \\
\text { Puerto Rican } \\
\text { parents; } \\
\text { Attended } \\
\text { public } \\
\text { institutions } \\
\text { for B.A., } \\
\text { M.A., and } \\
\text { Ph.D.; } \\
\text { Described } \\
\text { herself as a } \\
\text { working } \\
\text { mother, } \\
\text { activist, and } \\
\text { scholar; } \\
\text { Works as an } \\
\text { instructor at } \\
\text { a community } \\
\text { college in } \\
\text { California }\end{array}$ & $\begin{array}{l}\text { In her 20s; } \\
\text { Graduate with } \\
\text { her B.A. (May } \\
\text { 2013); Born } \\
\text { in San Juan, } \\
\text { Puerto Rico of } \\
\text { Puerto Rican } \\
\text { parents; } \\
\text { Attended a } \\
\text { small, all- } \\
\text { women's } \\
\text { college in } \\
\text { South } \\
\text { Carolina; } \\
\text { Works for a } \\
\text { bank in South } \\
\text { Carolina. }\end{array}$ & $\begin{array}{l}\text { In her } 40 \text {; } \\
\text { Graduating } \\
\text { with her } \\
\text { Ph.D. in } \\
\text { 2015; Born in } \\
\text { Vieques, } \\
\text { Puerto Rico } \\
\text { of Puerto } \\
\text { Rican and } \\
\text { African } \\
\text { American } \\
\text { parents; } \\
\text { Attended } \\
\text { public } \\
\text { colleges for } \\
\text { B.A. and } \\
\text { M.S., private } \\
\text { college for } \\
\text { Ph.D.; Works } \\
\text { as a lecturer } \\
\text { at a private } \\
\text { college in } \\
\text { California. }\end{array}$ \\
\hline $\begin{array}{l}\text { Thematic } \\
\text { Connections }\end{array}$ & $\begin{array}{l}\text { Her family } \\
\text { was the } \\
\text { biggest source } \\
\text { for how she } \\
\text { learned to } \\
\text { identify } \\
\text { herself, both } \\
\text { culturally, } \\
\text { racially and in } \\
\text { regards to } \\
\text { gender; } \\
\text { College was a } \\
\text { place where } \\
\text { her cultural } \\
\text { proclamations } \\
\text { were } \\
\text { challenged but }\end{array}$ & $\begin{array}{l}\text { Her family } \\
\text { was the } \\
\text { biggest } \\
\text { source for } \\
\text { how she } \\
\text { learned to } \\
\text { identify } \\
\text { herself, both } \\
\text { culturally and } \\
\text { racially; } \\
\text { College was } \\
\text { a place where } \\
\text { her cultural } \\
\text { claims were } \\
\text { challenged } \\
\text { but being } \\
\text { involved was }\end{array}$ & \begin{tabular}{|l} 
Political \\
activism \\
played \\
prominently \\
in her \\
identity \\
formation \\
(Puerto \\
Rican \\
politics: \\
Vieques, \\
Political \\
Prisons); \\
Her teachers \\
were \\
resistant to \\
the Puerto
\end{tabular} & $\begin{array}{l}\text { Her family } \\
\text { was the } \\
\text { biggest source } \\
\text { for how she } \\
\text { learned to } \\
\text { identify } \\
\text { herself, both } \\
\text { culturally, } \\
\text { racially and in } \\
\text { regards to } \\
\text { gender; } \\
\text { College was a } \\
\text { place where } \\
\text { she was } \\
\text { questioned } \\
\text { but saw being } \\
\text { involved as a }\end{array}$ & $\begin{array}{l}\text { My family } \\
\text { was the } \\
\text { biggest } \\
\text { source for } \\
\text { how I learned } \\
\text { to identify } \\
\text { herself, both } \\
\text { culturally, } \\
\text { racially and in } \\
\text { regards to } \\
\text { gender; } \\
\text { College was a } \\
\text { place where I } \\
\text { was } \\
\text { questioned } \\
\text { but saw being } \\
\text { involved as a }\end{array}$ \\
\hline
\end{tabular}




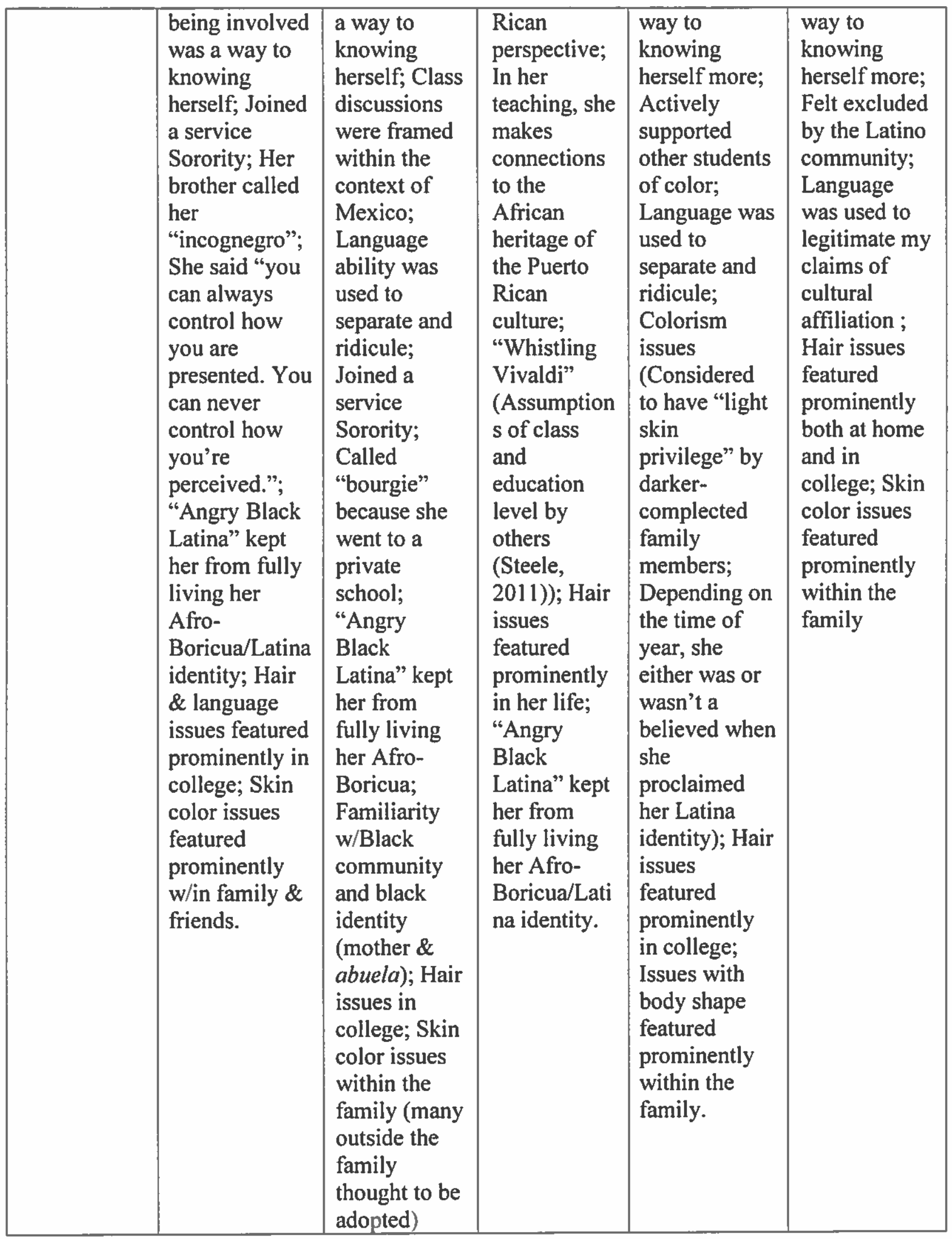




\section{Appendix 3: Map Images}

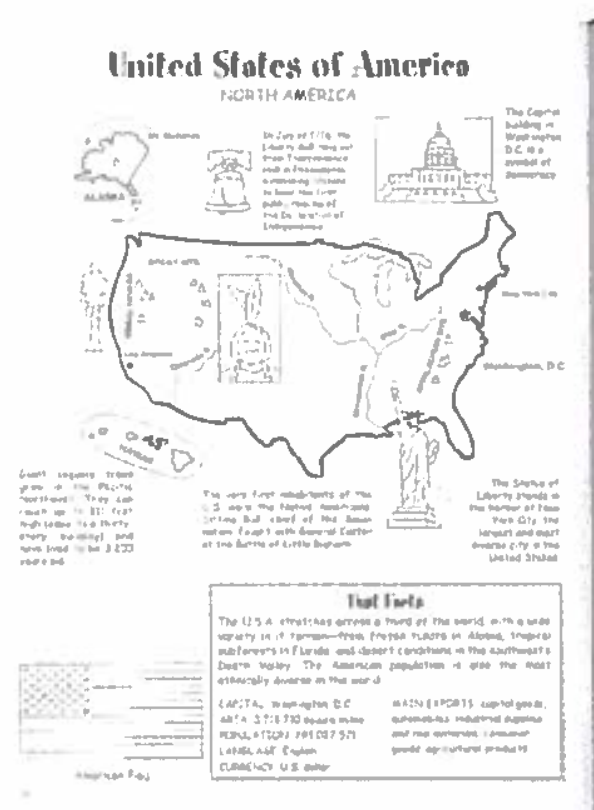

Coloring Book from Dubai

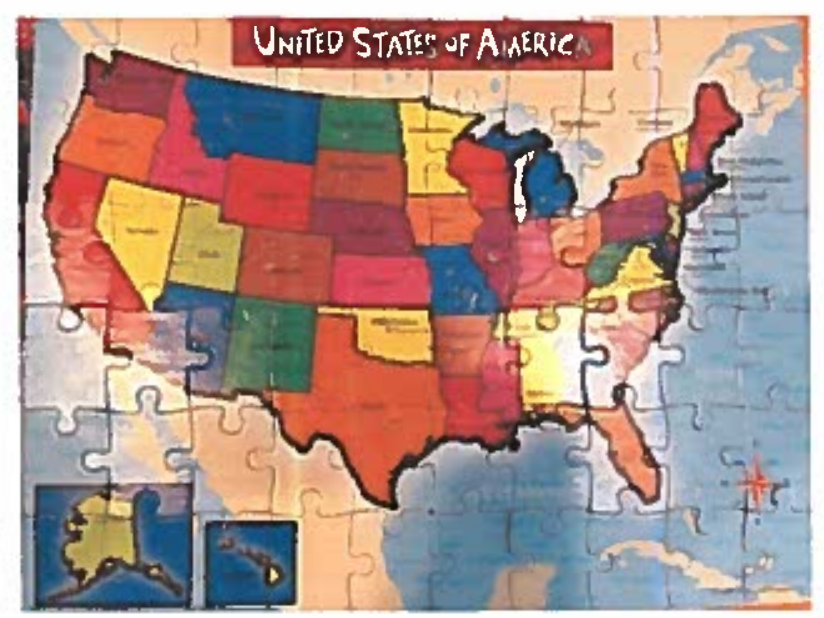

Children's US Map (Large Piece Puzzle)

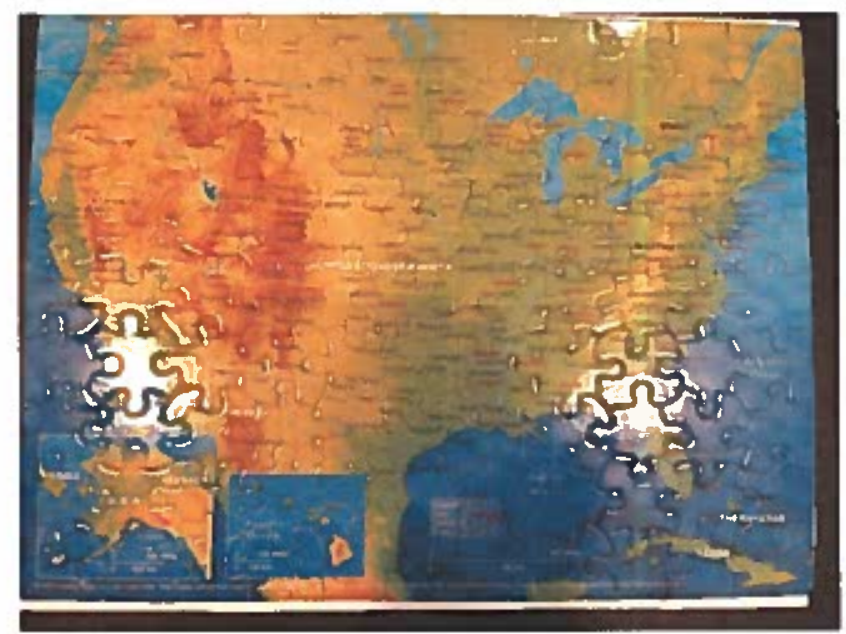

Children's US Map (Small Piece Puzzle) 


\section{Appendix 4: Common Core History Standards Books for Grades 3-5}
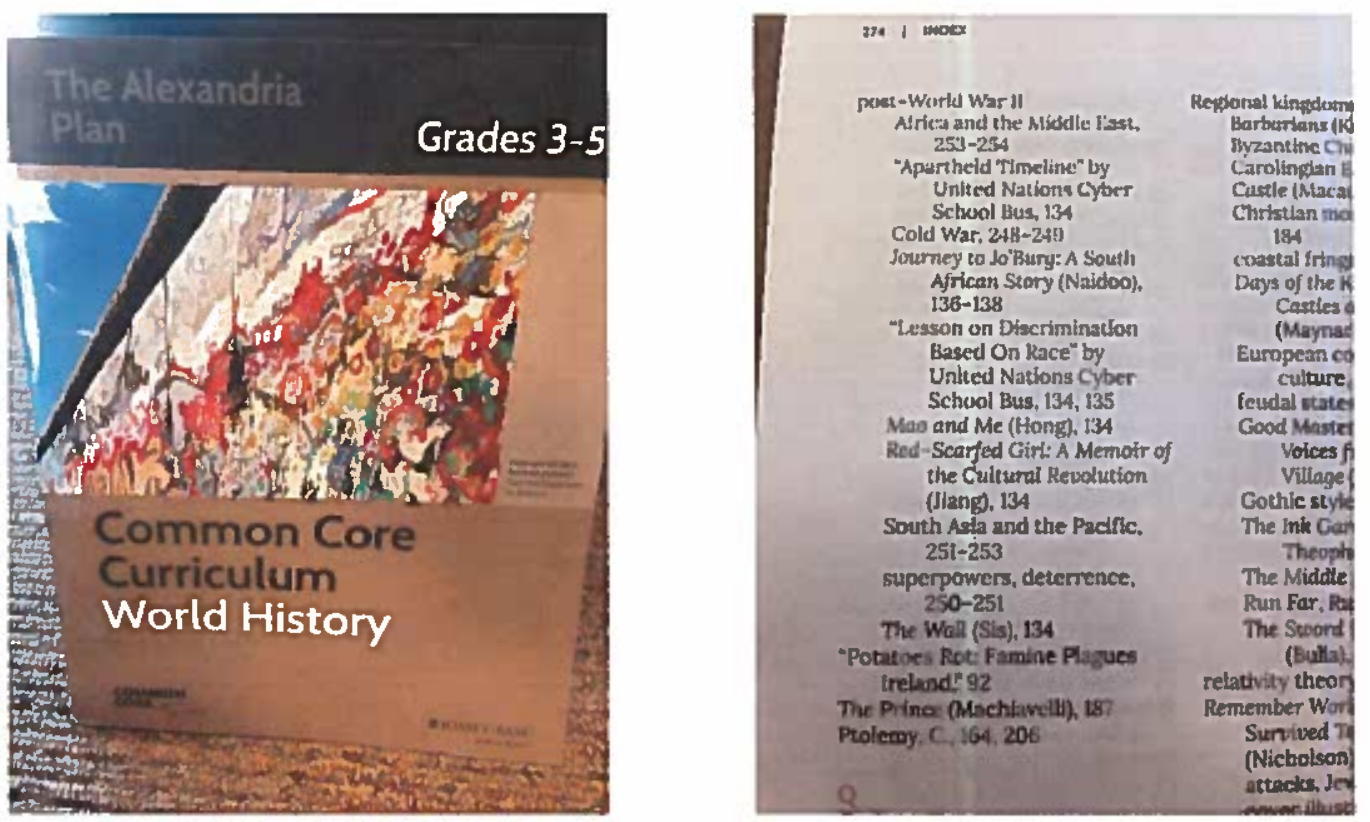

Notice that the "Ps" end at "Ptolemy" and continue to "Q"

Appendix 5: Sonia Sotomayor
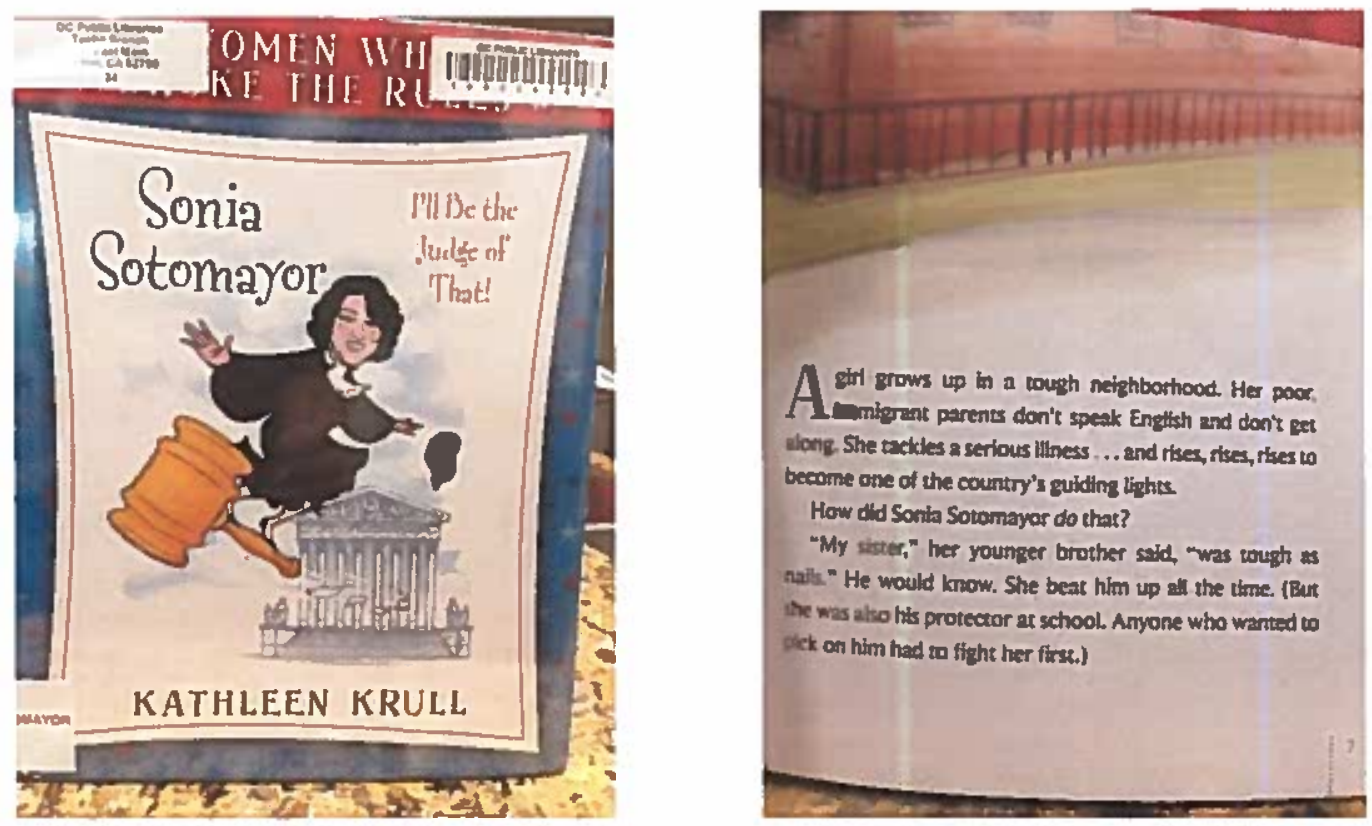

(The cross-out markings on page 7 were done by the researcher.)

Email:

On Thursday, January 28, 2016 6:24 PM, Marie Nubia-Feliciano

<menubia@yahoo.com>wrote:

Hi there,

My daughter checked out this book (see photos below) from the local library to prepare for a presentation on Supreme Court Justice Sonia Sotomayor. When helping her review a final draft of her report, she read out loud that Justice Sotomayor's parents were "poor immigrants". On page 7, I saw that it was indeed written "immigrant".

I am not sure if you fact-checked the book prior to publishing it, but Puerto Ricans are US citizens, and we are migrants. Citizens of other countries are immigrants to the US. I corrected the book passage before we will return it to the library. I hope that in future versions of the book you will correct the error.

A proud Puerto Rican professor,

Marie Nubia-Feliciano

"Education is a process, not a commodity." 
Appendix6: ¿Y tu agüela, aonde ejtá?

Poem written by Fortunato Vizcarrondo (3/13/1895 - 11/18/1977)

Ayé me dijite negro

Y hoy te boy a contejtá:

Mi mai se sienta en la sala.

¿Y tu agüela, aonde ejtá?

Yo tengo el pelo'e caíyo:

El tuyo ej seda namá;

Tu pai lo tiene bien lasio, ¿Y tu agüela, aonde ejtá?

Tu coló te salió blanco

Y la mejiya rosá;

Loj lábioj loj tiénej finoj... ¿Y tu agüela, aonde ejtá?

¿Disej que mi bemba ej grande

Y mi pasa colorá?

Pero dijme, por la binge, ¿Y tu agüela, aonde ejtá?

Como tu nena ej blanquita La sacaj mucho a pasiá ... $Y$ yo con ganae gritate ¿Y tu agüela, aonde ejtá?

A ti te gujta el fojtrote, Y a mi brujca maniguá.

Tú te laj tiraj de blanco

¿Y tu agüela, aonde ejtá?
Erej blanquito enchapao Que dentraj en sosiedá, Temiendo que se conojca

La mamá de tu mamá.

Aquí el que no tiene dinga Tiene mandinga .. ija, ja!

Por eso yo te pregunto ¿Y tu agüela, aonde ejtá?

Ayé me dijite negro Queriéndome abochoná. Mi agüela sale a la sala, Y la tuya oculta ajtá.

La pobre se ejtá muriendo Al belse tan maltratá.

Que hajta tu perro le ladra Si acaso a la sala bá.

¡Y bien que yo la conojco! Se ñama siña Tatá ... Tu la ejconde en la cosina, Po'que ej prieta de a beldá. 
And Yo Granma, Where She At?

Roberto Márquez

Yesterday yu called me nigger Today, I'm answerin' back: my momma sit in the parlor. An yo granma, where she at?

My hair ain't nuttin' but knots: yo locks fall down smooth as silk; yo popa's hair lank and straight, en yo granma, where she at?

Color yo skin is white; yo cheeks is rosy red; the lips yu got just so fine, en yo granma, where she at?

Yu say my bubbalips big, that my kinks are high yella red, for lord sakes, why 'ont yu tell me 'bout yo granma, where she at?

Yo little gal's so lily white yu always be takin' her out... and me 'bout bustin' to shout: en yo granma, where she at?

Yu like dancin' to de foxtrot. I likes my wild music's woods; forever braggin' you white: en yo granma, where she at?
Yo whiteness ain't but veneer for passin' 'mong high-tone folk, hopin' none know to invoke who's yo momma's momma dear.

Dem here with no toucha Dinga, descend from Mandinga direct... das why I ask, due respect, en yo granma, where she at?

Yesterday yu called me nigger, tryin' a make me feel shame.

My granma ain't ban from the parlor;

yours you be hidin' out back.

Po' lady's 'bout fit to die, see herself treated so.

Even the dog barkin' at'her dare she to the parlor go.

And it's good that I recognize her; her name is Señora Tatá. You hide her in the kitchen because she is really black!

Translation of the original poem by Fortunato Vizcarrondo March 13,1895-November 18, 1977 